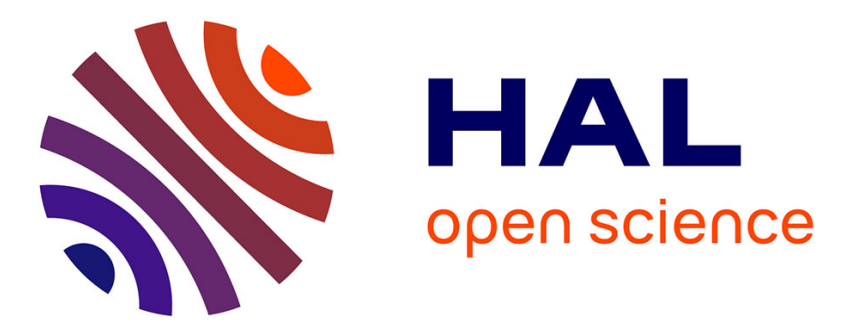

\title{
Estimating the mechanical properties of hydrating blended cementitious materials: An investigation based on micromechanics
}

\author{
F. Lavergne, A. Ben Fraj, I. Bayane, J.F. Barthélémy
}

\section{- To cite this version:}

F. Lavergne, A. Ben Fraj, I. Bayane, J.F. Barthélémy. Estimating the mechanical properties of hydrating blended cementitious materials: An investigation based on micromechanics. Cement and Concrete Research, 2018, 104, pp.37 - 60. 10.1016/j.cemconres.2017.10.018 . hal-01851380

\author{
HAL Id: hal-01851380 \\ https://hal.science/hal-01851380
}

Submitted on 22 Oct 2018

HAL is a multi-disciplinary open access archive for the deposit and dissemination of scientific research documents, whether they are published or not. The documents may come from teaching and research institutions in France or abroad, or from public or private research centers.
L'archive ouverte pluridisciplinaire HAL, est destinée au dépôt et à la diffusion de documents scientifiques de niveau recherche, publiés ou non, émanant des établissements d'enseignement et de recherche français ou étrangers, des laboratoires publics ou privés.

\section{(ㅇ)(1) $\$$}

Distributed under a Creative Commons Attribution - NonCommercial - NoDerivatives 44.0 


\title{
Estimating the mechanical properties of hydrating blended cementitious materials: an investigation based on micromechanics
}

\author{
F. Lavergne ${ }^{\mathrm{a}, *}$, A. Ben Fraj ${ }^{\mathrm{b}}$, I. Bayane ${ }^{\mathrm{b}}$, J. F. Barthélémy ${ }^{\mathrm{a}}$ \\ ${ }^{a}$ Centre Technique Ouvrage d'Art, CEREMA ITM, BP214 77487 Provins Cedex, France \\ ${ }^{b}$ Laboratoire Eco-Matériaux, CEREMA IdF, BP214 77487 Provins Cedex, France
}

\begin{abstract}
The hydration model of Parrot \& Killoh (1984) [1] has been extended to blended cements and coupled to a micromechanical scheme similar to that of Pichler \& Hellmich (2011) [2] to estimate the Young modulus and the compressive strength of cementitious materials as a function of time. A finite aspect ratio of 7 is introduced to describe the shape of the hydrates and improve the estimate of the early age strength by the micromechanical scheme. Furthermore, accounting for the stress fluctuations in the cement paste partly explains the fact that the compressive strength of a concrete can be lower than that of its cement paste. Finally, the estimated physical properties are compared to numerous experimental measurements from the literature and new experimental measurements on blended cement pastes featuring significant weight fractions of limestone filler, fly ash or silica fume. It is shown that the present model slightly overestimates the dilution effect.
\end{abstract}

Keywords:

homogenization, cement, silica fume, hydration, compressive strength

\section{Introduction}

Deriving the mechanical properties of cementitious materials from their compositions is a matter of interest for the design of optimized formulations and accurate estimates of stresses and strains in structures. Standards models often rely on the measurement of the compressive strength at 28 days $f_{c, 28}$ as the sole indicator of the mechanical performance of the concrete. An empirical formula is therefore applied to estimate the secant Young modulus of the concrete $E_{28}$. For instance, the one of the Eurocode 2 3 for concrete containing quartzite aggregates is $E_{28}=22\left(f_{c, 28} / 10\right)^{0.3}$, where $E_{28}$ is in $\mathrm{GPa}$ if $f_{c, 28}$ is provided in $\mathrm{MPa}$. The Young modulus can be $20 \%$ higher for basalt aggregates or $10 \%$ to $30 \%$ lower for limestone and sandstone aggregates. While the influence of the aggregate type is accounted for, this formula can not be applied to lightweight aggregates or recycled aggregates. Indeed, a corrective factor $\eta_{E}=(\rho / 2200)^{2}$, where $\rho$ is the dry density of the concrete in $\mathrm{kg} / \mathrm{m}^{3}$, is introduced to handle the case of lightweight aggregates $\left(\rho<2200 \mathrm{~kg} / \mathrm{m}^{3}\right)$. The standard itself considers this correction as inaccurate and requires an effective measurement of the Young modulus whenever this property becomes critical. The ACI 318 standards 4 s specifies a similar equation, except that the exponents are very different:

$$
E_{28} \approx 21\left(\frac{\rho}{2300}\right)^{1.5}\left(\frac{f_{c, 28}}{20}\right)^{0.5}
$$

The ACI 318 standards also points out that the modulus for concrete is sensitive to the modulus of the aggregates and that the measured values range typically from 120 to 80 percent of the estimated value 4. Moreover, it is well-known that this equation often overestimates the Young moduli of concretes featuring compressive strengths above $41 \mathrm{MPa}$ [5]. Lastly, these empirical formulae require a prior knowledge of the compressive strength of the concrete. Consequently, they become inadequate to design optimized formulations.

Models have been proposed in order to improve the accuracy of the estimates of the mechanical properties by relying on material sciences. For instance, Freyssinet proposed in 1933 that the strength and stiffness of cementitious materials are related to what is nowadays called the gel-space ratio [6]. Following the same reasoning, Powers later assumed that

${ }^{*}$ Corresponding author

Email address: francis.lavergne@cerema.fr (F. Lavergne )

Postprint of Cement \& Concrete Reserch doi.org/10.1016/j.cemconres.2017.10.018 
the strength of cement gel is the sole source of strength of the porous cement paste and uncovered a practical relationship between the gel-space ratio and the compressive strength of cement pastes [7]. Such models can address the heterogeneous nature of cementitious materials, the changes of their microstructures due to the hydration reactions, the stiffness of the components involved at microscopic scale and the failure mode if the compressive strength is estimated. At first, different homogenization schemes were introduced to estimate the properties of concrete starting from those of the cement paste [8, 9, 10, 11]. Then, coupling the existing knowledge about the chemical reactions occurring in concrete [12, 13, 14, and measurements of the stiffness of individual phases by nanoindentation [15] allowed the development of multiscale homogenization procedures dedicated to cementitious materials [16, 15, 17, 18, 19, 2, 20, 21], in which the cement paste itself is considered as an heterogeneous material. Furthermore, numerical simulations of the microstructure of the cement paste have been achieved [22, 23, 24]. Such numerical simulations require some data about the particle size distribution of the cement. Then, the generated artificial microstructures may be used as inputs of 3D numerical simulations so as to estimate the Young modulus or the strength of the material [25, 26]. Nevertheless, these computations can prove time-consuming: optimizing a formulation, validating the model against experimental results or using it for every element of a finite-element model of a structure still are intricate challenges. Consequently, the mean-field homogenization models based on a scalar description of cement hydration remain valuable for their ease of use and their low computational demand [27]. Indeed, extending these models to account for new evidences is often straightforward.

Recent advances on our understanding of cement hydration are to be incorporated in the model that is introduced in the present article. First, the products of the hydration of $\mathrm{C}_{4} \mathrm{AF}$, a phase of cement, have to be updated according to new evidences [28, 29] and the conditions for the formation of calcium monocarboaluminates have been defined by a thermodynamical framework [30]. Second, the effect of pozzolanic additions such as silica fumes and fly ashes can be modeled by accounting for the pozzolanic reactions [31]. Indeed, most of the existing multiscale homogenization models are focused on plain cements, while modern formulations often includes these additions to improve the durability or the mechanical performances, reduce the costs or the environmental footprint. Third, the effect of the fineness of cement and fillers, the relative humidity and temperature on the kinetic of the chemical reactions are modeled so as to provide an estimate of the mechanical properties as a function of time, not as a function of the hydration degree. Finally, the present model is validated against measurements published in the literature. The accuracy of the hydration model can be verified by XRD-Rietveld analysis, thermogravimetry and calorimetry. The estimates of compressive strength and Young modulus are also compared to the corresponding measurements. In addition, new measurements have been performed on blended cement pastes so as to extend the database of useful experimental results. The formulations and experimental procedures are detailed in order to help further validations of homogenization models.

\section{Evolution of the volume fractions of constitutive phases}

At early age, the evolutions of the mechanical properties of concrete are driven by the progressive hydration of the cement paste. In the present section, the volume fraction of the constitutive phases of concrete are estimated as functions of the time. First, an isothermal hydration model is introduced in order to rapidly produce an estimate of the volume of each phase of a cement paste. Then, the effect of temperature and relative humidity are accounted for. Lastly, the pozzolanic reactions are introduced.

\subsection{The hydration of the cement}

The considered hydration model is similar to that of Thiery et. al. [32] as modified by Nguyen [33. It is combined to the empirical expressions of the hydration rate of clinker phases described by Parrot \& Killoh [1, 30, 34. By describing the reaction rates as a function of the remaining amounth of reactant and other environmental parameters, the present hydration model is fully compliant with the concept of chemical affinity [16]. New evidences regarding the products of cement hydration [30, 28, 29] have been incorporated as updates.

The constitutive phases are the unhydrated reactants of cement, water, the products of the chemical reactions and filler. The different phases are listed in table 1.1, along with some of their physical properties. The hydration reactions are then listed in table 1.2 along with their volume changes per mole of solid reactant $\Delta V_{r}$ and balances of capillary voids per mole of solid reactant $\Delta V_{r, c a p}$. The volume change $\Delta V_{r}$ is related to the chemical shrinkage : products need less space than the reactants if water is included. Yet, since solid products 
need more space than the solid reactants, hydration reactions progress at the expense of the capillary porosity.

\begin{tabular}{|c|c|c|c|c|c|c|}
\hline name & formula & $\begin{array}{c}\text { molar mass } \\
\mathrm{g} / \mathrm{mol}\end{array}$ & $\begin{array}{l}\text { density } \\
\mathrm{g} / \mathrm{cm}^{3}\end{array}$ & $\begin{array}{c}\text { molar volume } \\
\mathrm{cm}^{3} / \mathrm{mol}\end{array}$ & $\begin{array}{c}\text { enthalpy of formation } \\
\mathrm{kJ} / \mathrm{mol} \text {, @ } 25^{\circ} \mathrm{C}\end{array}$ & $\begin{array}{c}C_{p} \\
\mathrm{~J} / \mathrm{mol} / \mathrm{K}, @ 25^{\circ} \mathrm{C}\end{array}$ \\
\hline \multicolumn{7}{|l|}{ Cement Bogue composition } \\
\hline Alite & $\mathrm{C}_{3} \mathrm{~S}$ & 228.335 & 3.15 & 72.5 & $(-2929.2)$ & 171.88 \\
\hline Belite & $\mathrm{C}_{2} \mathrm{~S}$ & 172.258 & 3.27 & 52.7 & $(-2307.5, \beta)$ & $(128.78, \beta)$ \\
\hline Tricalcium Aluminate & $\mathrm{C}_{3} \mathrm{~A}$ & 270.194 & 3.03 & 89.2 & -3587.8 & 209.87 \\
\hline Tetracalcium aluminoferrite & $\mathrm{C}_{4} \mathrm{AF}$ & 485.96 & 3.71 & 131.0 & -5090.3 & 396 \\
\hline gypsum & $\mathrm{CS}^{\bar{S}} \mathrm{H}_{2}$ & 172.172 & 2.31 & 74.5 & -2022.6 & 186.02 \\
\hline $\mathrm{C}-\mathrm{S}-\mathrm{H}$ & $\mathrm{C}_{17} \mathrm{SH}_{4}$ & 227.496 & 2.1 & 108.3 & $(-3283)$ & $(297)$ \\
\hline Portlandite & $\mathrm{CH}$ & 74.093 & 2.26 & 32.8 & -986.1 & 87.49 \\
\hline Ettringite & $\mathrm{C}_{6} \mathrm{AS}_{3} \mathrm{H}_{32}$ & 1255.108 & 1.78 & 705.1 & -17539 & 2174 \\
\hline MonosulphoAluminate & $\mathrm{C}_{4} \mathrm{~A} \overline{\mathrm{S}} \mathrm{H}_{12}$ & 622.519 & 2.02 & 308 & -8778 & 942 \\
\hline iron(III) oxide-hydroxide & $\mathrm{FH}_{3}$ & 213.734 & 2.2 & 97.2 & $(2 \times-832.616)$ & $(2 \times 101.671)$ \\
\hline Fe-Si hydrogarnet & $\mathrm{C}_{6} \mathrm{AFS}_{2.18} \mathrm{H}_{19}$ & 1071.43 & 2.18 & 491.5 & -14088 & 1682 \\
\hline hydrogarnet & $\mathrm{C}_{3} \mathrm{AH}_{6}$ & 378.285 & 2.52 & 150.1 & -5548 & 459 \\
\hline water & $\mathrm{H}$ & 18.015 & 1.0 & 18.0 & -285.83 & 75.291 \\
\hline amorphous silicate & $\mathrm{S}$ & 60.103 & 2.22 & 27.1 & -903.49 & 44.4 \\
\hline C-S-Hp & $\mathrm{C}_{1.1} \mathrm{SH}_{3.9}$ & 192.048 & 1.9 & 101.1 & $(-2841)$ & $(297)$ \\
\hline calcite & $\mathrm{C} \overline{\mathrm{C}}$ & 100.087 & 2.71 & 36.9 & -1128.79 & 81.88 \\
\hline calcium monocarboaluminate & $\mathrm{C}_{4} \mathrm{~A} \overline{\mathrm{C}} \mathrm{H}_{11}$ & 568.449 & 2.17 & 262.0 & -8250 & 881 \\
\hline
\end{tabular}

Table 1.1: The constitutive phases of the cement paste. Cement notation are used except for calcite : $\mathrm{C}=\mathrm{CaO} ; \mathrm{S}=\mathrm{SiO}_{2} ; \mathrm{A}=\mathrm{Al}_{2} \mathrm{O}_{3} ; \mathrm{F}=\mathrm{Fe}_{2} \mathrm{O}_{3} ; \overline{\mathrm{S}}=\mathrm{SO}_{3} ; \overline{\mathrm{C}}=\mathrm{CO}_{2}$. Molar masses are computed according to the python module pyisocalc, based on the data gathered by IUPAC[118].

\begin{tabular}{|c|c|c|c|c|}
\hline stochiometry of reaction & $\begin{array}{l}\text { volume change } \mathrm{S} \\
\mathrm{cm}^{3} / \mathrm{mol}\left(\mathrm{C}_{3} \mathrm{~S}\right)\end{array}$ & $\begin{array}{l}\text { balance capillary void } \\
\left./ \mathrm{C}_{2} \mathrm{~S} / \mathrm{C}_{3} \mathrm{~A} / \mathrm{C}_{4} \mathrm{AF}\right)\end{array}$ & $\begin{array}{c}\text { enthalpy of reaction } \Delta_{r} H @ 25^{\circ} \mathrm{C} \\
\text { kJ } / \mathrm{mol}\end{array}$ & $\begin{array}{l}\text { change of heat capacity } C_{p, r} \\
\mathrm{~J} / \mathrm{mol} / \mathrm{K}\end{array}$ \\
\hline $\mathrm{C}_{3} \mathrm{~S}+5.3 \mathrm{H} \rightarrow \mathrm{C}_{1.7} \mathrm{SH}_{4}+1.3 \mathrm{CH}$ & -17 & -78 & -121 & -160 \\
\hline $\mathrm{C}_{2} \mathrm{~S}+4.3 \mathrm{H} \rightarrow \mathrm{C}_{1.7} \mathrm{SH}_{4}+0.3 \mathrm{CH}$ & -12 & -65 & -42 & -129 \\
\hline $\mathrm{C}_{3} \mathrm{~A}+3 \mathrm{C} \mathrm{CS}_{2}+26 \mathrm{H} \rightarrow \mathrm{C}_{6} \mathrm{AS}_{3} \mathrm{H}_{32}$ & -76 & -392 & -452 & -551 \\
\hline $\mathrm{C}_{3} \mathrm{~A}+0.5 \mathrm{C}_{6} \mathrm{AS}_{3} \mathrm{H}_{32}+2 \mathrm{H} \rightarrow 1.5 \mathrm{C}_{4} \mathrm{AS} \mathrm{S}_{12}$ & -15 & -21 & -238 & -34 \\
\hline $\mathrm{C}_{3} \mathrm{~A}+6 \mathrm{H} \rightarrow \mathrm{C}_{3} \mathrm{AH}_{6}$ & -47 & -61 & -245 & -203 \\
\hline $\mathrm{C}_{4} \mathrm{AF}+3 \mathrm{CS} \mathrm{S}_{2}+30 \mathrm{H} \rightarrow \mathrm{C}_{6} \mathrm{AS}_{3} \mathrm{H}_{32}+\mathrm{CH}+\mathrm{FH}_{3}$ & -60 & -480 & -438 & -748 \\
\hline $\mathrm{C}_{4} \mathrm{AF}+0.5 \mathrm{C}_{6} \mathrm{AS}_{3} \mathrm{H}_{32}+6 \mathrm{H} \rightarrow 1.5 \mathrm{C}_{4} \mathrm{AS} \mathrm{H}_{12}+\mathrm{CH}+\mathrm{FH}_{3}$ & 1 & -109 & -224 & -231 \\
\hline $\mathrm{C}_{4} \mathrm{AF}+10 \mathrm{H} \rightarrow \mathrm{C}_{3} \mathrm{AH}_{6}+\mathrm{CH}+\mathrm{FH}_{3}$ & -31 & -149 & -232 & -399 \\
\hline $\mathrm{C}_{4} \mathrm{AF}+2.18 \mathrm{C}_{3} \mathrm{~S}+23.54 \mathrm{H} \rightarrow \mathrm{C}_{6} \mathrm{AFS}_{2} .18 \mathrm{H}_{19}+4.54 \mathrm{CH}$ & -73 & -351 & -360 & -464 \\
\hline $\mathrm{C}_{4} \mathrm{AF}+2.18 \mathrm{C}_{2} \mathrm{~S}+21.36 \mathrm{H} \rightarrow \mathrm{C}_{6} \mathrm{AFS}_{2} .18 \mathrm{H}_{19}+2.36 \mathrm{CH}$ & -62 & -323 & -189 & -396 \\
\hline $1.1 \mathrm{CH}+\mathrm{S}+2.8 \mathrm{H} \rightarrow \mathrm{C}_{1.1} \mathrm{SH}_{3.9}$ & -13 & -38 & -52 & -54 \\
\hline $\mathrm{C} \overline{\mathrm{C}}+\mathrm{C}_{3} \mathrm{~A}+11 \mathrm{H} \rightarrow \mathrm{C}_{4} \mathrm{~A} \overline{\mathrm{C}} \mathrm{H}_{11}$ & -62 & -136 & -389 & -239 \\
\hline $\mathrm{A}+5 \mathrm{CH}+25 \mathrm{H}+\mathrm{CS}_{2} \rightarrow \mathrm{C}_{6} \mathrm{AS}_{3} \mathrm{H}_{32}$ & -9 & -441 & -1777 & -411 \\
\hline $\mathrm{A}+3 \mathrm{CH}+0.5 \mathrm{C}_{6} \mathrm{AS}_{3} \mathrm{H}_{32} \rightarrow 1.5 \mathrm{C}_{4} \mathrm{AS} \mathrm{S}_{12}+\mathrm{H}$ & 4 & 14 & -62 & 60 \\
\hline $\mathrm{A}+3 \mathrm{CH}+3 \mathrm{H} \rightarrow \mathrm{C}_{3} \mathrm{AH}_{6}$ & -28 & -26 & -69 & -108 \\
\hline $\mathrm{A}+3 \mathrm{CH}+\mathrm{C} \overline{\mathrm{C}}+8 \mathrm{H} \rightarrow \mathrm{C}_{4} \mathrm{~A} \overline{\mathrm{C}} \mathrm{H}_{11}$ & -43 & -101 & -213 & -145 \\
\hline
\end{tabular}

Table 1.2: The considered set of chemical reactions is similar to those of Thiery et. al [32]. Since the formula $\mathrm{C}_{1.7} \mathrm{SH}_{4}$ corresponds to saturated $\mathrm{C}-\mathrm{S}-\mathrm{H}$, the balance of volume of solid phases reflects the change of capillary porosity. The values of heat released by hydration are coming from [70], on page 271.

The kinetics of the reactions at the constant temperature of $20^{\circ} \mathrm{C}$ is to be described. The model of hydration of Thiery et. al. [32] makes use of the power laws adjusted by Papadakis et. al. 35 to describe the rate of hydration of clinker compounds $\mathrm{C}_{3} \mathrm{~S}, \mathrm{C}_{2} \mathrm{~S}, \mathrm{C}_{3} \mathrm{~A}$ and $\mathrm{C}_{4} \mathrm{AF}$. The kinetics introduced by Ngugen [33] is more complex so as to account for the induction period, a period of nucleation and growth of hydrates and a period during which the kinetics of hydration is controlled by the diffusion of ions. The empirical hydration rates of Parrot and Killoh [1], used by existing hydration models [30, 34], also distinguish physically based limiting factors for the hydration rate, but it ensures that the hydration rate is finite and continuous. Hence, the latter will be considered in the present study.

The hydration degree $0 \leq \alpha_{i}(t) \leq 1$ traces the evolution of the molar quantity $N_{i}(t)$ of solid reactant $i \in\left\{\mathrm{C}_{3} \mathrm{~S}, \mathrm{C}_{2} \mathrm{~S}, \mathrm{C}_{3} \mathrm{~A}, \mathrm{C}_{4} \mathrm{AF}\right\}$ consumed by the reaction:

$$
\alpha_{i}(t)=1-\frac{N_{i}(t)}{N_{i}(0)}
$$

where $N_{i}(0)$ is the initial quantity of solid reactant $i$ in $1 \mathrm{~cm}^{3}$ of fresh cement paste. In the model of Parrot and Killoh, three phenomena limit the rate of hydration of the solid reactant $i$. Consequently, the actual rate of hydration $\dot{\alpha}_{i}$ is the lower of three rates corresponding the phenomena:

$$
\dot{\alpha}_{i}=\min \left(\dot{\alpha}_{i, 1}, \dot{\alpha}_{i, 2}, \dot{\alpha}_{i, 3}\right)
$$

The first rate $\dot{\alpha}_{i, 1}$ arises from a nucleation-growth mechanism. Hence, it is modeled by an Avrami equation [36, 37]:

$$
\dot{\alpha}_{i, 1}=\frac{k_{i, 1}}{n_{i, 1}}\left(1-\alpha_{i}\right)\left(-\ln \left(1-\alpha_{i}\right)\right)^{1-n_{i, 1}}
$$




$\begin{array}{ccccc}i & \mathrm{C}_{3} \mathrm{~S} & \mathrm{C}_{2} \mathrm{~S} & \mathrm{C}_{3} \mathrm{~A} & \mathrm{C}_{4} \mathrm{AF} \\ k_{i, 1}, \text { day }^{-1} & 1.5 & 0.5 & 1.0 & 0.37 \\ n_{i, 1} & 0.7 & 1.0 & 0.85 & 0.7 \\ k_{i, 2}, \text { day }^{-1} & 0.05 & 0.006 & 0.04 & 0.015 \\ k_{i, 3}, \text { day }^{-1} & 1.1 & 0.2 & 1.0 & 0.4 \\ n_{i, 3} & 3.3 & 5.0 & 3.2 & 3.7\end{array}$

Table 1.3: Parameters of Parrot and Killoh [1] reported in [30] are also used in the present study to model the isothermal hydration of the clinker compounds at $20^{\circ} \mathrm{C}$.

where the parameters $k_{i, 1}$ and $n_{i, 1}$ are parameters identified by Parrot and Killoh [1] (Tab. 1.3). The second rate $\dot{\alpha}_{i, 2}$ describes the diffusion of the solid reactant through the layers of hydrates that were previously formed. Hence, it is modeled according to a Jander equation [38]:

$$
\dot{\alpha}_{i, 2}=\frac{k_{i, 2}\left(1-\alpha_{i}\right)^{\frac{2}{3}}}{1-\left(1-\alpha_{i}\right)^{\frac{1}{3}}}
$$

The last rate $\dot{\alpha}_{i, 3}$ changes according to a power law describing the formation of a thick shell around unreacted cement particles [34]:

$$
\dot{\alpha}_{i, 3}=k_{i, 3}\left(1-\alpha_{i}\right)^{n_{i, 3}}
$$

where $k_{i, 3}$ and the order of the reaction $n_{i, 3}$ were adjusted by Parrot and Killoh [1] (Tab. 1.3 .

These adjustments are valid for a cement of Blaine fineness $B_{0}=385 \mathrm{~m}^{2} / \mathrm{kg}$. To account for the effect of the Blaine fineness on the rate of cement hydration, the rate of hydration is multiplied by the ratio $B / B_{0}$, where $B$ is the Blaine fineness of the cement [1, 34]. Indeed, hydration mechanisms such as the Avrami rate law regarding growth and the Jander rate law are related to the size of the cement particles 39 .

The model of Parrot and Killoh considered in the present study suffers from many drawbacks. It must be mentioned that using the values of parameters of Parrot and Killoh [1, there is no nucleation-growth step for $\mathrm{C}_{2} \mathrm{~S}$, and no diffusion-controlled step for $\mathrm{C}_{3} \mathrm{~S}$ and $\mathrm{C}_{2} \mathrm{~S}$. Indeed, the hydration of $\mathrm{C}_{2} \mathrm{~S}$ is in fact restricted to the power law rate and the hydration of $\mathrm{C}_{3} \mathrm{~S}$ directly jumps from the nucleation growth step to the power-law rate. On the contrary, modern numerical models of cement hydration relying of an 3D description of the microstructure do not need to introduce the third stage. Lastly, these models accurately account for the effect of the particle size distribution of the cement, while the Blaine fineness of the cement is often the only parameter of this distribution provided to the model of Parrot and Killoh. This limitation is of particular importance for modern cements : the span of their particle size distribution is smaller than those of old cements due to improvements of grinding process. As a result, there are fewer particles larger than $65 \mu \mathrm{m}$ in modern cements and these cements hydrate more rapidly despite comparable Blaine fineness. But the kinetic model of Parrot and Killoh is not able to model this effect. Nevertheless, this model proved both sound and practical for decades in spite of its drawbacks.

The previous set of equations describes the consumption of solid reactant $i$ as a function of time. But $\mathrm{C}_{3} \mathrm{~A}$ and $\mathrm{C}_{4} \mathrm{AF}$ can take part in many reactions (see table 1.1 for formulae and table 1.2 for reactions). To choose which reaction consumes the solid reactant, it is assumed that $\mathrm{C}_{3} \mathrm{~A}$ first reacts with gypsum $\left(\mathrm{C} \overline{\mathrm{S}} \mathrm{H}_{2}\right)$ to form the ettringite $\left(\mathrm{C}_{6} \mathrm{~A}_{3} \mathrm{H}_{32}\right)$. The reaction consuming ettringite starts as the gypsum is depleted. Following thermodynamical evidences [30, monocarboaluminate $\left(\mathrm{C}_{4} \mathrm{~A} \overline{\mathrm{C}} \mathrm{H}_{11}\right)$ is formed except if the calcite is depleted or if the temperature exceeds $48^{\circ} \mathrm{C}$. Otherwise, the ettringite reacts with the $\mathrm{C}_{3} \mathrm{~A}$ to produce monosulfoaluminate $\left(\mathrm{C}_{4} \mathrm{~A} \overline{\mathrm{S}} \mathrm{H}_{12}\right)$. Lastly, the reaction forming hydrogarnets $\left(\mathrm{C}_{3} \mathrm{AH}_{6}\right)$ is activated if and only if both the gypsum and the ettringite are depleted. Compared to existing models [32, 33], the reactions of $\mathrm{C}_{4} \mathrm{AF}$ have to be modified to account for new evidences. Indeed, the formation of $\mathrm{FH}_{3}$ is hard to detect in real cement paste since it is amorphous [40] and iron has been detected in silicious hydrogarnet [41, 42, 43]. Moreover, chemical investigations have shown that Fe-containing silicious hydrogarnet are more stable than Fe-ettringite and Fe-containing alumina, ferric oxide, monosulfate $(\mathrm{AFm})$ phases [28]: the formation of this phase is thermodynamically favored in aged paste [29]. Consequently, the reactions accounted for in the present model are similar to those of Brouwers [40] until all sources of silica are depleted. The product of the reactions is a mix between the hydrogarnets $\mathrm{C}_{3} \mathrm{FS}_{1.34} \mathrm{H}_{3.32}$ and $\mathrm{C}_{3} \mathrm{AS}_{0.84} \mathrm{H}_{4.32}$ investigated in [28]: $\mathrm{C}_{6} \mathrm{AFS}_{2.18} \mathrm{H}_{19}$. The additional water improves consistency with the formula introduced in [40]. 
In addition, an estimate of the mass of chemically bounded water $m_{w b}$ in a $\mathrm{cm}^{3}$ of cement paste can be computed as justified by Brouwers [40]:

$$
\begin{aligned}
\frac{m_{w b}}{M_{H}} & =1.2\left(N_{C S H}+N_{C S H p}\right)+N_{C H}+9 N_{C_{6} A \bar{S}_{3} H_{32}} \\
& +10 N_{C_{4} A \bar{S} H_{12}}+11 N_{C_{4} A \bar{C} H_{11}}+7.64 N_{C_{6} A F S_{2} H_{19}} \\
& +\quad+2 N_{C \bar{S} H_{2}}+6 N_{C_{3} A H_{6}}+3 N_{F H_{3}}
\end{aligned}
$$

Finally, the hydration model provides an estimate of the chemical shrinkage $\delta V_{c h}(t)$ and capillary porosity $\Phi_{\text {cap }}(t)$. Indeed, the chemical shrinkage writes:

$$
\delta V_{c h}(t)=\sum_{j} v_{j}\left(N_{j}(t)-N_{j}(0)\right)
$$

where $v_{j}$ is the molar volume of the chemical species $j$ in $\mathrm{cm}^{3} / \mathrm{mol}$ (Tab. 1.1). As the hydrates are formed in their saturated states, the volume of the water $v_{H} N_{H}(t)$ per $1 \mathrm{~cm}^{3}$ cement paste represents the water-filled capillary porosity. Hence, the capillary porosity, that is the volume fraction of capillary pores in the cement paste, writes:

$$
\Phi_{c a p}(t)=\left(-\delta V_{c h}(t)+v_{H} N_{H}(t)\right) / 1 \mathrm{~cm}^{3}
$$

As-is, hydration stops when either the capillary water or the anhydrous particles are totally consumed. The effect of the exhaustion of capillary water on the hydration kinetics is introduced in the next section.

\subsection{Influence of the relative humidity on hydration kinetics}

It is known that either the water content or the relative humidity $h$ can affect the pace of hydration reaction. For instance, the reduction coefficient $\beta_{h}$ introduced by Parrot et. al. (44], cited by [22]) is applied:

$$
\begin{aligned}
& \beta_{h}=\left(\frac{h-0.55}{0.45}\right)^{4} \quad \text { if } h>0.80 \\
& \beta_{h}=\quad 0 \text { if } h \leq 0.80
\end{aligned}
$$

Indeed, since the relative humidity is related to the chemical potential of water vapor, hydration reactions may become impossible at relative humidity lower than $75 \%-80 \%$ for thermodynamic reasons [45, 46]. For instance, it has been observed that the relative humidity in hydrating cement pastes remains above $80 \%$, even for a 7 -days-old cement paste with a water to cement ratio $w / c$ of 0.3 [47. This thermodynamic stopping of hydration introduces a discontinuity of the reaction rate. Nevertheless, the coefficient $\beta_{h}$ at $80 \%$ relative humidity is 0.095, implying that the hydration rate has already been divided by 10 compared to the $99 \%$ hydration rate. The Kelvin-Laplace equation can be applied to estimate the capillary pressure $p_{c a p}$ and the diameter $d_{w}$ of the largest pore full of liquid water if the relative humidity is high [48, 49]:

$$
p_{c a p}=-\frac{R T \ln (h)}{v_{H}}=4 \frac{\gamma_{w}}{d_{w}}
$$

where $R=8.314 \mathrm{~J} / \mathrm{mol} / \mathrm{K}$ is the universal gas constant, $v_{H}=18.015 \mathrm{~cm}^{3} / \mathrm{mol}$ is the molar volume of water and $\gamma_{w}=0.07197 \mathrm{~N} / \mathrm{m}$ is the surface tension of water/air interface.

The largest diameter $d_{w}$ is estimated according to the hydration model of HYMOSTRUCT 22]. Nevertheless, the adsorbed water is not accounted for in the present study. Hence, the capillary pore size distribution of the cement is assumed to be of the form:

$$
\Phi_{<d}=a \cdot \ln \left(\frac{d}{d_{0}}\right)
$$

where $\Phi_{<d}$ is the volume fraction of capillary pores of diameter smaller than $d$ in the cement paste and $d_{0}=4 \mathrm{~nm}$ is the diameter of the smallest capillary pore. The coefficient $a$ can be tuned to fit the span of the pore size distribution. Indeed, the diameter of the largest pore is $d_{\text {max }}(t)=d_{0} \exp (\Phi(t) / a)$. Moreover, a numerical model to estimate $a$ has been designed [50] : it is likely that $a$ depends on the temperature history, the hydration degree or the water to cement ratio. Following the results reported in [50], the following trend is considered:

$$
a=\begin{array}{ll}
0.1 & \text { if } w / c>0.4 \\
0.1+0.4(0.4-w / c) & \text { if } w / c<0.4
\end{array}
$$




$\begin{array}{ccc}i & E_{i}(\mathrm{~kJ} / \mathrm{mol}) & E_{i} / R(\mathrm{~K}) \\ \mathrm{C}_{3} \mathrm{~A} & 54 & 6500 \\ \mathrm{C}_{3} \mathrm{~S} & 42 & 5000 \\ \mathrm{C}_{4} \mathrm{AF} & 32 & 3800 \\ \mathrm{C}_{2} \mathrm{~S} & 21 & 2500\end{array}$

Table 1.4: The activation energies of the mineral species considered in the present study are taken from [60, 64].

This trend ensures a rapid decrease of $d_{\max }(t)$ for low $w / c$ ratios. The volume of water in the capillary pores is then estimated as:

$$
\Phi_{w}=\Phi_{c a p}+\delta V_{c h} / 1 \mathrm{~cm}^{3}=v_{H} N_{H} / 1 \mathrm{~cm}^{3}
$$

Finally, the diameter of the largest pore full of water $d_{w}$ is such that:

$$
\Phi_{w}=a \ln \left(\frac{d_{w}}{d_{0}}\right)
$$

Once $d_{w}$ is estimated, equations (11) and (10) are successively applied to compute $h$ and $\beta_{h}$. Lastly, if $h$ is lower than $80 \%$, the coefficient $\beta_{h}$ is set to zero so as to stop the hydration. This feature is of paramount importance to properly estimate the hydration degree of cement paste featuring a low $w / c$ ratio. The influence of the temperature is introduced in the next section.

By performing NRM relaxometry [51, 52], it has been shown that there is no capillary water at 28 days in a sealed sample of cement paste featuring a water to cement ratio of 0.4 . Nevertheless, the relative humidity of the sealed sample is still above $91 \%$ : pores of $23 \mathrm{~nm}$ in diameter are still full of water according to the Kelvin equation. As a consequence, the statement that the hydration continues to take place in the absence of remaining capillary water clearly refers to the capillary water identified by NRM, which strongly differs from the capillary water considered by Powers. As a result, the proposed model considering the effect of the relative humidity does not contradict recent evidence from NRM relaxometry.

\subsection{Influence of temperature on hydration kinetics}

The temperature and the rates of the hydration reactions are tightly coupled. On the one hand, raising the temperature increases the rates of the hydration reactions. On the other hand these chemical reactions release heat which triggers a raise of temperature in adiabatic conditions. Hence, semi-adiabatic calorimetry tests are performed to estimate the evolution of the hydration degree with time. In the present section, the hydration model is adapted to account for the effect of temperature on hydration kinetics and a semi-adiabatic calorimetry test is modeled.

\subsubsection{Acceleration of hydration reactions with temperature}

It is well-known that increasing the temperature speeds up the chemical reactions of hydration. The thermo-activation of the reactions is modeled by the Arrhenius law which links the actual time $t$ to an equivalent time $t_{e q}$ at the reference temperature $T_{0}$ [53] :

$$
t_{e q}(t)=\int_{0}^{t} e^{-\frac{E a}{R}\left(\frac{1}{T(t)}-\frac{1}{T_{0}}\right)} \mathrm{d} t
$$

where $E a$ is the activation energy in $\mathrm{J} / \mathrm{mol}$ and $R=8.314 \mathrm{~J} / \mathrm{mol} / \mathrm{K}$ is the gas constant. A default uniform value of the activation energy is often assumed to perform structural analysis [54, 55, 56, 57. Yet, the apparent activation energy of cementitious materials depends on the temperature, the hydration degree [22, 58, the cement type [59, the cement composition [22, 60, 61, 62, 63, 30], the Blaine fineness [62, 63] and the water to cement ratio 64]. In the hydration model of Maekawa et. al. 60, the activation energy $E_{i} / R$ depends on the mineral $i \in\left(\mathrm{C}_{3} \mathrm{~S}, \mathrm{C}_{2} \mathrm{~S}, \mathrm{C}_{3} \mathrm{~A}, \mathrm{C}_{4} \mathrm{AF}\right)$ and the stage of hydration. Indeed, the apparent activation energy decreases towards $21 \mathrm{~kJ} / \mathrm{mol}$ during the diffusion stage of hydration [65]. It must be noticed that this activation energy is comparable to the activation energy for ion diffusion in water $(18 \mathrm{~kJ} / \mathrm{mol})$ [66]. Consequently, the activation energies are lower for the minerals that hydrate later : $E_{\mathrm{C}_{3} \mathrm{~A}}>E_{\mathrm{C}_{3} \mathrm{~S}}>E_{\mathrm{C}_{4} \mathrm{AF}}>E_{\mathrm{C}_{2} \mathrm{~S}}$ (Tab. 1.4) 60, 64].

As-is, isothermal calorimetry tests at different temperatures can be modeled. Nevertheless, a very common test on cement hydration is the semi-adiabatic calorimetry test, where the heat released by the exothermic chemical reactions partly induces an increase of the temperature of the mortar. Therefore, a minimal thermodynamic framework is presented in the next section to investigate this coupling. 


\subsubsection{Modeling semi-adiabatic calorimetry test}

The change of enthalpy of a system $\mathrm{d} H$ balances the released heat $\delta Q$ as long as quasistatic isobaric processes are considered. Moreover, the enthalpy of the system is a function of its temperature $T$, its pressure $P$ and the molar content $N_{i}$ of each chemical species $i$. Consequently, the following equation can be written for quasi-static isobaric processes:

$$
-\delta Q=\mathrm{d} H=C_{p}\left(P, T, N_{i}\right) \mathrm{d} T+\sum_{i} \Delta_{f} H_{i}(P, T) \mathrm{d} N_{i}
$$

where $C_{p}\left(P, T, N_{i}\right)$ is the total heat capacity of the system and $\Delta_{f} H_{i}(P, T)$ is the molar enthalpy of formation of the chemical species. The heat capacity reads:

$$
C_{p}\left(P, T, N_{i}\right)=\sum_{i} C_{p, i}(P, T) N_{i}
$$

where $C_{p, i}(P, T)$ is the molar heat capacity of the chemical species $i$. It is assumed that the heat capacity is independent from the temperature, which is reasonable given the narrow range of temperature that is considered for cement hydration $\left(10^{\circ} \mathrm{C}-70^{\circ} \mathrm{C}\right)$. This hypothesis is no longer valid if the solubilities of the various chemical species and their phase diagrams were to be studied. Lastly, the dependence on pressure is beyond the scope of the present study : it is assumed that the hydration occurs at a constant pressure equal to the standard pressure of $P=0.1 \mathrm{MPa}$ (1bar). The molar enthalpy of formation $\Delta_{f} H_{i}(P, T)$ of the chemical species $i$ depends logically on temperature through the corresponding molar heat capacity:

$$
\Delta_{f} H_{i}(P, T)=\Delta_{f} H_{i}\left(P, T_{0}\right)+\int_{T_{0}}^{T} C_{p, i}(P, \theta) \mathrm{d} \theta
$$

where $\Delta_{f} H_{i}\left(P, T_{0}\right)$ is the standard enthalpy of formation at the reference temperature of $25^{\circ} \mathrm{C}$ and $P=0.1 \mathrm{MPa}$ as given in the tables of chemical thermodynamic properties [67. The changes of the molar contents is related to the chemical reactions:

$$
-\delta Q=\mathrm{d} H=\left(\sum_{i} C_{p, i} \cdot N_{i}\right) \mathrm{d} T+\sum_{i}\left(\Delta_{f} H_{i}\left(P, T_{0}\right)+\left(T-T_{0}\right) \cdot C_{p, i}\right) \mathrm{d} N_{i}
$$

The change of enthalpy related the consumption of reactants and formation of products can be grouped by reaction:

$$
-\delta Q=d H=\left(\sum_{i} C_{p, i} \cdot N_{i}\right) d T+\sum_{r}\left(\Delta_{r} H\left(P, T_{0}\right)+\left(T-T_{0}\right) \cdot C_{p, r}\right) d \alpha_{r} N_{0, r}
$$

where $\Delta_{r} H\left(P, T_{0}\right)$ is the heat released by an isothermal reaction of one mole of the reference reactant (one of $\mathrm{C}_{3} \mathrm{~S}, \mathrm{C}_{2} \mathrm{~S}, \mathrm{C}_{3} \mathrm{~A}, \mathrm{C}_{4} \mathrm{AF}$ ) of the reaction $r, N_{0, r}$ is the initial quantity of the reference reactant and $C_{p, r}$ is the difference of heat capacity of the reactants and the products, for one mole of the reference reactant:

$$
\begin{array}{llr}
\Delta_{r} H\left(P, T_{0}\right) & = & \sum_{i \in r} \nu_{r, i} \Delta_{f} H_{i}\left(P, T_{0}\right) \\
C_{p, r} & = & \sum_{i \in r} \nu_{r, i} C_{p, i}
\end{array}
$$

where $\nu_{r, i}$ is the signed stochiometric coefficient of reactant $i$ in reaction $r$, the stochiometric coefficient of the reference reactant being $\nu_{r, i_{r}}=-1$. The effect of temperature on the enthalpy of formation is limited in the considered range of temperature due to the orders of magnitude of the molar changes of heat capacity $(\approx 100 \mathrm{~J} / \mathrm{mol} / \mathrm{K})$ and molar enthalpy of reactions $(\approx 100 \mathrm{~kJ} / \mathrm{mol})$.

The heat released $Q$ depends on the calorimeter and the temperature outside of it $T_{\text {out }}$ as in 68, 69, 56, 57.

$$
\delta Q=\left(a\left(T-T_{\text {out }}\right)+b\left(T-T_{\text {out }}\right)^{2}\right) \mathrm{d} t
$$

where the coefficients $a$ and $b$ result from the calibration of the calorimeter according to the standard NF EN 196-9 68.

The enthalpies of formation of the chemical species come from [67, 70, 71]. The enthalpy of formation of $\mathrm{C}_{1.7} \mathrm{SH}_{4}$ is set so as to comply with the heat of hydration of $\mathrm{C}_{3} \mathrm{~S}$ and $\mathrm{C}_{2} \mathrm{~S}$. The value of $\Delta_{f} H=-3287 \mathrm{~kJ} / \mathrm{mol}$ for $\mathrm{C}_{1.7} \mathrm{SH}_{4}$ is comparable to the value of $-2890 \mathrm{~kJ} / \mathrm{mol}$ estimated by Fujii and Kondo [72] for $\mathrm{C}_{1.7} \mathrm{SH}_{2.617}$ if the enthalpy of formation of the additional water $(4-2.161) \mathrm{H}$ is similar to that of liquid water $\Delta_{f} H=-285.83 \mathrm{~kJ} / \mathrm{mol}$. The heat capacity of $\mathrm{C}_{1.7} \mathrm{SH}_{4}$ is estimated at $C_{p}=297 \mathrm{~J} / \mathrm{mol} / \mathrm{k}$ starting from the heat capacity $C_{p}=190.10$ $\mathrm{J} / \mathrm{mol} / \mathrm{K}$ of $\mathrm{C}_{1.6} \mathrm{SH}_{2.58}$ obtained by Blanc et. al. [73, 74] if the heat capacity of the additional water is similar to that of liquid water $C_{p}=75.291 \mathrm{~J} / \mathrm{mol} / \mathrm{K}$. Heat capacities measured by Ederová and Šatava [75, 76] are colored in blue in table 1.1. Thermochemical values of 
$\mathrm{Fe}(\mathrm{OH})_{3}$ are available in the NIST-JANAF thermochemical tables [77]. Finally, the molar heat capacity and molar enthalpy of formation of $\mathrm{C}_{6} \mathrm{AFS}_{2.18} \mathrm{H}_{19}$ are the sums of the ones of $\mathrm{C}_{3} \mathrm{FS}_{1.34} \mathrm{H}_{3.32}$ and $\mathrm{C}_{3} \mathrm{AS}_{0.84} \mathrm{H}_{4.32}$ as reported in [28] plus 11.36 times that of liquid water. Derived values of the heat of hydration $\Delta_{r} H\left(P, T_{0}\right)$ and changes of heat capacities $C_{p, r}$ of each reaction $r$ are reported in table 1.2 .

\subsection{Effect of additional silicate}

As in [78, 79], a pozzolanic reaction consumes the silicate $\mathrm{S}$ and Portlandite to produce pozzolanic $\mathrm{C}_{1.1} \mathrm{SH}_{3.9}$ featuring a $\mathrm{C} / \mathrm{S}$ ratio lower than that of the $\mathrm{C}_{1.7} \mathrm{SH}_{4}$ produced by the hydration of $\mathrm{C}_{3} \mathrm{~S}$. The molar volume is assumed to be $101.8 \mathrm{~cm}^{3} / \mathrm{mol}$, to be compliant with the measured chemical shrinkage of $0.2 \mathrm{~cm}^{3}$ per gram of hydrated silicate [78, 799]. Similarly, the enthalpy of formation of $\mathrm{C}_{1.1} \mathrm{SH}_{3.9}$ is set to $-2841 \mathrm{~kJ} / \mathrm{mol}$ so that the heat released by the pozzolanic reaction is $870 \mathrm{~kJ} / \mathrm{kg}$ of $\mathrm{S}[11$. It must be noticed that this specific heat is often higher than that of the cement. Fly ashes may contain aluminate as part of their oxyde composition and a reaction system similar to that of $\mathrm{C}_{3} \mathrm{~A}$ is considered [31](Table 1.2. Hence, the fact that some of the aluminate can be incorporated into the $\mathrm{C}-\mathrm{S}-\mathrm{H}$ phase is not accounted for in the present model. The pozzolanic reactions are more sensitive to temperature than the hydraulic reactions of cement and the influence of temperature on the rate of pozzolanic reactions is modeled by an activation energy of $E_{S, A}=83,14 \mathrm{~kJ} / \mathrm{mol}$ $\left(E_{S, A} / R=100 \mathrm{~K}\right)$.

The reactivity of silica fume is due to its high specific surface, which is measured at about $20000 \mathrm{~m}^{2} / \mathrm{kg}$ by B.E.T. technics 31. It could be compared to the Blaine surface of cements $\left(350-400 \mathrm{~m}^{2} / \mathrm{kg}\right)$ or fly ashes $\left(375-450 \mathrm{~m}^{2} / \mathrm{kg}\right)$. Nevertheless, it must be mentioned that the measurement procedures refer to different physical phenomena (adsorption and air permeability) which may not depend on the same surface. B.E.T. and Mercury Intrusion Porosimetry suggest that the specific surface of silica fume could be considered as 20 times higher than that of a typical cement [80. Finally, since our hydration model makes use of the Blaine fineness, a specific surface of $2000 \mathrm{~m}^{2} / \mathrm{kg}$ is considered as default for silica fume to keep the same kinetics for both silica fumes and fly ashes and provide a reasonable estimate of the degree of hydration of cement blended with silica fumes.

The kinetics of the pozzolanic reactions is set according to the results of Waller [31]. The degree of pozzolanic reactions $\alpha_{S}$ of a fly ash of Blaine fineness $400 \mathrm{~m}^{2} / \mathrm{kg}$ at $20^{\circ} \mathrm{C}$ writes:

$$
\alpha_{S}=\frac{1}{1+\left(\frac{\tau}{t}\right)^{n}}
$$

where $n=0.7$ and $\tau=80$ days are coefficients adjusted to the results of analysis of Scanning Electron Microscopy (SEM) images reported in [81, assuming a fly ash of pozzolanic activity of $60 \%$. The corresponding reaction rate writes [31]:

$$
\dot{\alpha}_{S}=\frac{n}{\tau}\left(\alpha_{S}\right)^{1-\frac{1}{n}}\left(1-\alpha_{S}\right)^{1+\frac{1}{n}}
$$

Finally, this equation can be tuned to account for the effect of the Blaine fineness, the relative humidity and temperature as shown in the previous sections.

The updated hydration model produces estimates of the volume fractions of the constitutive phases of blended cement pastes as a function of the hydration degree and time (Fig. 1.1). These volume fractions are provided as inputs to a micromechanical scheme in the next section.

\section{Using homogenization schemes to estimate the mechanical properties}

\subsection{Estimating the overall behavior of concrete}

In the present section, concrete is depicted as a multiscale composite material. A brief overview of up-to-date mean-field homogenization models dedicated to cementitious materials is to be performed. At each scale, depending on the microstructural morphology, either the Mori-Tanaka scheme [82] or the self-consistent scheme [83] are applied to estimate the timedependent mechanical properties of the composite material starting from the properties of the constitutive phases and their geometrical shapes. The expressions of the overall stiffnesses derived by using these schemes are recalled in Appendix A.

Multiscale models designed to upscale the mechanical properties of cementitious material can significantly differ. For instance, in the micromechanical model of Constantinides and Ulm [15], the low density C-S-H (LD-C-S-H) and the high density C-S-H (HD-C-S-H) 

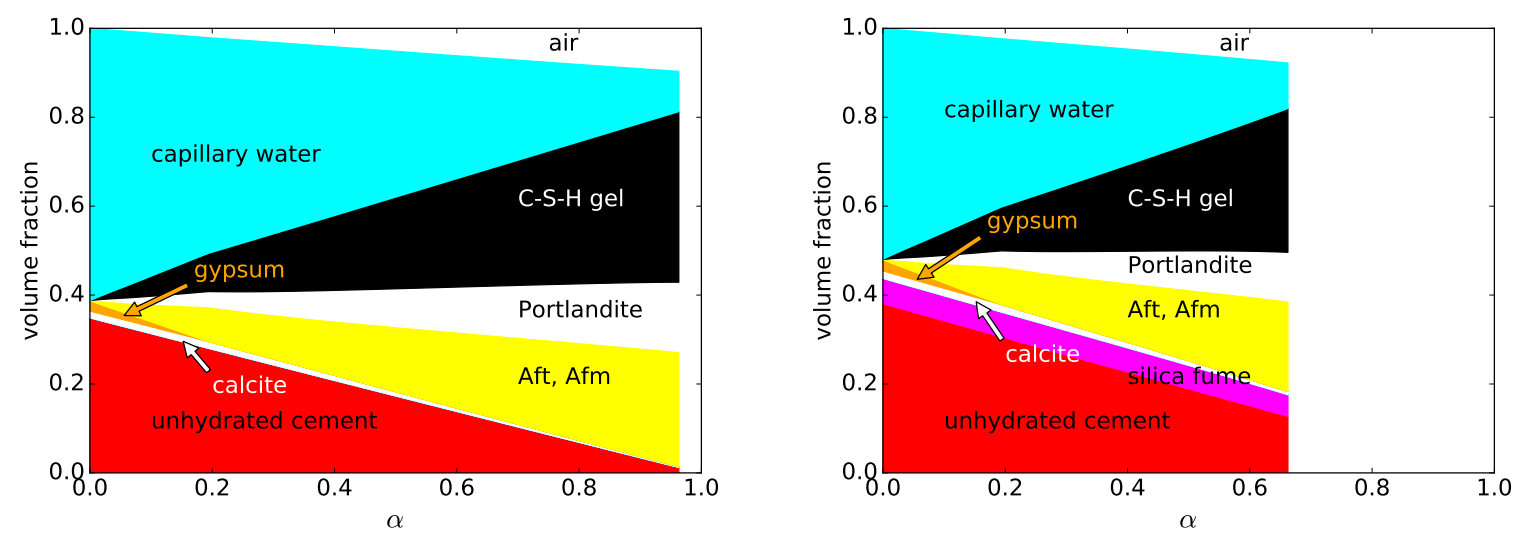

Figure 1.1: Evolutions of the volume fractions of the main constitutive phases of sealed cement pastes as functions of the hydration degree of the cement $\alpha$. Left: a plain cement paste $w / c=0.5$, (Tab. 4.1), right: a cement blended with $10 \%$ silica fume, $w /(c+s f)=0.35$ (Tab. 4.1).

[13, 84] are merged by using the Mori-Tanaka scheme, the low density $\mathrm{C}-\mathrm{S}-\mathrm{H}$ being the matrix. This mix defines the matrix of the cement paste, in which the capillary porosity, unhydrated particles and $\mathrm{CH}$ are embedded. Hence, the Mori-Tanaka scheme is used to estimate the behavior of the cement paste. Finally, at the scale of the mortar, the aggregates and the cement paste are respectively the inclusions and the matrix in the Mori-Tanaka scheme applied to estimate the overall elastic properties. Modeling of the setting of concrete is achieved by introducing the self-consistent scheme at the scale of the cement paste [16. To model the autogenous shrinkage, Pichler et. al. [17] have introduced an additional scale, that of porous $\mathrm{C}-\mathrm{S}-\mathrm{H}$, where the $\mathrm{C}-\mathrm{S}-\mathrm{H}$ and the capillary porosity are merged using the Mori-Tanaka scheme to define the matrix of the cement paste. Similarly, Sanahuja et. al. [18] handled HD-C-S-H as a coating of unhydrated particles at the scale of the cement paste. The properties of the porous $\mathrm{LD}-\mathrm{C}-\mathrm{S}-\mathrm{H}$ are defined by a self-consistent scheme and an aspect ratio of LD-C-S-H of 0.033 is introduced to recover an acceptable estimate of the hydration degree at setting. On the contrary, Ghabezloo recovered a reasonable estimate of the overall stiffness by using the self-consistent scheme at the scale of the cement paste, but all phases (LD-C-S-H, HD-C-S-H, big capillary pores...) featured a spherical morphology [19]. In the model of Pichler and Hellmich [2, 20, which relies on the hydration model of Powers and Brownyard [12], the self-consistent scheme is applied to estimate the elastic properties and the compressive strength of the porous hydrates, the hydrates being considered as infinitely long cylinders mixed with the capillary porosity. Yet, by performing experiments on $\mathrm{C}_{3} \mathrm{~S}$ and $\mathrm{C}_{2} \mathrm{~S}$ pastes, Termkhajornkit et. al. 21] have questioned the fact that the gel-space ratio, related to the capillary porosity, is a good indicator of the strength of a mortar [7]. Their micromechanical model relies on a porous $\mathrm{C}-\mathrm{S}-\mathrm{H}$ matrix defined as a mix between solid $\mathrm{C}-\mathrm{S}-\mathrm{H}$ and the total porosity, including gel porosity, so as to ensure a better agreement with their experimental data on compressive strength. The molar volume of solid $\mathrm{C}_{1.7} \mathrm{SH}_{1.8}$ is set to $v_{s C-S-H}=70 \mathrm{~cm}^{3} / \mathrm{mol}$ according to NMR Relaxometry [51] and the Young modulus and aspect ratio of the solid $\mathrm{C}-\mathrm{S}-\mathrm{H}$ respectively are $57 \mathrm{GPa}$ and 15 . The Portlandite and the unhydrated clinker are then introduced as inclusions in the porous $\mathrm{C}-\mathrm{S}-\mathrm{H}$. But this homogenization model significantly underestimates the overall elastic stiffness of the cement paste.

Finally, introducing infinite, large or small aspect ratios in a porous microstructure suggests buckling as a potential failure mode, as introduced in [11. Indeed, a cylinder of aspect ratio 35 , stiffness $29 \mathrm{GPa}$, fixed at both ends will reach the Euler critical strength and experience buckling as soon as the axial compressive stress exceeds $120 \mathrm{MPa}$, which corresponds to the critical Von Mises value considered in Pichler and Hellmich for infinite aspect ratio 2,20$]$. Since the only reason for introducing elongated particles in the self-consistent scheme is to produce an acceptable estimate of the setting and early strength development, accounting for the hydration degree at setting is required. First, the hydration degree at setting is in the range $2.7-4.3 \%$ for cement pastes of water to cement ratio in the range $0.25-0.4$ [85]. These figures correspond to a gel-space ratio of about $7 \%$ below which the compressive strength is null. It has been observed on mortars of $\mathrm{w} / \mathrm{c}$ in the range $0.3-0.5$ that the onset of the shear moduli measured by ultrasonic tests corresponds to a minimum heat release of at least $100 \mathrm{~J} / \mathrm{ml}$ of water [86]. Retaining an heat of hydration of $500 \mathrm{~kJ} / \mathrm{kg}$ for the cement, it 
corresponds to gel-space ratios of about $13 \%$. Though setting at gel-space ratios of $7 \%$ and $13 \%$ would be properly described by choosing aspect ratios of 35 or 21 in the self-consistent scheme, an aspect ratio of 7 is chosen so as to ensure a better agreement with experimental measurements of the compressive strength on cement pastes and mortars [87, 88].

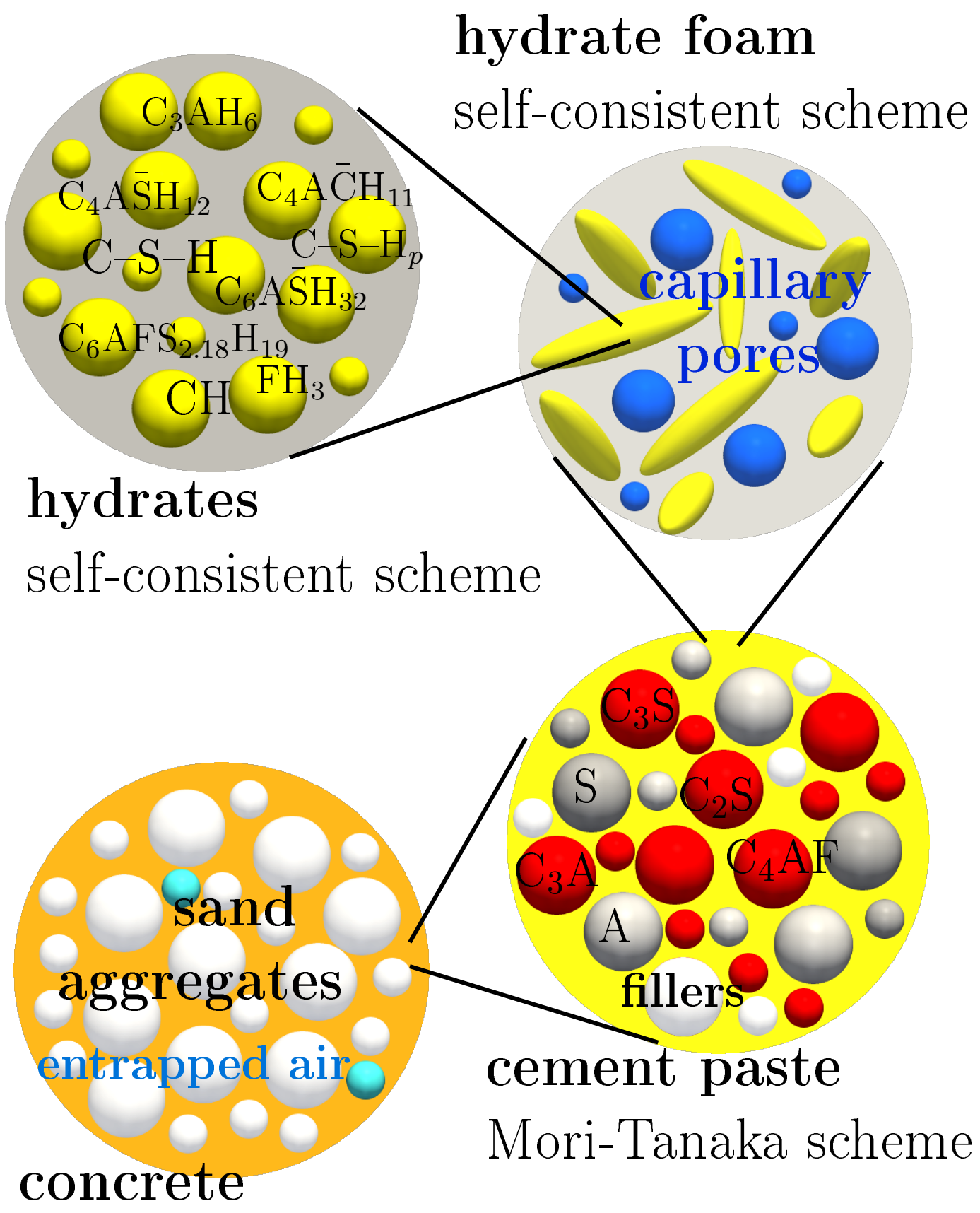

\section{Mori-Tanaka scheme}

Figure 2.1: The different scales considered for the homogenization of cementitious materials. The phases and the homognization schemes are detailled at each scale.

Hence, the multiscale homogenization scheme introduced in the present article (Fig. 2.1) is very similar to the one introduced by Pichler and Hellmich [2, 20, 89] as it proved able to estimate the elastic stiffness, the compressive strength and the short term non-aging creep strain of cement pastes:

1. At the smallest scale, all the hydrates are merged by using the self consistent scheme. The Young modulus of the $\mathrm{C}_{1.7} \mathrm{SH}_{4}$ and $\mathrm{C}_{1.1} \mathrm{SH}_{3.9}$ of respective density $2.08 \mathrm{~g} / \mathrm{cm}^{3}$ and $1.9 \mathrm{~g} / \mathrm{cm}^{3}$ is set to $25 \mathrm{GPa}$ and the Poisson ratio to 0.24 . This value is a median of the stiffness of HD-C-S-H and LD-C-S-H identified by Constantinides and Ulm [15] on C-S-H foams. To compute Eshelby tensors, all phases are considered as spherical at this scale.

2. At the scale of the hydrate foam, the hydrates are merged with the capillary porosity using the self-consistent scheme. As underlined in [16], the bulk modulus of the pores strongly affects the estimated overall Poisson's ratio. Consequently, the bulk modulus of the pores is considered to be null for static measurements of the Young modulus, but the bulk modulus of water $(2.2 \mathrm{GPa})$ is accounted for to estimate the dynamic 


\begin{tabular}{cccc}
$i$ & $E$, GPa & $\nu$ & ref. \\
$\mathrm{HD}-\mathrm{C}-\mathrm{S}-\mathrm{H}$ & 29.4 & 0.24 & {$[15]$} \\
$\mathrm{LD}-\mathrm{C}-\mathrm{S}-\mathrm{H}$ & 21.7 & 0.24 & {$[15]$} \\
\hline $\mathrm{C}_{3} \mathrm{~A}, \mathrm{C}_{3} \mathrm{~S}, \mathrm{C}_{4} \mathrm{AF}, \mathrm{C}_{2} \mathrm{~S}$ & 130. & 0.3 & {$[25]$} \\
$\mathrm{CS} \mathrm{H}_{2}$ & 45.7 & 0.33 & {$[119,[120]$} \\
$\mathrm{S}, \mathrm{A}$ & 72.8 & 0.167 & {$[105]$} \\
$\mathrm{C} \overline{\mathrm{C}}$ & 83.8 & 0.31 & {$[121]$} \\
$\mathrm{CH}$ & 42.3 & 0.324 & {$[122]$} \\
$\mathrm{C}_{6} \mathrm{~A} \overline{\mathrm{S}} \mathrm{H}_{32}$ & 22.4 & 0.25 & {$[105]$} \\
$\mathrm{C}_{3} \mathrm{AH}_{6}$ & 22.4 & 0.25 & {$[105$} \\
$\mathrm{C}_{6} \mathrm{AFS}_{2.18} \mathrm{H}_{19}$ & 22.4 & 0.25 & {$[105]$} \\
$\mathrm{FH}_{3}$ & 22.4 & 0.25 & {$[105]$} \\
$\mathrm{C}_{4} \mathrm{~A} \overline{\mathrm{C}} \mathrm{H}_{11}$ & 42.3 & 0.324 & {$[105]$} \\
$\mathrm{C}_{4} \mathrm{~A} \overline{\mathrm{S}} \mathrm{H}_{12}$ & 42.3 & 0.324 & {$[105]$}
\end{tabular}

Table 2.1: The stiffnesses of the different phases of the $\mathrm{C}-\mathrm{S}-\mathrm{H}$ foam and the cement paste. The Young modulus $E$ and the Poisson's ratio $\nu$ of each phase are given.

\begin{tabular}{ccc}
$i$ & $E$, GPa & $\nu$ \\
fillers & 65 & 0.2 \\
\hline bauxite & 150 & 0.2 \\
andesite, basalt & 80 & 0.25 \\
sand & 70 & 0.07 \\
quartzite & 70 & 0.1 \\
limestone & 60 & 0.15 \\
sandstone & 45 & 0.15 \\
\hline other & 65 & 0.15
\end{tabular}

Table 2.2: The default stiffnesses of the different inert phases involved at the different scales. The Young modulus $E$ and the Poisson's ratio $\nu$ of each phase are given.

Young modulus and dynamic Poisson's ratio. In this case, a bulk modulus $K_{c a p}$ is set for the water-filled fraction of the capillary porosity, which turn the hydrate foam into a three-phase material.

An aspect ratio of 7 is chosen for the fibrillar, directional morphology of the hydrates, which has been observed at the scale of 100-500nm on Transmission Electron Microscopy (TEM) images [90. Moreover, this aspect ratio, combined to the self-consistent scheme, ensures a reasonable estimate of the strength at early age.

3. At the scale of cement paste $(1 \mu \mathrm{m}-65 \mu \mathrm{m})$, all reactants of chemical reactions and the fillers are considered as inclusions embedded in the hydrate foam. Hence, the Mori-Tanaka scheme is applied to estimate the elastic stiffness and the strength of the cement paste. Mechanical stiffness are reported in table 2.1. To estimate the brittle failure of the cementitious material, a Von Mises criteria is set for the hydrate inclusions as in [2, 20]. The quadratic mean of the Von Mises stress is estimated by using Kreher's lemma [91] (see appendix Appendix A) on a collection of 20 orientations for hydrate inclusions introduced at the scale of the hydrate foam. For each orientation, this quadratic mean is compared to the Von Mises stress at failure set to $\sigma_{V M \text {,hyd }}=120$ MPa. It is perfectly consistent with the 70MPa criteria introduced by Pichler and Hellmich on the quadratic average of the deviatoric part of the stress field, which must be multiplied by $\sqrt{3}$ if the Von Mises stress is considered. The cement paste fails as soon as a single orientation reaches the criterion, thus defining the compressive strength of the cement paste $f_{c, p}$.

4. The scale of concrete $(>65 \mu \mathrm{m})$ : the sand and the entrapped air are considered as inclusions embedded in the cement paste. Again, the elastic stiffness is estimated according to the Mori-Tanaka scheme, the cement paste being the matrix. The Interfacial Transition Zone that could exists at the interface between the aggregates and the cement paste is not accounted for in the present model and a perfect bonding is assumed between the aggregates and the cement paste, which is considered as homogeneous at this scale. Nevertheless, estimating the compressive strength of the mortar starting from that of the cement paste requires a particular attention. The new procedure and the underlining assumptions are described in the following section. 


\subsection{Estimating the compressive strength of mortar}

Even if the quadratic mean of the equivalent stress in the hydrate is estimated according to Kreher's equation [91, the stress concentrations in the cementitious matrix due to the aggregates are not properly accounted for. Indeed, in the article of Pichler et. al. [2, the estimated compressive strength of a mortar featuring a water to cement ratio of 0.5 is estimated to be similar to that of a cement paste of water to cement ratio 0.42 . Hence, the homogenization method of Pichler et. al. suggests that a mortar is significantly stronger (up to about 20\%) than a cement paste featuring the same water to cement ratio and the same hydration degree. It contradicts experimental evidences : the strengths of mortar and concrete are expected to be lower that those of their cementitious matrices (down to about $-10 \%$ for mortar and about $-30 \%$ for concrete), even if the tested prismatic samples all feature the same aspect ratio of 3:1 to reduce the confining effect of end restraint 92. On the one hand, this contradiction could be resolved by introducing an heterogeneous cementitious matrix featuring an Interfacial Transition Zone as the weakest link. On the other hand, a better way to estimate the stress fluctuations in the cementitious matrix can be introduced.

In the present article, the stress fluctuations in the cementitious matrix are accounted for as performed in the range of polycrystals [93. But the theoretical analysis need to be adapted to matrix-inclusion composite materials and checked. To this end, the local values of the stress are assumed to be multivariate normally distributed, the covariance matrix being isotropic. Hence, the deviatoric part of the stress in the matrix $s$ is 5-variate normally distributed using $\sigma_{11}, \sigma_{22}, \sqrt{2} \sigma_{23}, \sqrt{2} \sigma_{13}, \sqrt{2} \sigma_{12}$ as scalar variables. Indeed, the density function of the deviatoric stress is:

$$
f(s)=\frac{1}{(2 \pi)^{\frac{5}{2}} V^{\frac{5}{2}}} \exp \left(-\frac{1}{2 V}\left(s-s_{0}\right):\left(s-s_{0}\right)\right)
$$

where $\boldsymbol{s}_{0}$ is the mean deviatoric stress in the matrix computed according to the Mori-Tanaka scheme and the standard deviation $V$ drives the fluctuation of the stress field. Consequently, the scaled double dot product $(s: s) / V$ is distributed according to the noncentral chi-squared distribution of 5 degrees of freedom and noncentrality parameter $\lambda=\left(s_{0}: s_{0}\right) / V$ :

$$
s: s \sim V \chi_{5}^{2}\left(\frac{\boldsymbol{s}_{0}: \boldsymbol{s}_{0}}{V}\right)
$$

Hence, the average $\langle s: s>$ writes:

$$
<s: s>=5 V+s_{0}: s_{0}
$$

As $\langle\boldsymbol{s}: \boldsymbol{s}\rangle$ is estimated according to Kreher's lemma 91 and $\boldsymbol{s}_{0}: \boldsymbol{s}_{0}$ is estimated according to the localization tensor (Eq. A.5), the previous equation allows access to the variability $V$ of the deviatoric part of the stress field. In particular, if the considered material is homogeneous, the local stress is uniform and $\langle s: s\rangle=s_{0}: s_{0}$. Hence $V$ is null, and the noncentral chisquared distribution becomes a degenerate distribution. The consistency with the fact that the local stress is uniform is to be noticed. Finally, the cementitious matrix is expected to fail if and only if a volume fraction $c_{f a i l}$ of it has reached a Von Mises stress higher than the compressive strength of the cement paste $f_{c, p}$. The criteria to enforce is:

$$
\mathcal{F}_{V \chi_{5}^{2}(\lambda)}\left(\frac{2}{3} f_{c, p}^{2}\right) \geq 1-c_{f a i l}
$$

where $\mathcal{F}_{V \chi_{5}^{2}(\lambda)}$ is the repartition function of the double dot product $s: s$. To estimate the compressive strength of the mortar, it must be noticed that the noncentrality parameter $\lambda$ is independent from the magnitude of the overall stress: it is evaluated once for all by setting an a priori value of the overall uniaxial stress $\Sigma$. Then, the critical value $V_{c}$ is such that:

$$
V_{c}=\frac{\frac{2}{3} f_{c, p}^{2}}{\mathcal{F}_{\chi_{5}^{2}(\lambda)}^{-1}\left(1-c_{\text {fail }}\right)}
$$

The function stats.ncx2.ppf of scipy 94 is applied to evaluate the inverse of this repartition function. Again, it must be noticed that the value of $\sqrt{V}$ varies directly with the magnitude of the overall uniaxial stress $\Sigma$, the ratio $\beta=\Sigma / \sqrt{V}$ being evaluated at the same time as $\lambda$. Finally, the compressive strength of mortar $f_{c, m}$ writes:

$$
f_{c, m}=\beta \sqrt{V_{c}}
$$


The case of an infinite $\beta$ corresponds to an homogeneous stress in the cementitious matrix. In this particular case, the quadratic average of the Von Mises stress on the matrix is considered so as to define the failure of the mortar.

A value of $c_{f a i l}=1 \%$ is set so as to comply with the observed decrease of compressive strength of mortars compared to the one of cement pastes (10-15\%) [92]. The compressive strength is almost unchanged for $c_{\text {fail }}=10 \%$ and the estimated compressive strength of mortars would become $10 \%$ higher than the strength of the paste if $c_{\text {fail }}$ were set to $25 \%$.

The most critical step of this estimate is the assumption regarding the distribution of the Von Mises stress in the matrix. To investigate the effect of these assumptions, the estimated distribution of the Von Mises stress is compared to that estimated by performing 3D numerical simulation on a cubic representative elementary volume, as performed for polycrystals 95 . The considered periodic unit cell features 597 spherical inclusions packed to a volume fraction of $61 \%$ thanks to the Lubachevsky-Stillinger algorithm (Fig. 2.2] [96, 97]. Periodic boundary conditions are applied to the unit cell, the macroscopic loading being an uniaxial stress $\Sigma_{X X}$. The inclusions are stiffer than the matrix, its Young modulus being 65GPa compared to $15 \mathrm{GPa}$ for the matrix. The Poisson ratio of both phases is 0.2 . Then, the FFT algorithm [98, 99] is applied to compute the elastic response of the unit cell, that is the values of the stress field for each voxel on a regular $160 \times 160 \times 160$ grid. The behavior of "grey voxel", overlapping on both the matrix and the inclusions, is set according to the Reuss bound, using 64 sensing points in each voxel to estimate the local volume fraction as in [97. The estimated overall Young modulus is about $34.4 \mathrm{GPa}$, comparable to $33.5 \mathrm{GPa}$ for a Mori-Tanaka scheme, which corresponds to the Hashin-Strikman lower bound in this case. In addition, full-field and mean-field estimates of the arithmetic and quadratic averages of the Von Mises stress in the matrix are similar. Indeed, the arithmetic averages divided by $\Sigma_{X X}$ respectively are 0.71 and 0.72 , while the scaled quadratic averages respectively are 0.74 and 0.81 . The proposed mean-field model of stress fluctuation is interesting as the span of the distribution of the Von Mises stress is comparable to that obtained by full-field simulations (Fig. 2.2). As a result, $1 \%$ volume of the matrix features Von Mises stress above $1.40 \Sigma_{X X}$ according to full-field simulations, compared to $1.16 \Sigma_{X X}$ according to the proposed meanfield estimate. Regarding the numerical simulations, modifying the inclusion size distribution by requiring that half the volume of inclusions must consist in inclusions featuring volumes 8 times larger than inclusions from the other half does not significantly change the numerical values listed above and the estimated distributions. As a consequence, the last difference can be attributed to the fact that the distribution of the components of the stress in the matrix is not multivariate normally distributed. In addition, the distribution of the Von Mises stress in the matrix is similar to that of the component $\sigma_{x x}(x)$ of the stress as other components are smaller. Moreover, this component is high in particular areas of the matrix, where the load is transferred from one inclusion to the closest ones in the direction of loading (Fig. 2.2). As a conclusion, the proposed model of stress fluctuations provide a practical estimate of the Von Mises stress distribution in the matrix, though the accuracy of 3D numerical simulations is clearly not achieved. Nevertheless, a single 3D elastic computation takes more than a minute: since hundreds of cases are to be considered, the proposed mean field estimate is preferred in the sequel.

\section{Comparisons to existing experimental results}

\subsection{Measures regarding the hydration process from the literature}

The hydration model is now to be validated against evidences from the literature, cement compositions being reported in table 3.1. Various experimental procedures have been designed to assess the accuracy of such models. For instance, the kinetics of hydration reactions described by the model of Parrott and Killoh [1] were adjusted to measurements obtained by quantitative analysis of X-ray diffraction patterns. The results are reproduced in [22]. In addition, the degree of hydration of each phase estimated by the model of Parrott and Killoh can be compared to novel results of XRD/Rietveld analysis [100, 101, 102] (Fig. $3.1,3.2,3.3)$. Although the model features correct characteristic times for the hydration rate of $\mathrm{C}_{3} \mathrm{~S}, \mathrm{C}_{2} \mathrm{~S}$ and $\mathrm{C}_{3} \mathrm{~A}$, the error on the estimate of the hydration degree can be significant. Moreover, the measurements of the hydration degree of $\mathrm{C}_{4} \mathrm{AF}$ seem uncertain and the corresponding estimates can prove inaccurate. Additional sources of uncertainty includes the Bogue composition, which is different if computed according to oxide composition measured by XRD/Rietveld [101], and the Blaine fineness. Nevertheless, the influence of temperature on the hydration degree of each phase of cement is correctly modeled as shown by comparison to the measurements of Escalante García \& Sharp [100]. 


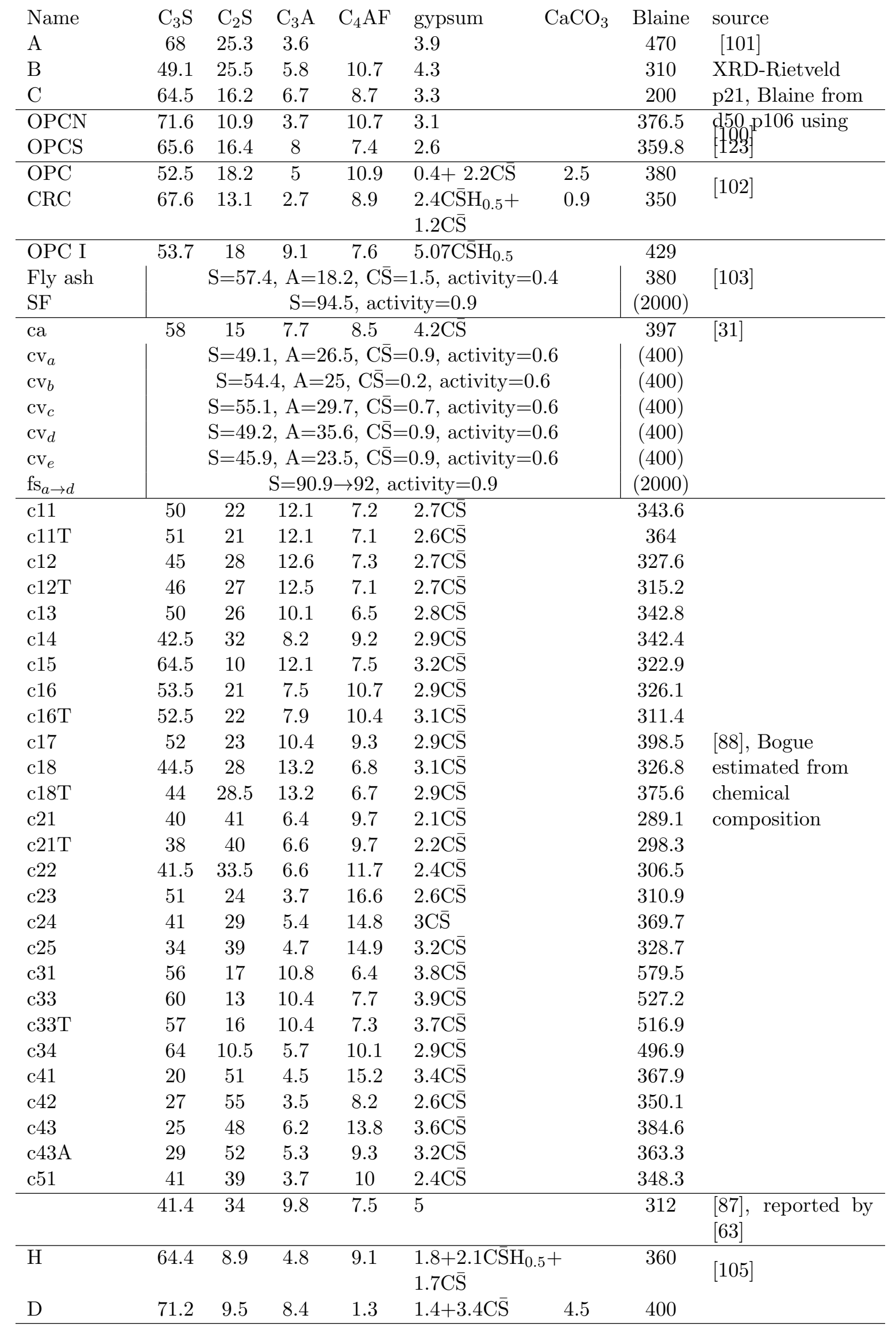

Table 3.1: Parameters of cements considered in the present study. 

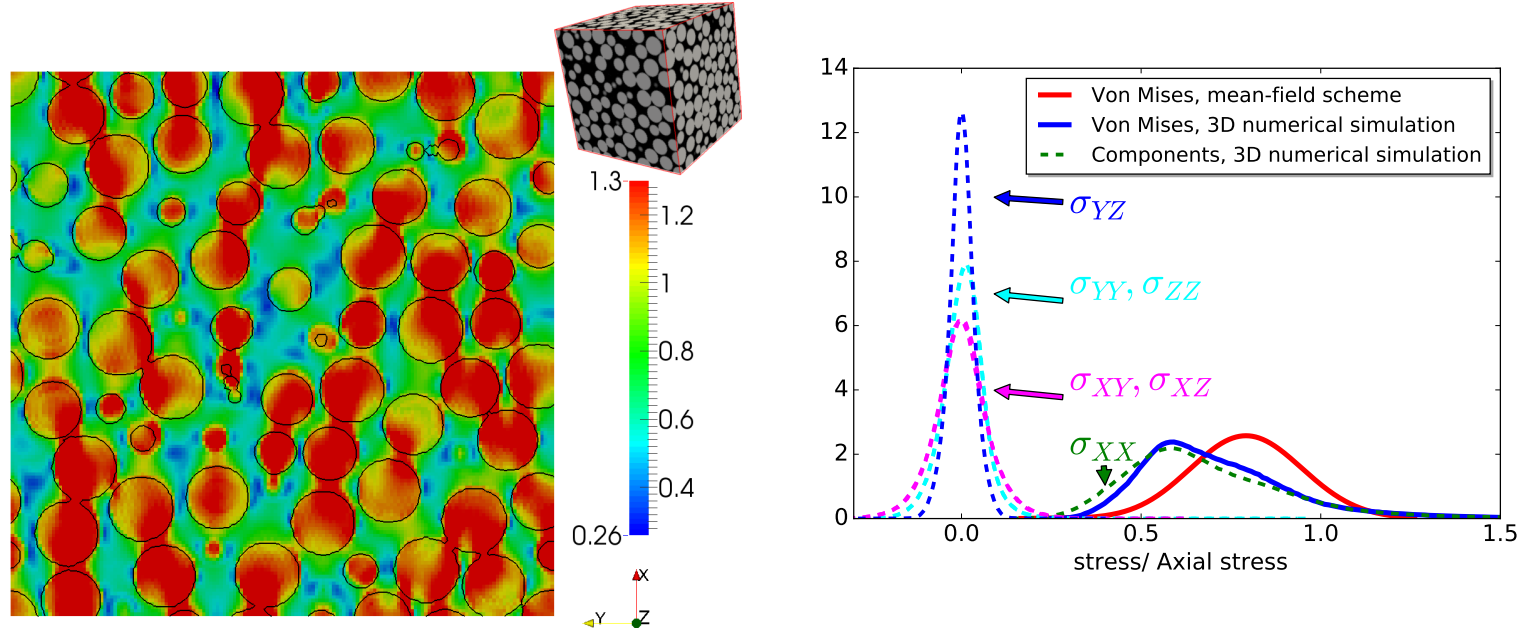

Figure 2.2: Left: local values of the Von Mises stress divided by $\Sigma_{X X}$ within a periodic unit cell as predicted by 3D numerical simulations. Right: Comparisons between the distribution of the Von Mises stress in the matrix estimated by 3D numerical simulations and the proposed mean field method. Distributions of the local components of the stress estimated by $3 \mathrm{D}$ numerical simulations are also reported.
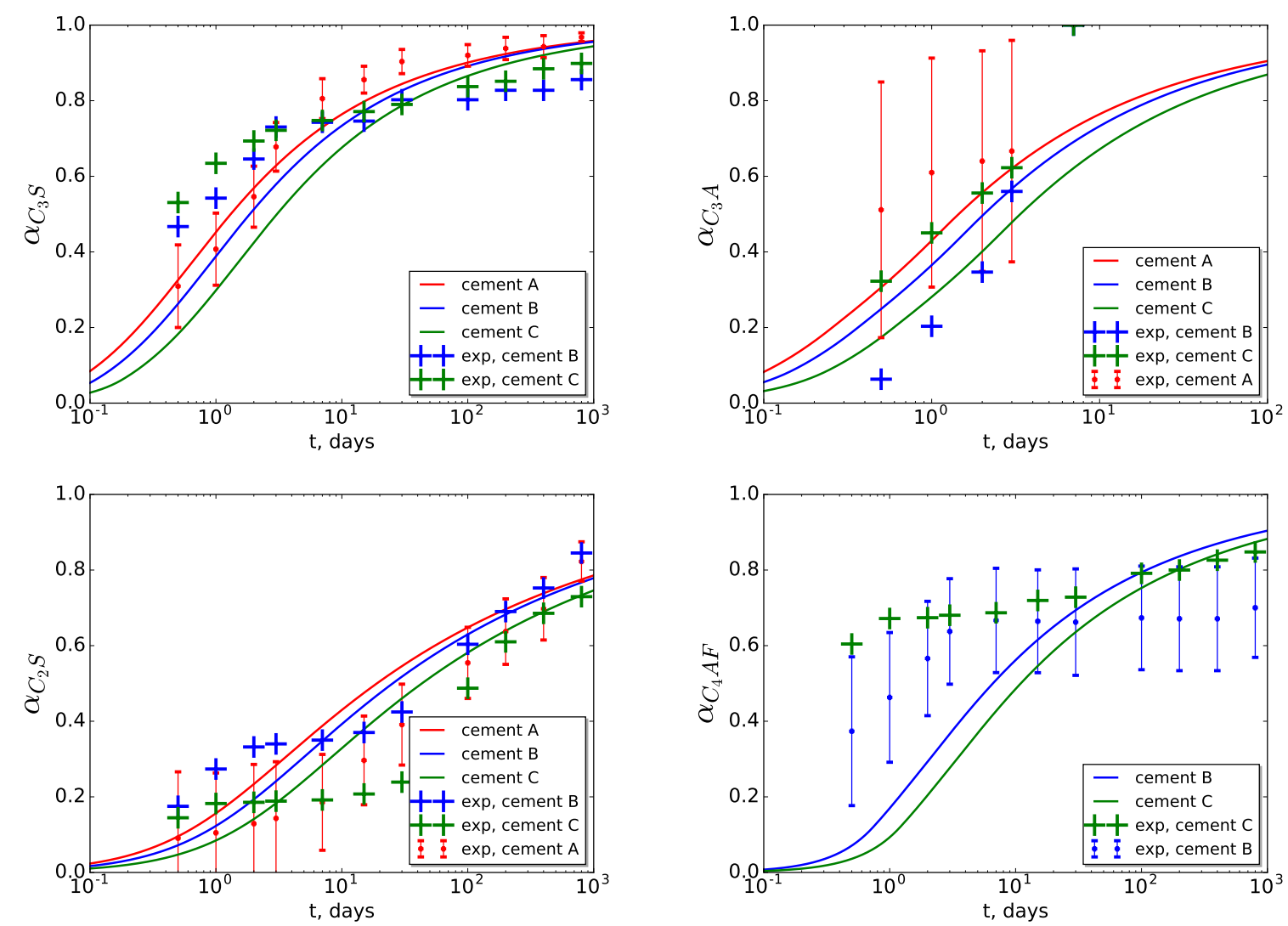

Figure 3.1: Results of XRD/Rietveld analysis [101] are compared to corresponding estimates. The uncertainty is given for a single experimental series for the sake of clarity.

Results of isothermal [88, 31, 103] or semi-adiabatic calorimetry tests [31] can be compared to estimates produced by the hydration model (Fig. 3.3 3.4 3.5). The heat of hydration of cement pastes of water to cement ratio equal to 0.4 is satisfyingly modeled for different ASTM cement types and different temperature tested by Lerch and Ford [88. However, for a given temperature and a given cement type, the estimate of the heat of hydration depends on both the Bogue composition and the Blaine fineness. Since the Bogue composition is computed according to the oxide composition of the cement, a significant uncertainty on the estimated heat of hydration is introduced. The adiabatic calorimetry tests of Waller [31] were performed to measure the effect of silica fumes and fly ashes on the heat of hydration. On the one hand, the present hydration model overestimates the final temperature for low water to cement ratios. On the other hand, the final temperature is accurately estimated for high water to cement ratios. A potential explanation is that concrete featuring a low water to cement ratio can reach adiabatic temperature higher than $70^{\circ} \mathrm{C}$ if the initial temperature of the mix is $20^{\circ} \mathrm{C}$. Hence, the validity range of the hydration model must be limited to temperatures 

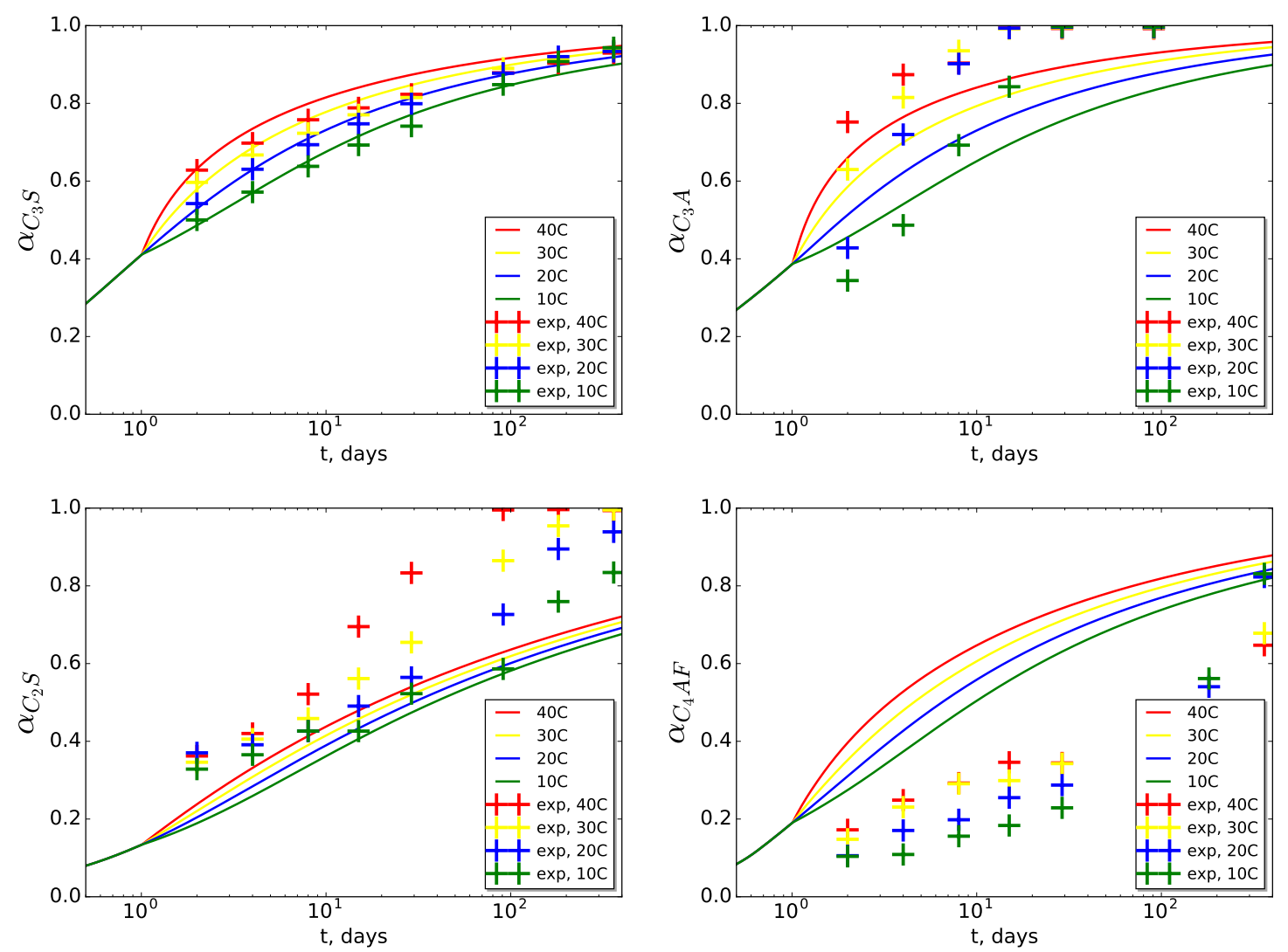

(a) OPCN
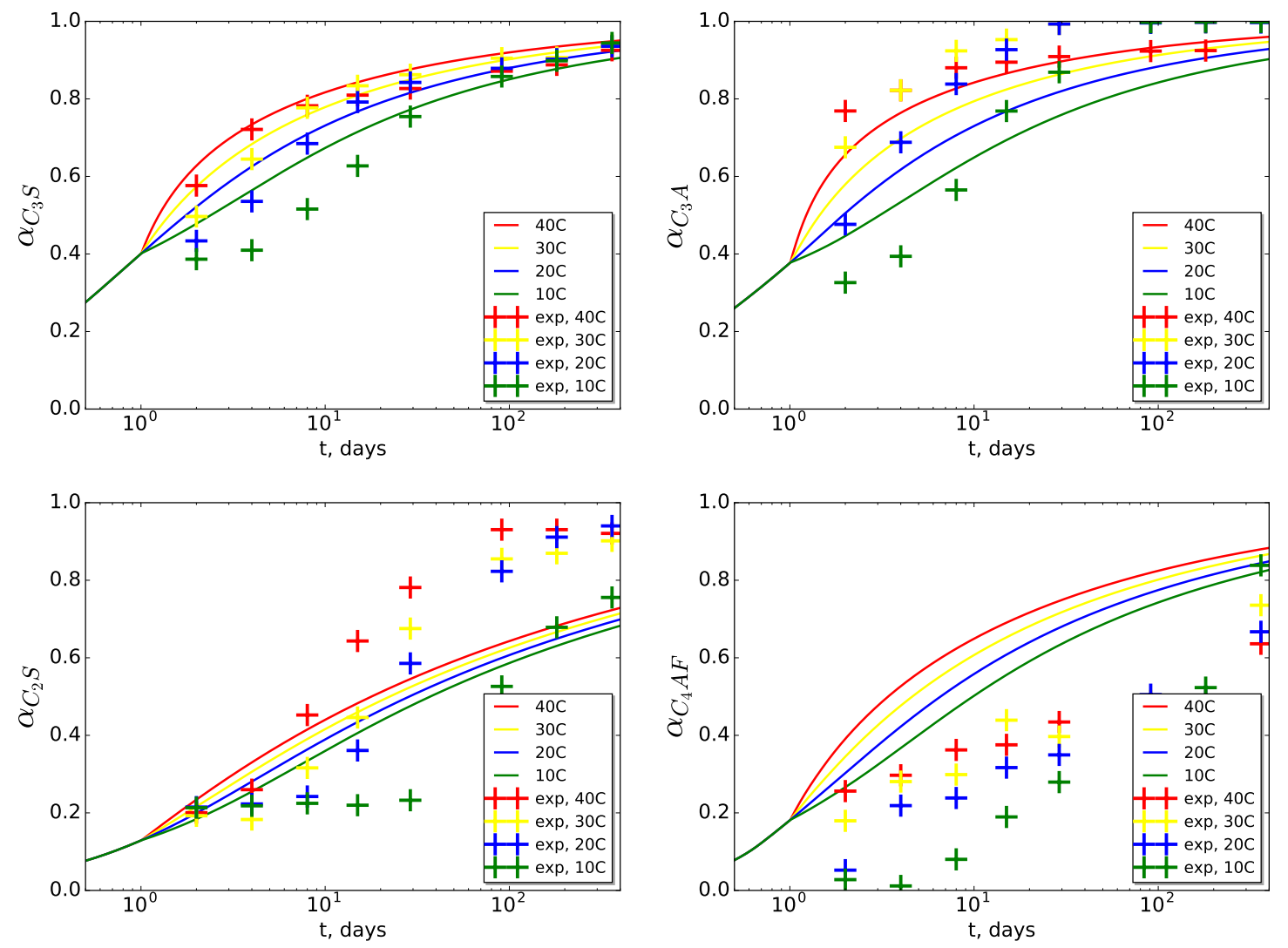

(b) OPCS

Figure 3.2: Results of XRD/Rietveld analysis [100] are compared to corresponding estimates. Samples were cured at $20^{\circ} \mathrm{C}$ for one day and then stored at different temperatures.

lower than $70^{\circ} \mathrm{C}$. Pane and Hansen [103] have also investigated the hydration of cement by isothermal calorimetry and thermogravimetry. The measured heat of hydration, mass of bounded water and mass of Portlandite are successfully compared to their corresponding estimates. In particular, displaying the mass of Portlandite as a function of the mass of bounded water for different temperatures reveals the fact that pozzolanic reactions are more sensitive to temperature than hydraulic reactions. 

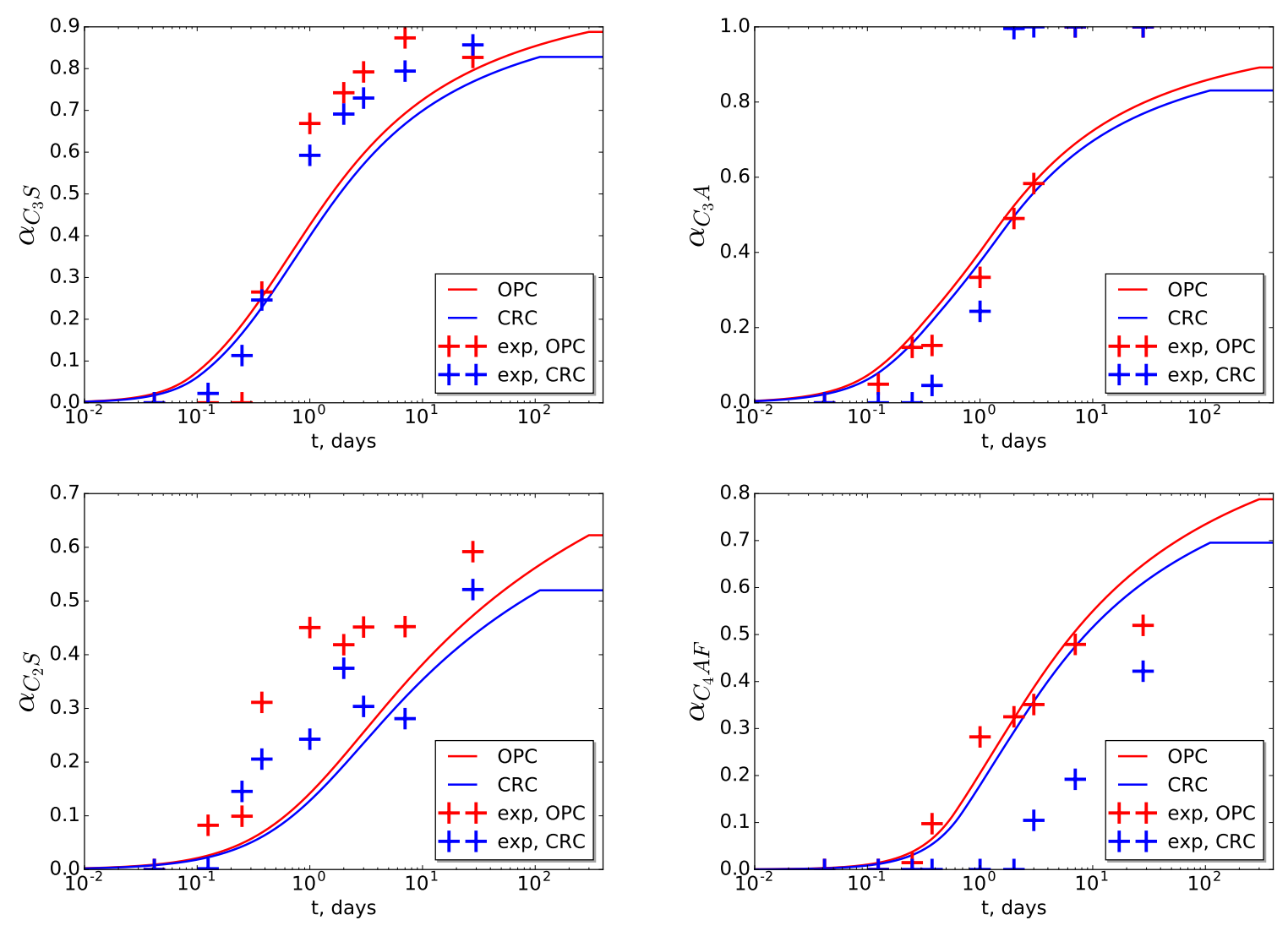

Figure 3.3: Results of XRD/Rietveld analysis [102] are compared to corresponding estimates. 

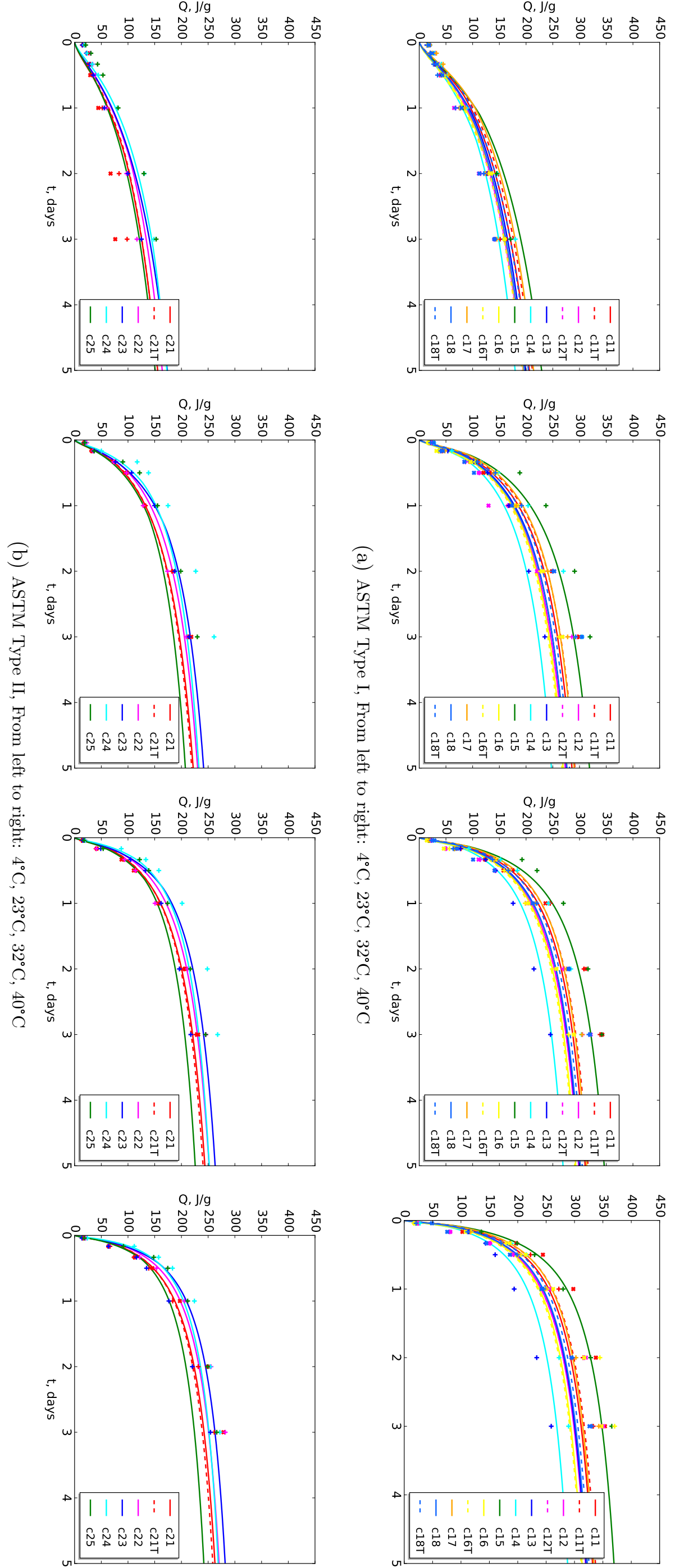

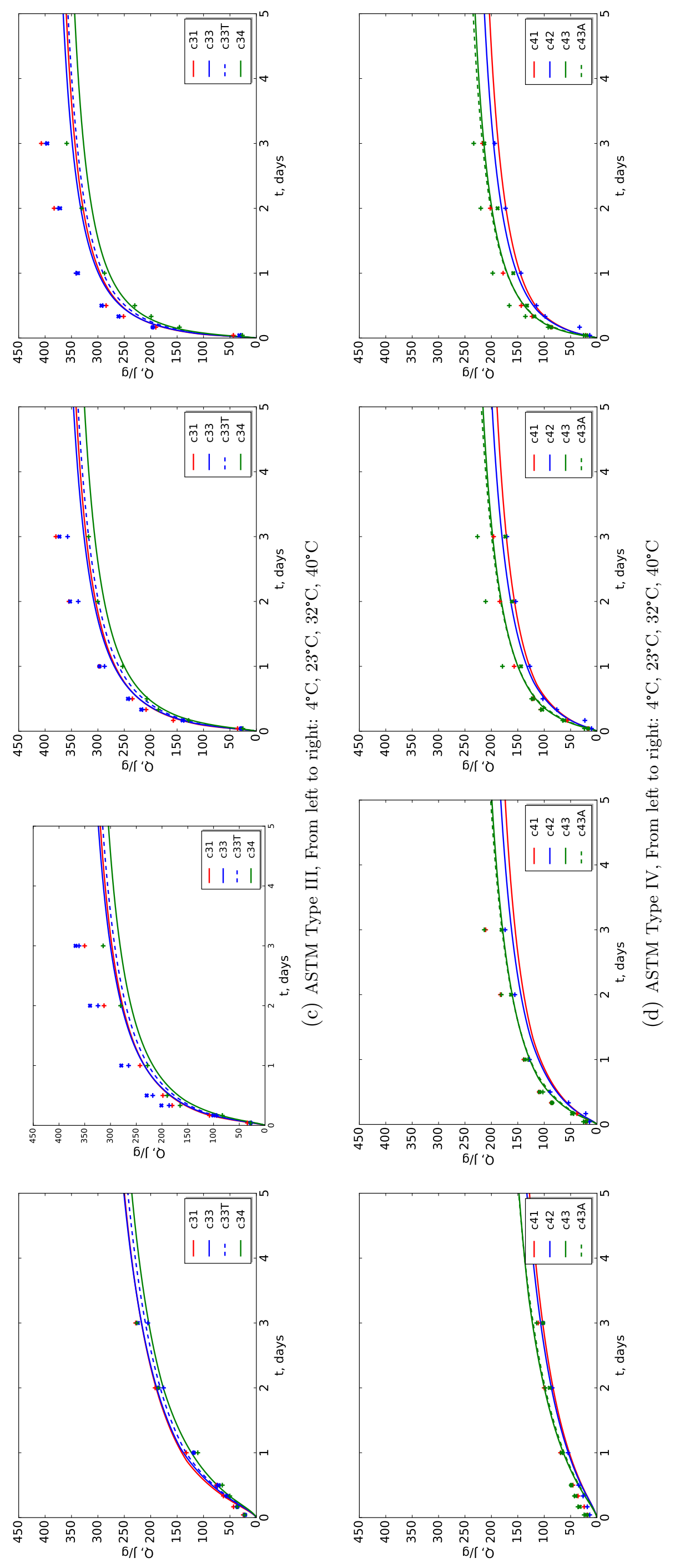


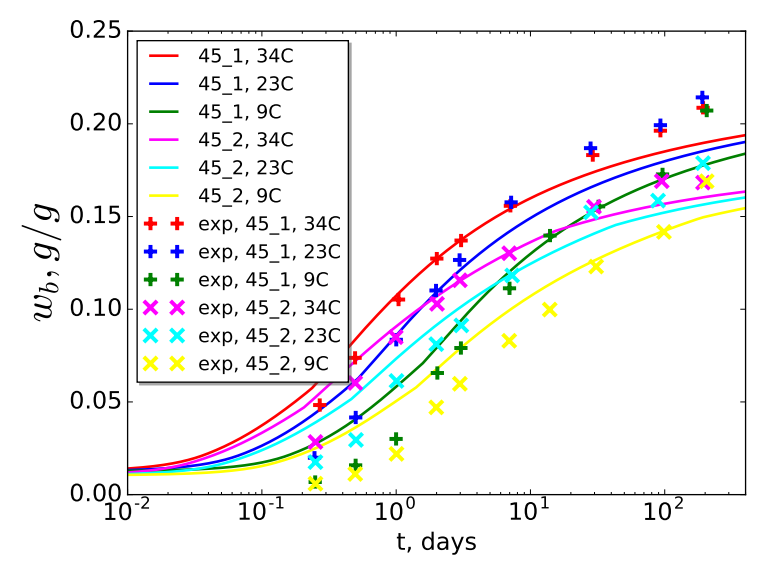

(a) The weight of bounded water per gram of binder is plotted as a function of time for different temperatures. $w / c=0.45$
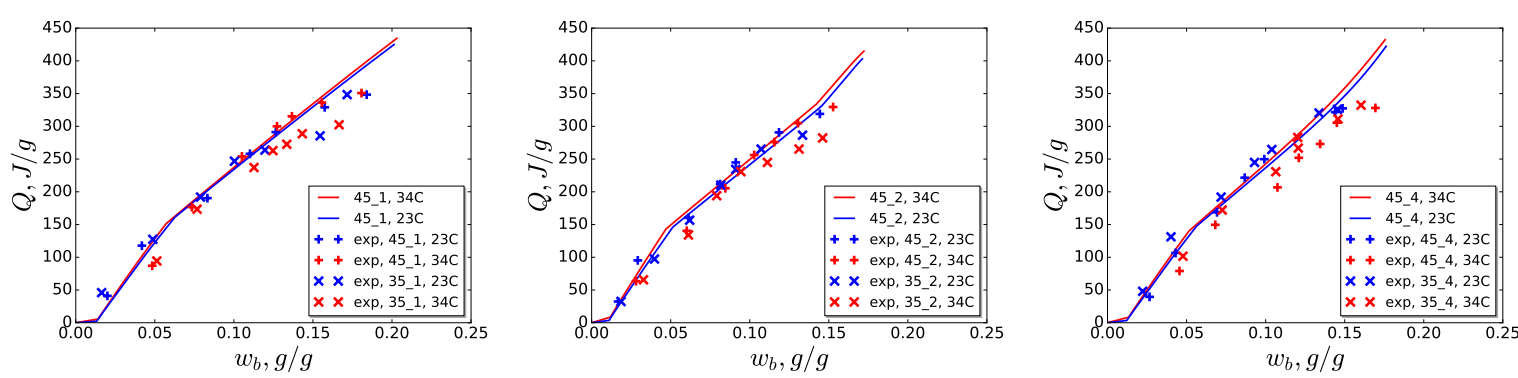

(b) The heat of hydration is plotted as a function of the weight of bounded water for pure cement (left), cement blended with silica fume (center) and cement blended with fly ash (right). $w / c=0.45$
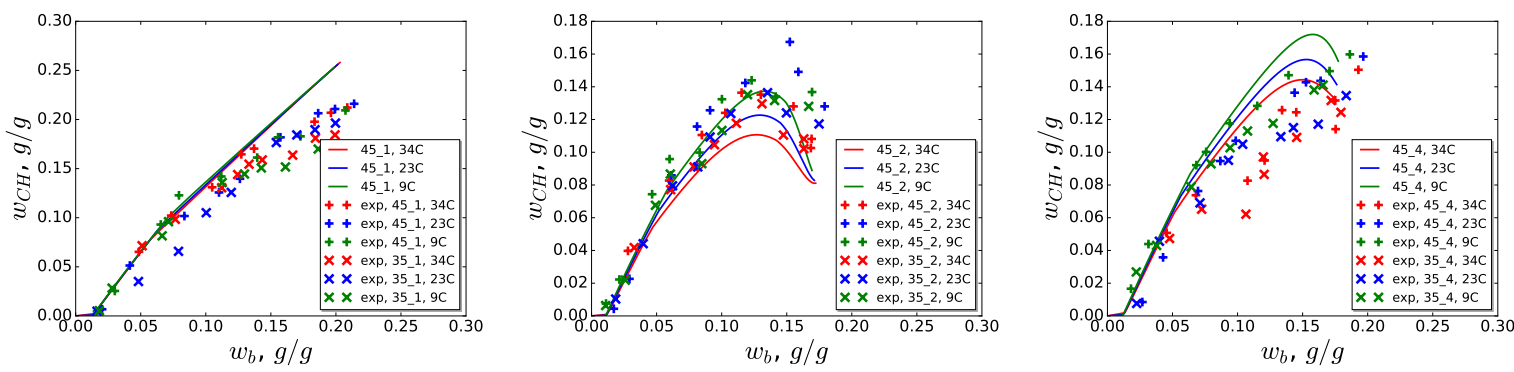

(c) The weight of $\mathrm{CH}$ formed is plotted as a function of the weight of bounded water for pure cement (left), cement blended with silica fume (center) and cement blended with fly ash (right). $w / c=0.45$

Figure 3.4: Results of isothermal calorimetry and thermogravimetry [103] are compared to corresponding estimates. 

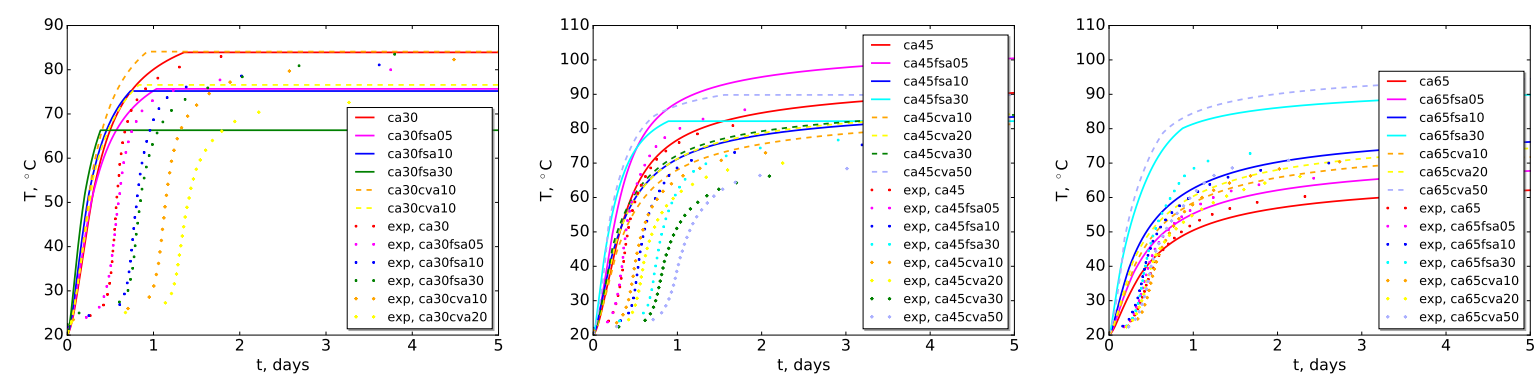

(a) The temperature is plotted as a function of time during adiabatic calorimetry tests of cement blends featuring different $\mathrm{w} / \mathrm{c}$ ratios. $w / c=0.3$ (left), $w / c=0.45$ (center) and $w / c=0.65$ (right)

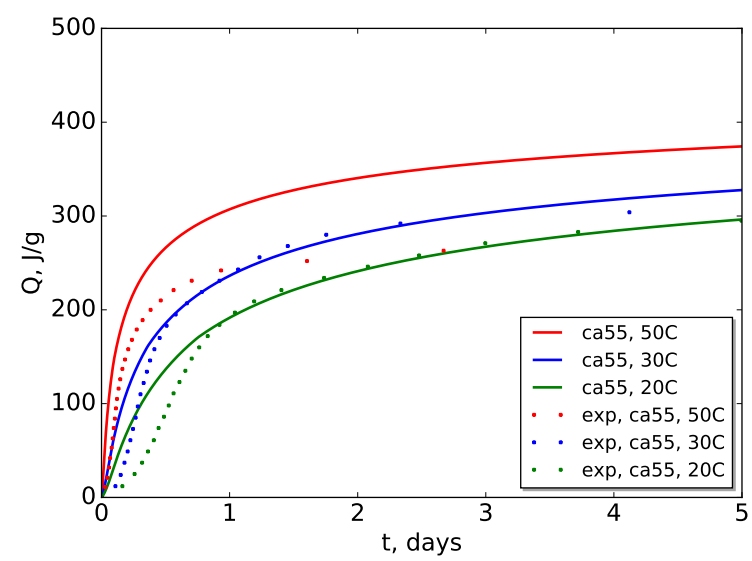

(b) The heat of hydration measured by isothermal calorimetry is plotted as a function of time for different temperatures. $w / c=0.55$

Figure 3.5: Results of calorimetry on concrete and mortars 31] are compared to corresponding estimates. It must be noticed that the estimates lack precision as the temperature reaches $65^{\circ} \mathrm{C}$. 


\begin{tabular}{|c|c|c|}
\hline estimate & $\begin{array}{c}\text { mean percent error } \\
\mathrm{MPE}=\frac{1}{n} \sum_{1}^{n} \frac{Y_{i}^{\text {exp }}-Y_{i}^{\text {model }}}{Y_{i}^{\text {exp }}}\end{array}$ & $\begin{array}{c}\text { mean absolute percent error } \\
\mathrm{MAPE}=\frac{1}{n} \sum_{1}^{n}\left|\frac{Y_{i}^{\text {exp }}-Y_{i}^{\text {model }}}{Y_{i}^{\text {exp }}}\right|\end{array}$ \\
\hline compressive strength, present model & $-14 \%$ & $19 \%$ \\
\hline Young modulus, present model & $2 \%$ & $12 \%$ \\
\hline Young modulus, ACI209 & $-6 \%$ & $12 \%$ \\
\hline Young modulus, Eurocode & $9 \%$ & $18 \%$ \\
\hline
\end{tabular}

Table 3.2: Comparisons related to the Japanese database [104]. The mean percent error and the mean absolute percent error are computed for the compressive strengths and the Young Moduli estimated by the present model. They are compared the those of the Young Moduli estimated by the ACI209 and Eurocode.

\subsection{Measures of Young modulus and compressive strength from the literature}

The micromechanical model is to be validated against various experimental results regarding the mechanical properties of mortar and concrete [88, 87, 104, 105, 21]. The investigations of Termkhajornkit et. al. [21] on the dependence of compressive strength on phase assemblage in cement paste reveals the specific role of $\mathrm{C}-\mathrm{S}-\mathrm{H}$. The present model is not able to reproduce these results as all hydrates, including the Portlandite and the $\mathrm{C}-\mathrm{S}-\mathrm{H}$ behave as binders at the scale of the hydrate foam. Nevertheless, for the considered pure $\mathrm{C}_{3} \mathrm{~S} / \mathrm{C}_{2} \mathrm{~S}$ pastes, the gel-space ratio at setting and the ultimate value of the compressive strength are reasonable (Fig. 3.6). Lerch and Ford have performed compressive strength tests on mortars of water to cement ratio 0.53 and sand to cement ratio 2.77 at different ages. The effect of the cement type on the development of mortar strength is satisfyingly described during the first month (Fig. 3.7). Yet, the long-term strength of the mortars are overestimated. If the samples were stored in air, it is likely that drying could have slowed down or even stopped hydration, while the present model considers hydration without exchange of moisture with the environment. If the samples were stored in water, calcium leaching could have occurred. Taplin [87] investigated the effect of the water to cement ratio on the compressive strength of cement pastes: his experimental measurements have also been used to validate the micromechanical model of Pichler and Hellmich [2, 20. Unsurprisingly, the present model is also able to account for this effect (Fig. 3.8): the use of a finite aspect ratio for the hydrates even improves the estimate of the setting time. Moreover, Haecker et. al. have measured the growth of the Young moduli of cement pastes featuring different water to cement ratios in order to appraise the quality of their 3D elastic numerical simulations [105]. The present hydration model does not perfectly estimates the hydration degree, which triggers some errors on the estimated Young moduli (Fig. 3.9). It also expects lower moduli for the cement paste of cement $\mathrm{H}$ than for those of cement $\mathrm{D}$ because the cement $\mathrm{H}$ contains more inert fillers than cement $\mathrm{D}$ according to the chemical phase composition. However, the experimental measurements do not feature such a discrepancy. Lastly, the results of tests on more than 3000 concretes have been gathered by Tomosawa and Noguchi [104 along with some data about their formulation. Despite the lack of information about the Bogue compositions of the cements, this database can prove useful to challenge the present hydration model. Nevertheless, concretes featuring a water to cement ratio lower than 0.35 are discarded from the comparison if the curing conditions did not correspond to a sealing of the sample. Similarly, cases where the sand or the gravel saturated density is lower than $2.4 \mathrm{~g} / \mathrm{cm}^{3}$ were discarded because the Young moduli of the corresponding light aggregates are not known. Moreover, steam-cured samples are assumed to experience a temperature of $65^{\circ} \mathrm{C}$. Yet, the major source of uncertainty is the moduli of the aggregates. Indeed, the aggregates considered in the database can feature different stiffness depending on their type and density. Indeed, some concretes are made of stiff Bauxite aggregates of density $3.16 \mathrm{~g} / \mathrm{cm}^{3}$. Unsurprisingly, the Eurocode2 standards does not seems to be adequate to estimate the Young moduli of such concretes starting from their compressive strengths. On the other hand, the ACI 318 standard accounts for the density of the concrete. But it does not prove more reliable than the Eurocode 2 because most of the concretes of the database are made of hard sandstone, which can be a rather soft material despite its density. Assumptions regarding the stiffnesses of aggregates are reported in table 2.2 and the estimates of the compressive strengths and Young Moduli are compared to reported measurements for more than 600 samples (Fig. 3.10). On average, the present model slightly overestimates the strengths of the concretes as shown by computing the mean percent error (Tab. 3.2). But the estimated Young modulus is slightly less biased than that estimated by the ACI 318 code and the Eurocode2. Regarding the Eurocode 2 estimate, the 0.7 reduction factor applied to the case of sandstone aggregates could be responsible for the bias. 


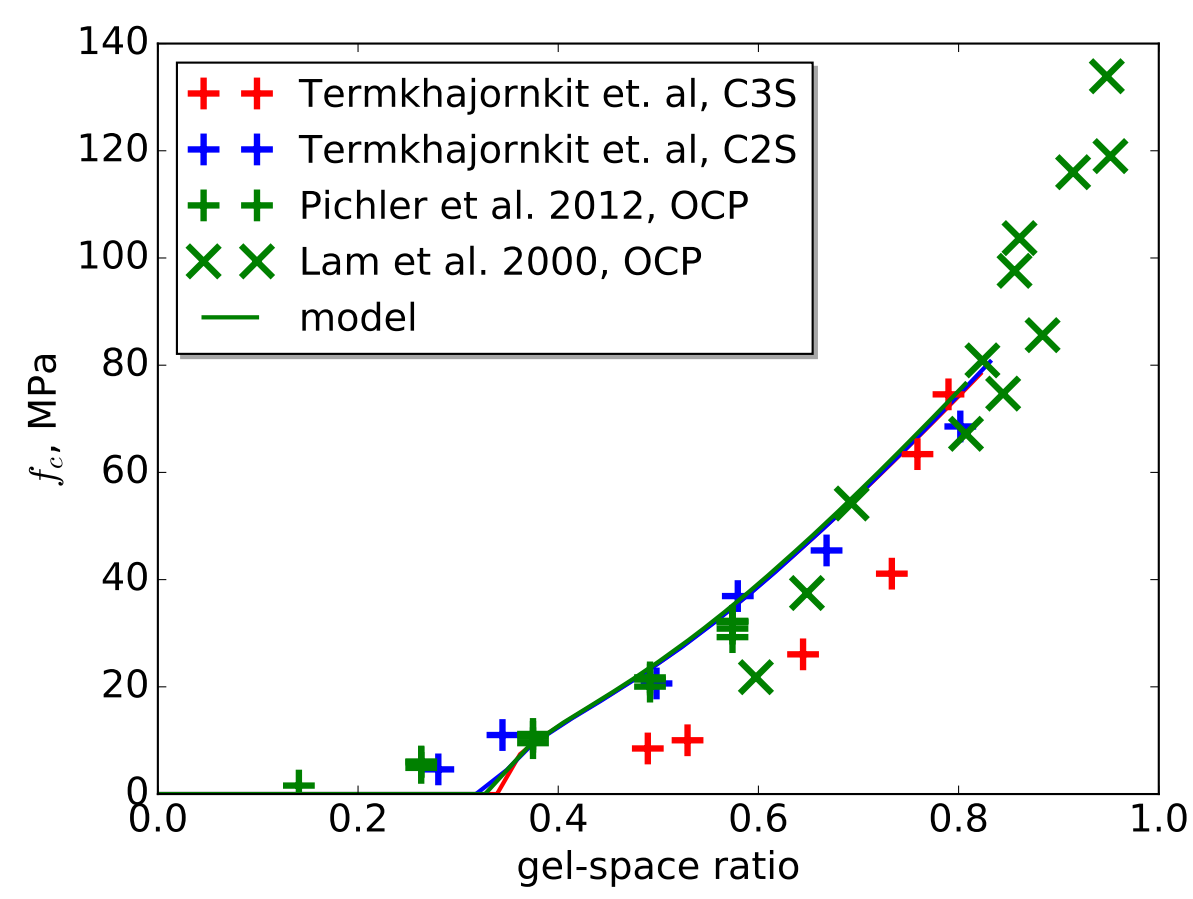

Figure 3.6: Results of compressive strength tests of Termkhajornkit et. al. 21] on pure C3S/C2S paste are compared to corresponding estimates. Water to cement ratios are respectively 0.45 and 0.43 . Tests are performed on cylinders of diameter $7.4 \mathrm{~mm}$ and height $22.7 \mathrm{~mm}$. Results of Lam et. al [117] on cubes of side $70.7 \mathrm{~mm}$ and Pichler et. al [20] on cylinders of diameter $29 \mathrm{~mm}$ and height $58 \mathrm{~mm}$ are added.

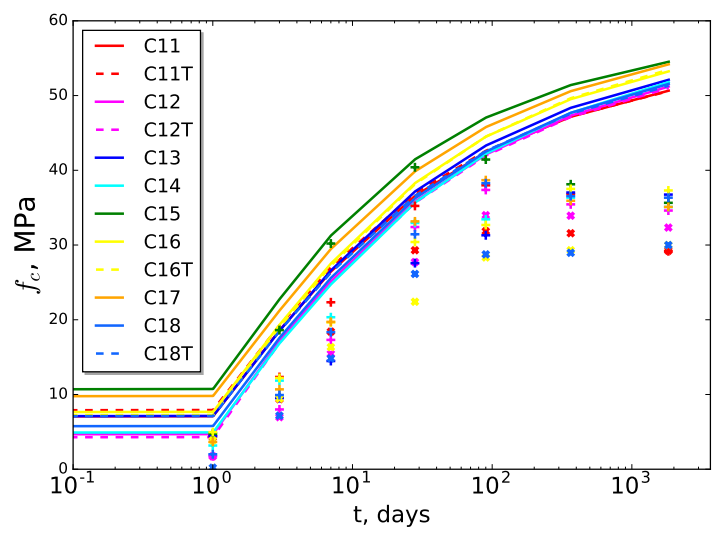

(a) ASTM Type I

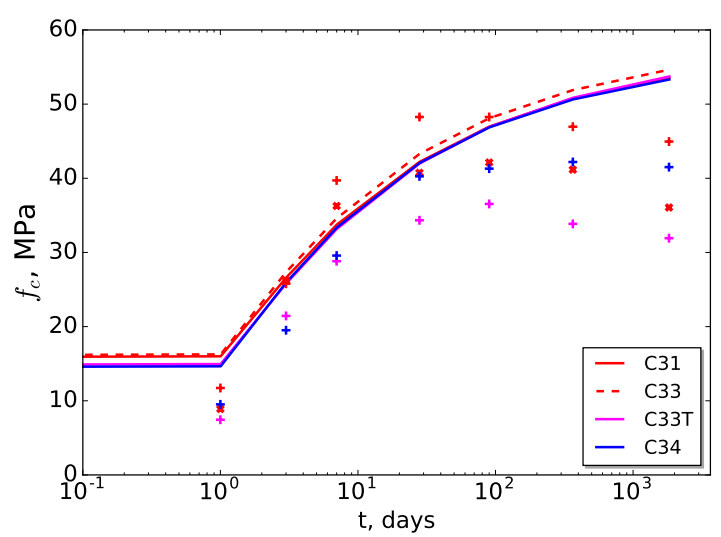

(c) ASTM Type III

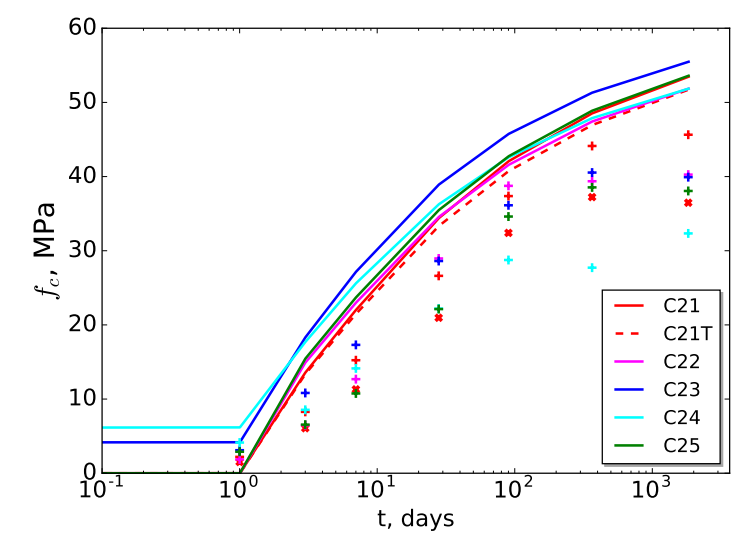

(b) ASTM Type II

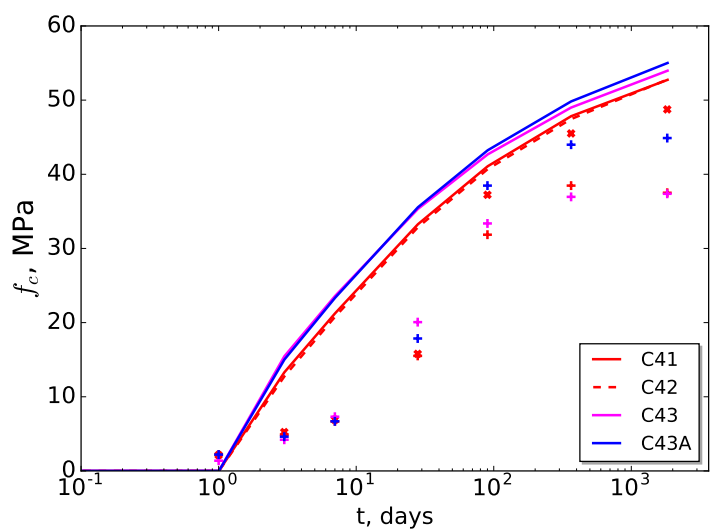

(d) ASTM Type IV

Figure 3.7: Results of compressive strength tests of Lerch and Ford [88] are compared to corresponding estimates. $w / c=0.53, a / c=2.77$. Tests are performed on 2 -inch cubes according to ASTM C109-40T.

One of the major difficulty in assessing the accuracy of micromechanical models of cementitious materials is the lack of complete database on formulation, properties of raw materials and corresponding measurements of moduli and strength. 


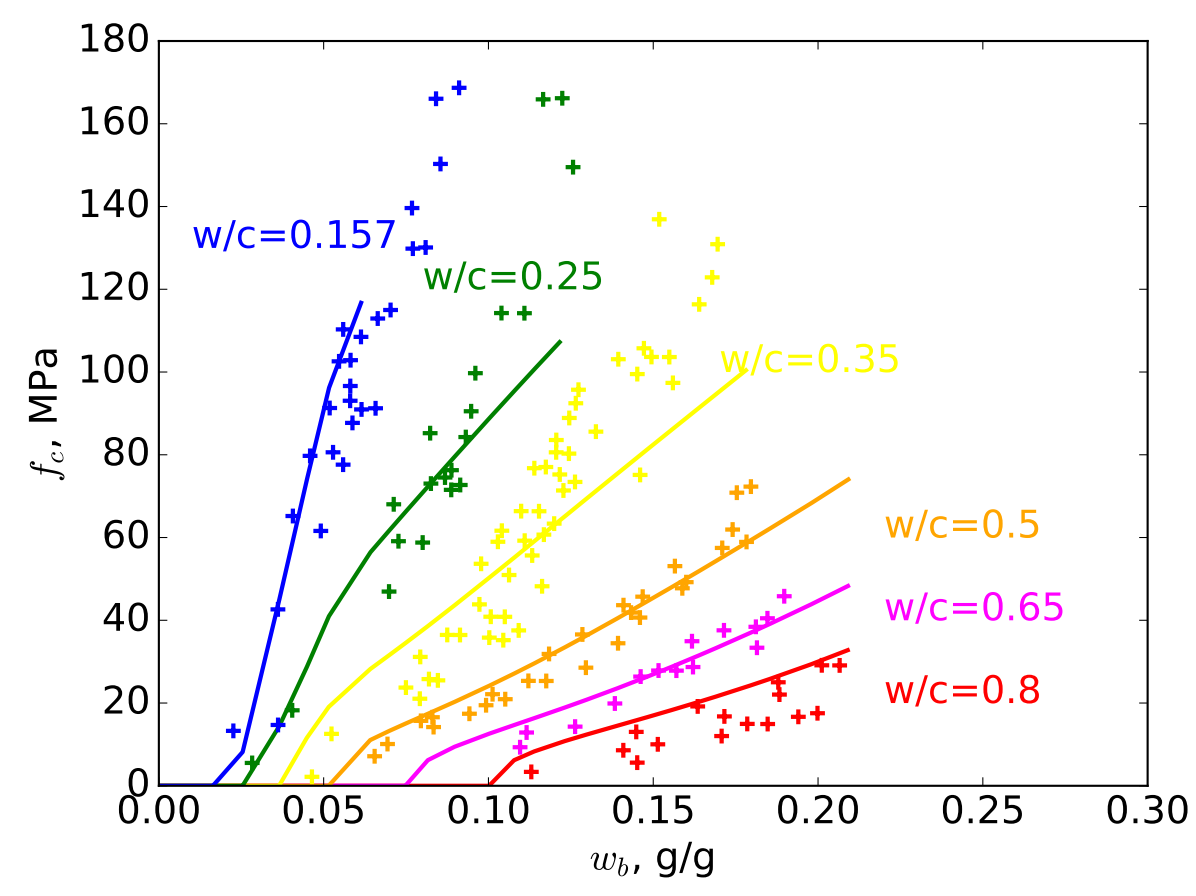

Figure 3.8: Results of compressive strength tests of Taplin [87] on cement pastes featuring different $w / c$ ratios are compared to corresponding estimates. The results of Taplin had to be scaled because he published the measured ultimate force instead of the compressive strength. The loaded area of the rectangular prismatic sample reported in [20] is $0.373 \times 0.5$ square inch, the height being 0.5 inch.
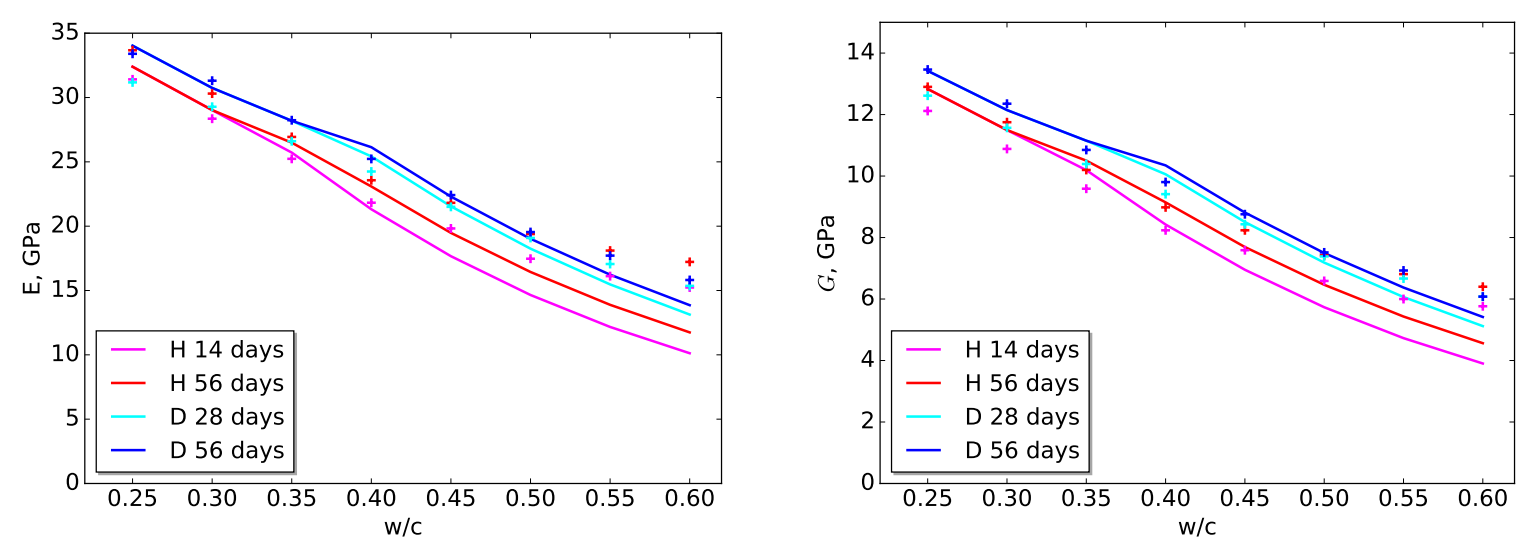

Figure 3.9: Measurements of Young moduli (left) and shear moduli (right) of cement pastes [105] are compared to corresponding estimates. 

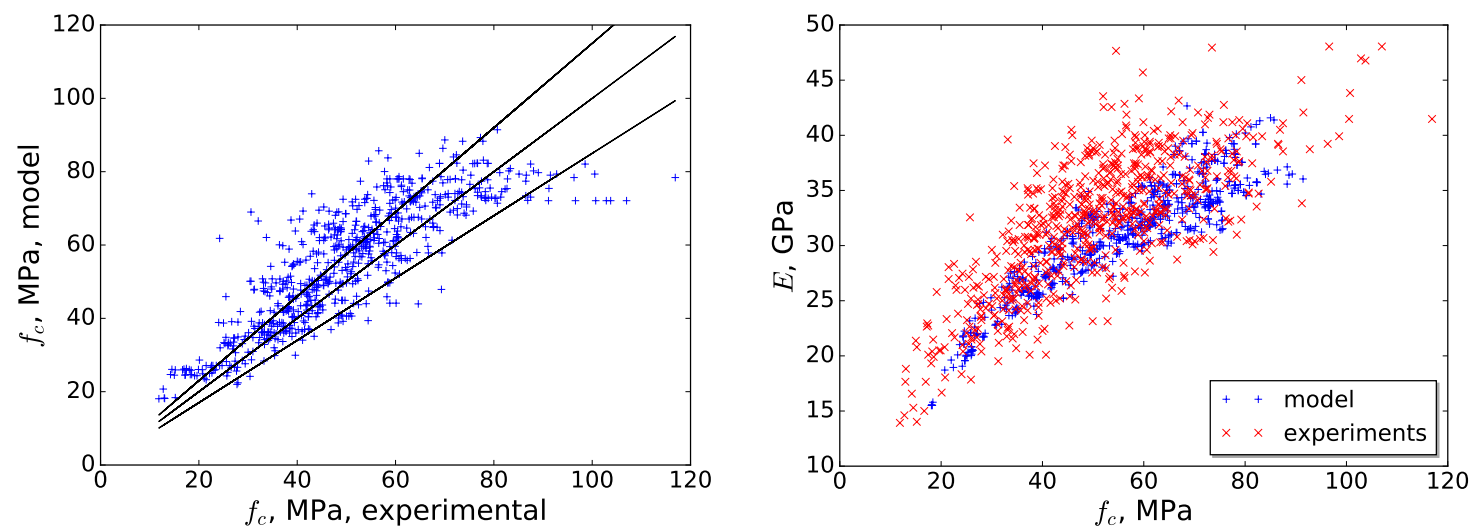

(a) Comparison between the estimated compressive(b) The Young modulus as a function of the compresstrength and the measured one. sive strength.
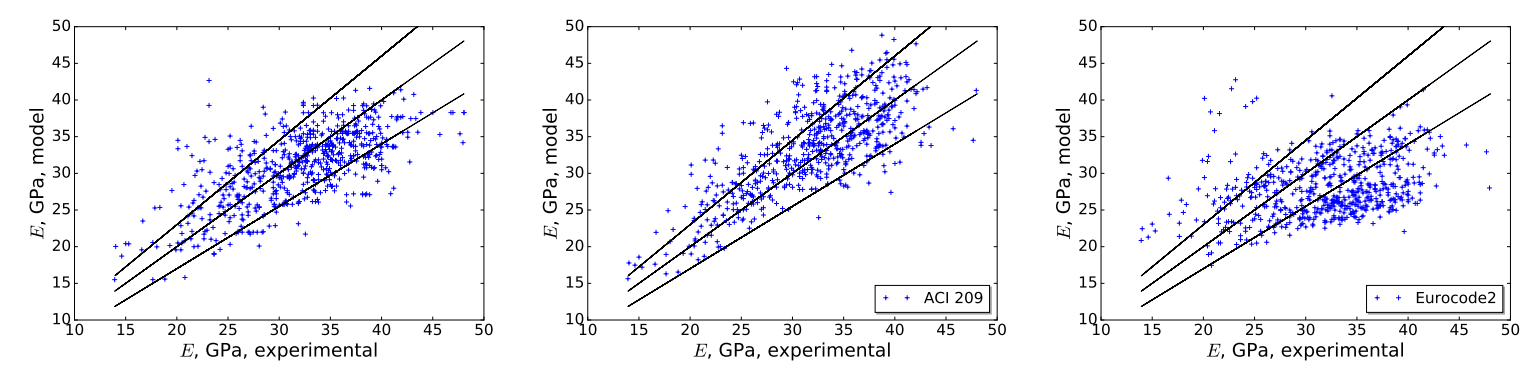

(c) Comparison between the esti-(d) Comparison between the Young(e) Comparison between the Young mated Young Moduli and the mea-moduli estimated by the ACI209moduli estimated by the Eurocode sured one. standards and the measured ones. standards and the measured ones.

Figure 3.10: Comparisons related to the Japanese database [104]. Lines correspond to equality between estimates and measured results and $15 \%$ relative errors. 


\begin{tabular}{cc} 
clinker & $96 \%$ \\
\hline $\mathrm{C}_{3} \mathrm{~S}$ & 65 \\
$\mathrm{C}_{2} \mathrm{~S}$ & 11 \\
$\mathrm{C}_{3} \mathrm{~A}$ & 11 \\
$\mathrm{C}_{4} \mathrm{AF}$ & 8 \\
\hline $\mathrm{CaCO}_{3}$ & $3.5 \%$ \\
\hline & $100 \%$ \\
\hline gypsum & 4.6 \\
\hline Blaine fineness & $380 \mathrm{~m}^{2} / \mathrm{kg}$ \\
density & $3.12 \mathrm{~g} / \mathrm{cm}^{3}$
\end{tabular}

Table 4.1: The Bogue composition of the clinker and the composition of the cement.

\section{Additional experiments on blended cement pastes}

\subsection{Raw materials, formulations and procedures}

The present section aims at providing a comprehensive set of data about the formulation of different cement pastes containing different additions. Results of semi-adiabatic calorimetry and compressive strength tests are gathered and compared to the corresponding estimates produced by the hydration model.

Blends are defined based on weight fractions. For instance, the blend denoted by C85L15 contains $15 \%$ weight of limestone filler, $5 \%$ weight of silica fume are used in the blend C95SF05 and C50FA50 contains 50\% weight of class F fly ash. Two water to binder ratios are considered: 0.32 and 0.5. The cement that has been used is a CEM I $52.5 \mathrm{~N} \mathrm{CE} \mathrm{CP2} \mathrm{NF} \mathrm{from}$ the plant of Beffes (Tab. 4.1). The considered silica fume is made of $95 \% \mathrm{SiO}_{2}$. The Blaine fineness of the limestone-based filler is $462 \mathrm{~m}^{2} / \mathrm{kg}$. To ensure sealed hydration conditions, the three $4 \mathrm{~cm} \times 4 \mathrm{~cm} \times 16 \mathrm{~cm}$ samples are taken out of their steel mold at $24 \mathrm{~h}$ and stored at $20^{\circ} \mathrm{C}$ in sealed watertight plastic bags until the flexural and compressive strength tests are performed. As a result, the mass of the samples at the time of the test are close to those measured when the samples are unmolded (relative differences of weights are less than 1\%). Compressive strength tests of cement pastes were performed at 1, 3, 7, 14, 28 and 90 days according to NF EN 196-1 [106]. Three flexural tests are performed and the six resulting halves are loaded and crushed during compression tests. Measurements of the compressive strength are reported in table 4.2 .

Semi-adiabatic calorimetry tests are performed according to the standard NF EN 196-9 68. To avoid large temperatures, about 1000g of sand was added to the cement paste (Tab. 4.3). The heat capacity of the calorimeter is about $380 \mathrm{~kJ} / \mathrm{K}$ and its released heat can be estimated by using $a=75 . \mathrm{J} / \mathrm{h} / \mathrm{K}, b=0.260 \mathrm{~J} / \mathrm{h} / \mathrm{K}^{2}$ in equation 23).

\subsection{Experimental results}

On the one hand, fillers may accelerate the hydration reactions due to their specific surface. On the other hand, the heat released per unit weight of the binder is lower if a filler is substituted to the cement since the filler does not react (except for the formation of monocarboaluminate). In the second case, the reached temperature are lower during semiadiabatic tests, a phenomenon which is largely visible on the experimental results (Fig. 4.1). The compressive strength can be underestimated by the model, in particular at early age and for high weight fractions of limestone fillers. Comparisons to measurements performed on cement pastes containing pozzolanic additions lead to similar conclusions (Fig. 4.2). Indeed, the heat of hydration at the end of semi-adiabatic calorimetry tests is correctly estimated for both water to cement ratios. But the model overestimates the reduction of compressive strength due to substitution of the cement by the fly ash. Indeed, for $50 \%$ weight substitution, the long term compressive strength is similar to that of the pure cement paste while the model expects a significant decrease. 


\begin{tabular}{ccccccc} 
Name & 1 day & 3 days & 7 days & 14 days & 28 days & 90 days \\
\hline w/b=0.5 & & & & & & \\
C100 & $18.2(0.3)$ & $36.4(1.8)$ & $44.8(1.7)$ & $49.9(1.9)$ & $55.2(1.9)$ & $59.0(6.8)^{*}$ \\
C95L05 & $17.1(0.6)$ & & $46.0(1.2)$ & $48.6(2.2)$ & $52.0(2.4)$ & $57.2(1.4)$ \\
C90L10 & $17.1(0.4)$ & & $40.82(1)$ & $46.35(1.1)$ & $50.6(2.3)$ & $54.1(1.4)$ \\
C85L15 & $16.6(0.5)$ & & $40.2(1)$ & $43.7(1.7)$ & $47.1(1.2)$ & $51.1(1.5)$ \\
C70L30 & $13.5(0.6)$ & & $35.9(0.9)$ & $39.7(1.4)$ & $43.2(1.6)$ & $43.9(2.5)$ \\
C95SF05 & $15.3(0.4)$ & $32.8(0.5)$ & $45.9(1.8)$ & $53.2(2.0)$ & $58.5(3.12)$ & $60.5(2.0)$ \\
C85SF15 & $14.2(0.3)$ & $31.0(0.9)$ & $51.9(1.8)$ & $47.7(1.4)$ & $58.4(2.9)$ & $63.2(2.8)$ \\
C75FA25 & $11.2(0.2)$ & $25.5(0.6)$ & $38.9(1.3)$ & $44.7(2.0)$ & $50.6(2.4)$ & $60.3(2.2)$ \\
C50FA50 & $7.0(0.1)$ & $19.5(0.7)$ & $33.5(1.4)$ & $38.5(1.5)$ & $45.3(2.1)$ & $56.6(3.5)$ \\
\hline w/b=0.32 & & & & & & \\
C100 & $46.4(4.1)$ & $63.6(3.4)$ & $69.6(1.8)$ & $75.5(1.8)$ & $78.13(5.6)$ & $83.1(3.9)$ \\
C95L05 & $43.9(2.0)$ & $63.1(2.0)$ & $68.5(2.1)$ & $75.4(3.1)$ & $79.8(3.1)$ & $85.0(1.4)$ \\
C90L10 & $44.4(0.9)$ & $61.9(2.1)$ & $68.3(1.4)$ & $71.7(2.6)$ & $71.9(3.1)$ & $83.4(3.8)$ \\
C85L15 & $43.6(0.8)$ & $64.4(2.5)$ & $72.2(1.9)$ & $72.0(2.1)$ & $79.4(4.7)$ & $77.9(2.6)$ \\
C70L30 & $39.3(0.9)$ & $57.0(1.7)$ & $63.9(1.8)$ & $68.4(3.4)$ & $72.3(4.3)$ & $80.2(3.0)$ \\
C95SF05 & $50.1(1.1)$ & $65.5(1.7)$ & $65.6(3.4)$ & $68.1(3.0)$ & $78.2(3.2)$ & $83.3(2.4)$ \\
C85SF15 & $43.7(1.4)$ & $55.7(2.4)$ & $65.0(3.1)$ & $69.6(5.1)$ & $68.7(1.9)$ & $84.1(2.7)$ \\
C75FA25 & $42.6(0.9)$ & $60.5(2.1)$ & $61.4(3.5)$ & $63.9(3.8)$ & $69.1(4.5)$ & $83.1(4.8)$ \\
C50FA50 & $33.4(1.7)$ & $47.4(1.8)$ & $53.0(2.5)$ & $61.3(1.8)$ & $71.6(2.4)$ & $90.7(3.2)$
\end{tabular}

Table 4.2: Measurements of the compressive strength $f_{c}$, MPa. Sample standard deviations $s=\sqrt{\frac{1}{N-1} \sum\left(f_{c}-\bar{f}_{c}\right)^{2}}$ are reported in parenthesis. $*: 2 \times 2$ compressive tests only.

\begin{tabular}{cccc}
$\begin{array}{c}\text { Name } \\
\text { /b=0.5 }\end{array}$ & binder(g) & dry sand(g) & water(g) \\
C100 & 371 & 1113 & 196 \\
C95L05 & 503 & 947 & 257 \\
C90L10 & 517 & 924 & 252 \\
C85L15* & 516 & 905 & 258 \\
C70L30 & 566 & 870 & 291 \\
C95SF05 & 510 & 971 & 263 \\
C85SF15 & 536 & 932 & 277 \\
C75FA525 & 546 & 873 & 280 \\
C50FA50 & 580 & 773 & 297 \\
\hline w/b=0.32 & & & \\
C100 & 566 & 1131 & 191 \\
C95L05 & 616 & 1173 & 208 \\
C90L10 & 629 & 1143 & 211 \\
C85L15 & 645 & 1121 & 216 \\
C70L30 & 686 & 1055 & 229 \\
C95SF05 & 567 & 1080 & 191 \\
C85SF15 & 593 & 1030 & 199 \\
C75FA25 & 601 & 963 & 202
\end{tabular}

Table 4.3: Mix proportions for semi adiabatic calorimetry. The water to binder ratio accounts for the $0.9 \%$ absorption of the dry sand. *: The water to binder ratio is 0.48 . 


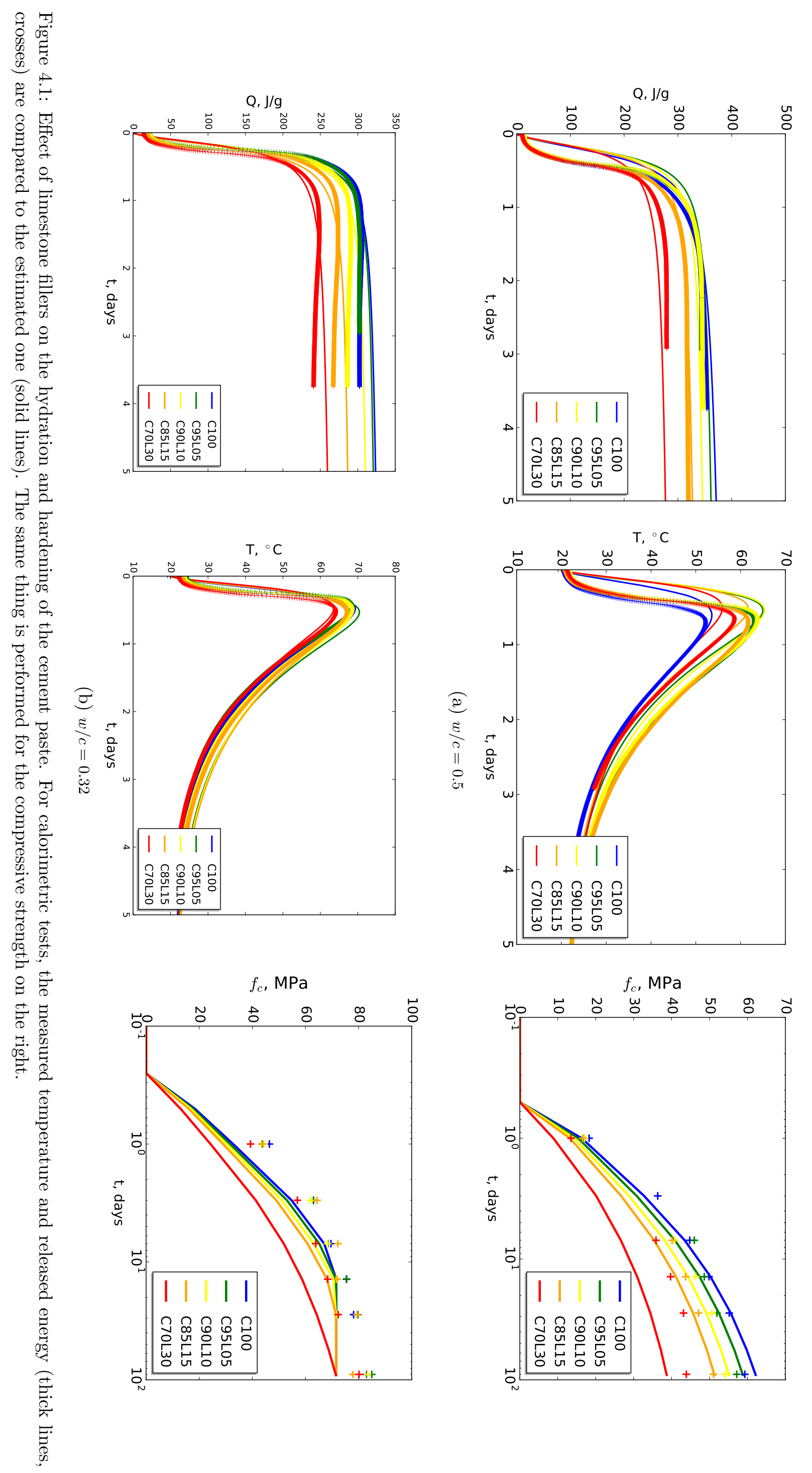



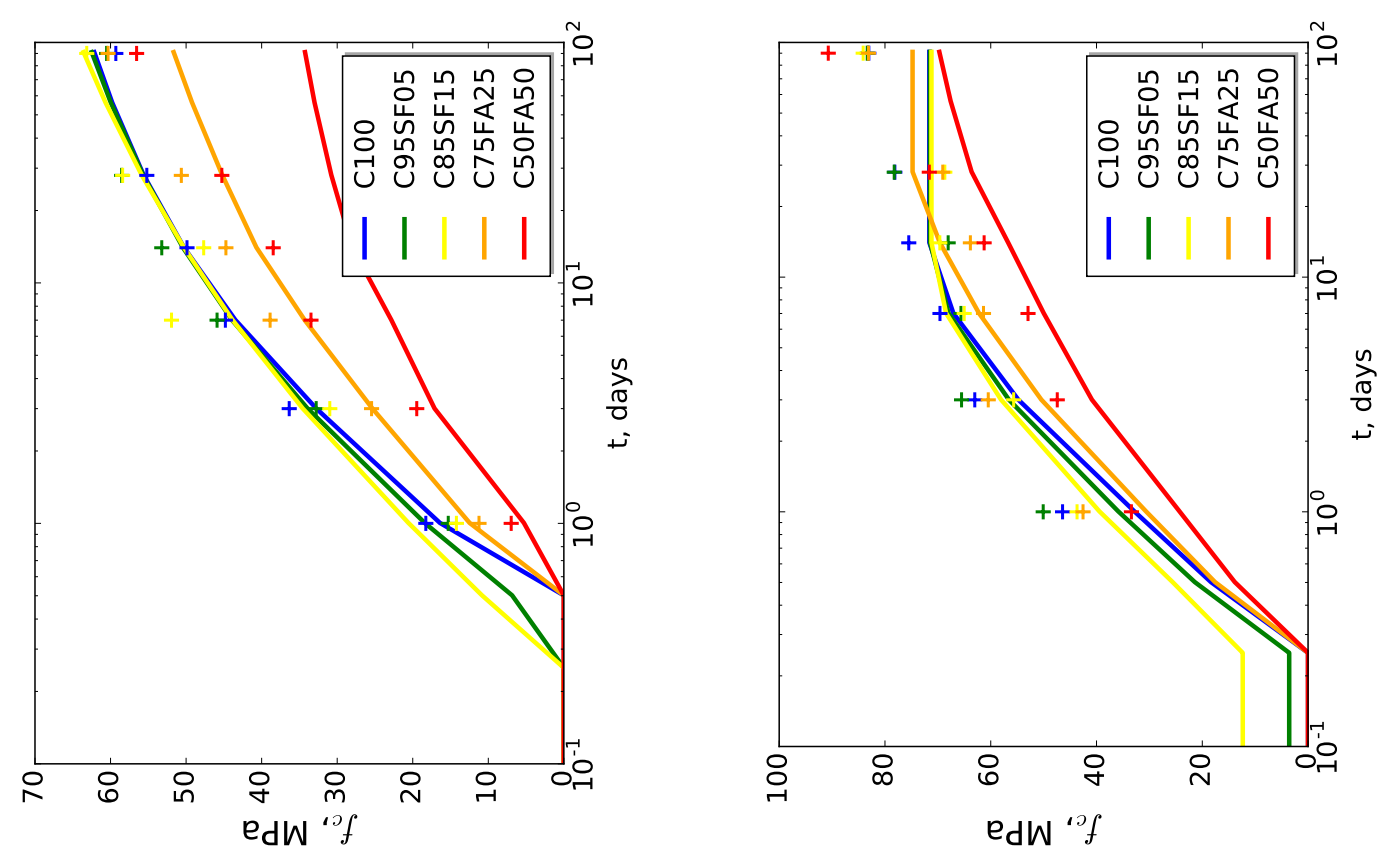

迅
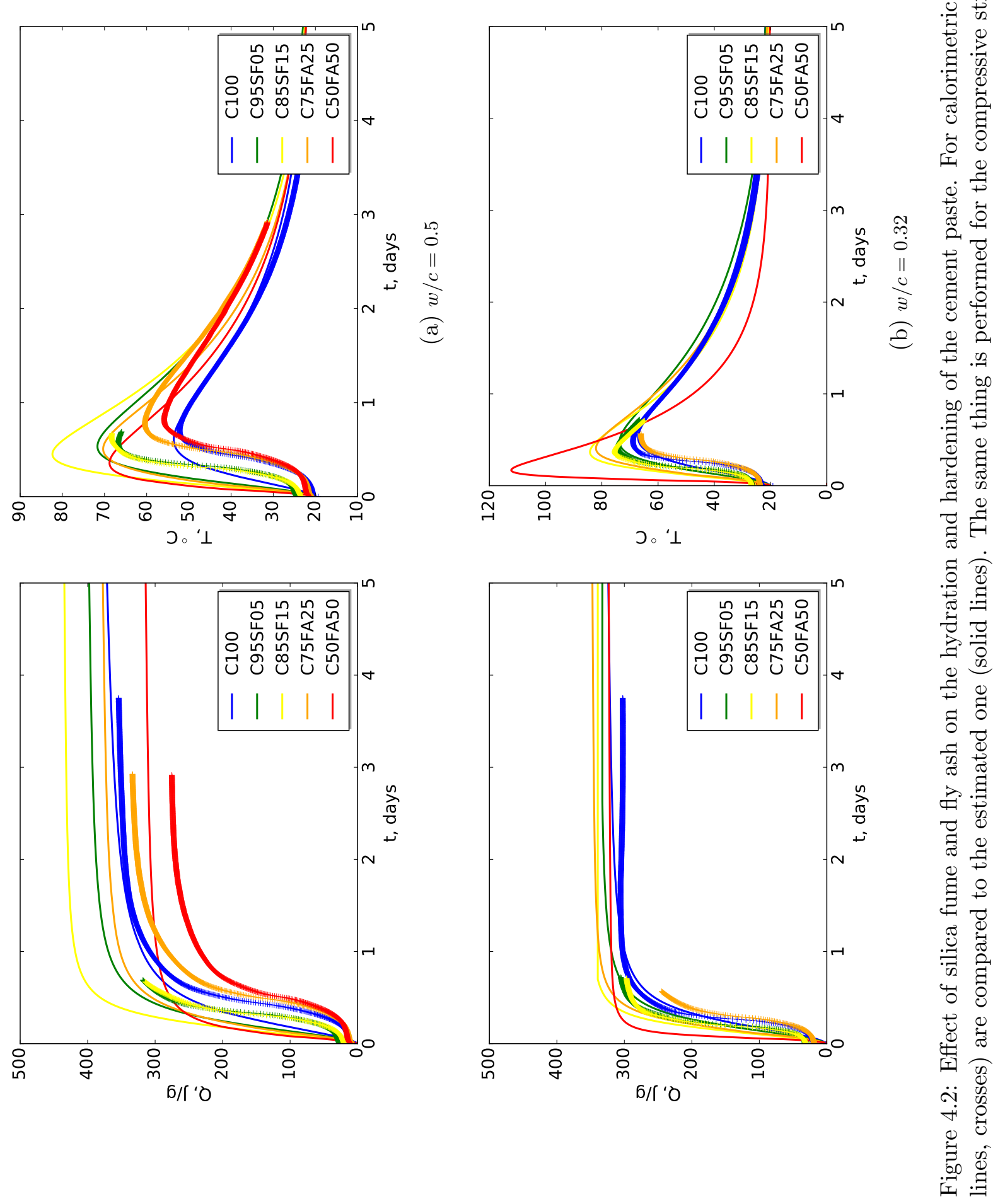


\section{Limitations of the present model}

Unsurprisingly, the duration of the induction period is not accurately estimated by the present hydration model. Indeed, studying this period would require a precise modeling of the dissolution kinetic of species accounting for the concentration of ions in the solution and the effect of additives or organic acids.

The micromechanical model introduced above relies on the average of the Von Mises stress on the hydrate needles to define the failure of the material as in [2, 20]. The most serious problem of this approach is that the failure criteria is symmetric in traction and compression. Hence, the failure at the local scale is not properly described since the traction strength of concrete can be more than ten times smaller than its compressive strength. Recent investigations on the failure of $\mathrm{C}-\mathrm{S}-\mathrm{H}$ and multiscale modeling were able to account for discrepancies between compression and traction [107]. Nevertheless, the micromechanical model of Pichler and Hellmich correctly depicts the failure of the cement paste in case of biaxial compressive loadings [20], where confinement improves the strength. Even if the proposed model is able to estimate the strength of the cement paste in case of biaxial compressive loadings, the effect of confinement is not accounted for in the statistical procedure introduced herein. As a consequence, the proposed upscaling of strength must indeed be limited to the predicition of uniaxial compressive strengths for mortars. In this particular case, the stress in the cementitious matrix remains mostly uniaxial as shown on figure 2.2 and relying on an estimate of the uniaxial compressive strength of the cementitious matrix is sufficient. Otherwise, the proposed statistical procedure can be extended to multiaxial loadings, though the resulting estimate must be validated. Indeed, local stresses in the cement paste can be generated according to the proposed estimate of its distribution and compared to the multiaxial criterion as computed in [20]. Then, the strength of the mortar can be defined by introducing the volume fraction $c_{\text {fail }}$. However, it must be recalled that concrete is rarely linear elastic up to failure, thus limiting the ultimate scope of the proposed model.

The present homogenization scheme does not describe the nanometric scale of the $\mathrm{C}-\mathrm{S}-\mathrm{H}$, which is a mix of the gel porosity and globules. Indeed, in the present model, the density of the $\mathrm{C}-\mathrm{S}-\mathrm{H}$ is assumed to be uniform with respect to time. On the contrary, by combining Rietveld analysis and thermogravimetry analysis, it has been shown that curing at high temperature significantly reduces the gel porosity of the $\mathrm{C}-\mathrm{S}-\mathrm{H}$ [108]. As a result, the density of the $\mathrm{C}-\mathrm{S}-\mathrm{H}$ increases from 1.91 at $5^{\circ} \mathrm{C}$ to 2.27 at $60{ }^{\circ} \mathrm{C}$ [108. On the one hand, increasing the density raises the stiffness of the $\mathrm{C}-\mathrm{S}-\mathrm{H}$. On the other hand, the capillary porosity is also increased, thus leading to a significant decrease of the strength [109]. Consequently, as the present model has been validated against various tests of samples stored at temperatures around $20^{\circ} \mathrm{C}$, it would be reasonable to limit its use to concrete experiencing temperatures in the range $10^{\circ} \mathrm{C}$ to $30^{\circ} \mathrm{C}$. In addition, NMR relaxometry [51] points out that the global density of the $\mathrm{C}-\mathrm{S}-\mathrm{H}$ gel is driven by the available precipitation space, thus implying a variable gel porosity [110]. Indeed, the density of the saturated B-class $\mathrm{C}-\mathrm{S}-\mathrm{H}$ introduced in [110] can be as low as $1.34 \mathrm{~g} / \mathrm{cm}^{3}$ or higher than $1.89 \mathrm{~g} / \mathrm{cm}^{3}$, corresponding to porosities in the range $[79 \%, 44 \%]$. According to nanoindentation results on cement paste featuring $\mathrm{w} / \mathrm{c}=0.5$, the packing density triggering a percolation of the gel is about 50\% [111]. It would correspond to an available precipitation space of about $51 \%$ in the model of Königsberger et al. [110]. However, such an available precipitation space is not reached at 28 days according to the present hydration model, for a w/c of 0.5 at $20^{\circ} \mathrm{C}$. As result, the authors acknowledge that combining the knowledge stemming from NMR relaxometry to a predictive micromechanical scheme accounting for evidences brought by nanoindentation measurements is not achieved by the proposed model, likely because it requires a deeper understanding of the gel structure. Different classes of $\mathrm{C}-\mathrm{S}-\mathrm{H}$ of prescribed densities and mechanical properties can also be distinguished by performing nano-indentation measurements [112. But the volume fractions of each $\mathrm{C}-\mathrm{S}-\mathrm{H}$ class depends on the water to cement ratio, hydration degree and temperature history. Combining these data into a single consistent model might lead to improved estimates of the cement mechanical properties.

Lastly, the Young modulus of cement pastes at early age can be significantly underestimated and the dilution effect for large weight fraction of fly ash or limestone filler seems overestimated. Indeed, this feature can be explained by the fact that some of fillers, mineral additions and unreacted particles are fully incorporated in the solid skeleton of the cement paste, thus influencing its setting and the rapid development of the mechanical properties [113]. Numerical models [22, 23, 105, 24] naturally account for this phenomenon while most of existing micromechanical models do not consider these phases at the scale where the selfconsistent model is applied. 


\section{Conclusion}

Despite its simplicity, the updated hydration model is able to provide a reasonable estimate of the hydration degree and mass of each phase of the cement paste as a function of time. Indeed, providing a couple of inputs on the binder composition, the formulation and the environmental conditions is sufficient to recover valuable estimates of the heat of hydration and masses of the various co-existing chemical species of the cement paste. Introducing molar volumes, mechanical properties and a simplified description of the morphology of the cement paste allows the use of mean-field schemes producing estimates of the compressive strength. The model of Pichler \& Hellmich [2] was adopted and modified. First, introducing a finite aspect ratio to describe the hydrates at the scale of the hydrate foam improves the the estimated compressive strength at early age. Second, refining the estimate of the stress fluctuation in the cement paste at the scale of the concrete partially explains the fact that a mortar and a concrete can be weaker than its cementitious matrix. Nevertheless, the estimated compressive strength is underestimated at early age and for high weight substitution of the cement by limestone filler of pozzolanic additions.

Knowing the secant Young modulus as defined in the Eurocode and ACI 318 standards [3, 4] is also required to estimate creep strains, to anticipate strains and bending deflection and to address buckling issues. Indeed, the present estimate of the elastic stiffness as a function of time and composition can prove useful to estimate the basic creep of concretes as long as loading occurs after a few days. For instance, in the solidification model [114] and in the model of Granger [54, the changes of the volume fractions of phases at the scale of the cement paste is held responsible for both the increase of the elastic stiffness and the aging property of basic creep. Indeed, the model of Granger directly uses the Young modulus at the time of loading as a parameter while the solidification model refers to a function describing the volume fraction of the load-bearing solidified matter, which affects both the static Young modulus and the basic creep compliance. Hence, these parameters could be tuned depending on the composition prior to a simulation at structural scale. Nevertheless, given the limited accuracy of the present model, performing systematic experiments to measure the Young modulus is clearly recommended whenever strains become critical.

The most serious drawback of the present model is that it is limited to simple curing conditions. Indeed, a significant improvement of the understanding of effects of curing conditions could be performed if the present model were tightly coupled to a structural analysis.

\section{Appendix A. Multiscale homogenization by mean field schemes in brief}

In the present appendix, the overall stiffness of a composite material is estimated by using mean field schemes $[82,83$.

Let $\mathbb{C}_{m}$ being the elastic stiffness of the matrix $\mathbb{C}_{i}, c_{i}, a_{i}, \phi_{i}$ being the stiffness, the volume fraction, the aspect ratios and orientation of the class $i$ of inclusions. For each class $i$, the Eshelby's tensor $\mathbb{S}_{i}\left(\mathbb{C}_{m}, a_{i}, \phi_{i}\right)$ is introduced [115]. Closed-form expressions of the Eshelby's tensor for ellipsoidal inclusions are detailed in [116]. As computed by Eshelby, the relation between the strain in the inclusion $\varepsilon_{i}$ and the strain $\varepsilon_{m}$ in the remote matrix defines the influence tensor $\mathbb{A}_{i}\left(\mathbb{C}_{m}, \mathbb{C}_{i}, a_{i}, \phi_{i}\right)$ such that $\varepsilon_{i}=\mathbb{A}_{i}: \varepsilon_{m}$, where:

$$
\mathbb{A}_{i}\left(\mathbb{C}_{m}, \mathbb{C}_{i}, a_{i}, \phi_{i}\right)=\left(\mathbb{1}+\mathbb{S}_{i}\left(\mathbb{C}_{m}, a_{i}, \phi_{i}\right): \mathbb{C}_{m}^{-1}:\left(\mathbb{C}_{i}-\mathbb{C}_{m}\right)\right)^{-1}
$$

where $\mathbb{1}$ is the identity tensor of order 4 . In the Mori-Tanaka scheme [82, all inclusions are considered to be embedded in the matrix, experiencing the same strain $\varepsilon_{m}$ in a distance. Hence, the average of the strain $E$ in the composite writes:

$$
\boldsymbol{E}=\sum_{i} c_{i} \mathbb{A}_{i}\left(\mathbb{C}_{m}, \mathbb{C}_{i}, a_{i}, \phi_{i}\right): \varepsilon_{m}+\left(1-\sum_{i} c_{i}\right) \boldsymbol{\varepsilon}_{m}
$$

Similarly, the overall stress $\boldsymbol{\Sigma}$ writes:

$$
\boldsymbol{\Sigma}=\sum_{i} c_{i} \mathbb{C}_{i}: \mathbb{A}_{i}\left(\mathbb{C}_{m}, \mathbb{C}_{i}, a_{i}, \phi_{i}\right): \varepsilon_{m}+\left(1-\sum_{i} c_{i}\right) \mathbb{C}_{m}: \varepsilon_{m}
$$

Hence, the overall stiffness estimated according to the Mori-Tanaka scheme $\mathbb{C}_{M T}$ is:

$$
\mathbb{C}_{M T}=\left(\sum_{i} c_{i} \mathbb{C}_{i}: \mathbb{A}_{i}\left(\mathbb{C}_{m}, \mathbb{C}_{i}, a_{i}, \phi_{i}\right)+\left(1-\sum_{i} c_{i}\right) \mathbb{C}_{m}\right):\left(\sum_{i} c_{i} \mathbb{A}_{i}\left(\mathbb{C}_{m}, \mathbb{C}_{i}, a_{i}, \phi_{i}\right)+\left(1-\sum_{i} c_{i}\right) \mathbb{1}\right)^{-1}
$$


If an overall stress $\boldsymbol{\Sigma}$ is applied to the composite material, the average stress in the matrix $\sigma_{m}$ writes:

$$
\boldsymbol{\sigma}_{m}=\mathbb{C}_{m}:\left(\sum_{i} c_{i} \mathbb{A}_{i}\left(\mathbb{C}_{m}, \mathbb{C}_{i}, a_{i}, \phi_{i}\right)+\left(1-\sum_{i} c_{i}\right) \mathbb{1}\right)^{-1}: \mathbb{C}_{M T}^{-1}: \boldsymbol{\Sigma}
$$

An alternative to the Mori-Tanaka scheme is the self-consistent scheme [83, in which all phases are assumed to be embedded in a matrix as stiff as the overall composite itself. In this case, the overall stiffness $\mathbb{C}_{S C}$ must satisfy the following implicit equation:

$$
\mathbb{C}_{S C}=\left(\sum_{i} c_{i} \mathbb{C}_{i}: \mathbb{A}_{i}\left(\mathbb{C}_{S C}, \mathbb{C}_{i}, a_{i}, \phi_{i}\right)\right):\left(\sum_{i} c_{i} \mathbb{A}_{i}\left(\mathbb{C}_{S C}, \mathbb{C}_{i}, a_{i}, \phi_{i}\right)\right)^{-1}
$$

These schemes can be combined to design multiscale homogenization procedures, thus delivering estimates of the overall stiffness $\mathbb{C}_{o}$ as well as estimates of the mean stress in each microscopic phases. Lastly, the quadratic mean of the Von Mises stress in the phase $p$ can be estimated according to Kreher's lemma [91] as performed by Pichler and Hellmich [2] as:

$$
\sqrt{\left\langle\sigma_{e q}^{2}>_{p}\right.}=\sqrt{\frac{3}{2}<\boldsymbol{\sigma}: \mathbb{K}: \boldsymbol{\sigma}>_{p}}=\sqrt{\frac{3}{2 c_{p}} \boldsymbol{\Sigma}: \frac{\partial \mathbb{C}_{o}^{-1}}{\partial \frac{1}{2 G_{p}}}: \boldsymbol{\Sigma}}=\sqrt{\frac{3 G_{p}^{2}}{c_{p}} \boldsymbol{\Sigma}: \mathbb{C}_{o}^{-1}: \frac{\partial \mathbb{C}_{o}}{\partial G_{p}}: \mathbb{C}_{o}^{-1}: \boldsymbol{\Sigma}}
$$

where $\mathbb{K}=\left(-\frac{1}{3} \delta_{i j} \delta_{k l}+\frac{1}{2} \delta_{i k} \delta_{j l}+\frac{1}{2} \delta_{i l} \delta_{j k}\right) e_{i} \otimes e_{j} \otimes e_{k} \otimes e_{l}$ is the deviatoric fourth order unit tensor, $G_{p}$ is the shear modulus of the phase $p$ and $c_{p}$ it's volume fraction.

[1] L. J. Parrot, D. C. Killoh, Prediction of cement hydration, in: F. P. Glasser (Ed.), British Ceramic Proceedings, Vol. 35, British Ceramic Society, 1984, pp. 41-53.

[2] B. Pichler, C. Hellmich, Upscaling quasi-brittle strength of cement paste and mortar: A multi-scale engineering mechanics model, Cement and Concrete Research 41 (5) (2011) 467 - 476. doi:10.1016/ j.cemconres.2011.01.010

URL http://ww. .sciencedirect.com/science/article/pii/S0008884611000111

[3] AFNOR, Eurocode 2, calcul des structures en béton, section 3: Matériaux, Tech. Rep. NF EN 1992-1-1, AFNOR (2005)

[4] American Concrete Institute, Building code requirements for structural concrete, Tech. rep., American Concrete Institute (1995).

[5] ACI Committee 363, State-of-the-art report on high-strength concrete, Tech. rep., American Concrete Institute (1992).

[6] E. Freyssinet, Idées et voies nouvelles, Science et industrie. Construction et travaux publics 1 (1933) 3 $-17$.

[7] T. C. Powers, Structure and physical properties of hardened portland cement paste, Journal of the American Ceramic Society 41 (1) (1958) 1-6. doi:10.1111/j.1151-2916.1958.tb13494.x URL http://dx.doi.org/10.1111/j.1151-2916.1958.tb13494.x

[8] T. J. Hirsch, Modulus of elasticity iof concrete affected by elastic moduli of cement paste matrix and aggregate, ACI Journal Proceedings 59 (3) (1962) 427 - 452. doi:10.14359/7924

[9] U. J. Counto, The effect of the elastic modulus of the aggregate on the elastic modulus, creep and creep recovery of concrete, Magazine of Concrete Research 16 (48) (1964) 129-138. arXiv:http://dx.doi. org/10.1680/macr.1964.16.48.129, doi:10.1680/macr.1964.16.48.129 URL http://dx.doi.org/10.1680/macr.1964.16.48.129

[10] A. U. Nilsen, P. J. Monteiro, Concrete: A three phase material, Cement and Concrete Research 23 (1) (1993) $147-151$. doi:10.1016/0008-8846(93) 90145-Y. URL http://www.sciencedirect.com/science/article/pii/000888469390145Y

[11] F. de Larrard, Structures granulaires et formulation des bétons - Concrete Mixture - Proportionning A scientific approach, Modern technology Series, E \& FN SPON, Londres, 1999.

[12] T. C. Powers, T. L. Brownyard, Studies of the physical properties of hardened portland cement paste, Journal Proceedings 43. doi:10.14359/15301

[13] H. M. Jennings, P. D. Tennis, Model for the developing microstructure in portland cement pastes Journal of the American Ceramic Society 77 (12) (1994) 3161-3172. doi:10.1111/j.1151-2916.1994. tb04565.x

URL http://dx.doi.org/10.1111/j.1151-2916.1994.tb04565.x

[14] R. Berliner, M. Popovici, K. Herwig, M. Berliner, H. Jennings, J. Thomas, Quasielastic neutron scattering study of the effect of water-to-cement ratio on the hydration kinetics of tricalcium silicate, Cement and Concrete Research 28 (2) (1998) 231 - 243. doi:10.1016/S0008-8846(97)00260-3. URL http://www.sciencedirect.com/science/article/pii/S0008884697002603

[15] G. Constantinides, F.-J. Ulm, The effect of two types of c-s-h on the elasticity of cement-based materials: Results from nanoindentation and micromechanical modeling, Cement and Concrete Research 34 (1) (2004) $67-80$. doi:10.1016/S0008-8846(03) 00230-8

URL http://www.sciencedirect.com/science/article/pii/S0008884603002308

[16] O. Bernard, F.-J. Ulm, E. Lemarchand, A multiscale micromechanics-hydration model for the early-age elastic properties of cement-based materials, Cement and Concrete Research 33 (9) (2003) 1293 - 1309. doi: $10.1016 /$ S0008-8846(03) 00039-5

URL http://www.sciencedirect.com/science/article/pii/S0008884603000395 
[17] C. Pichler, R. Lackner, H. A. Mang, A multiscale micromechanics model for the autogenous-shrinkage deformation of early-age cement-based materials, Engineering Fracture Mechanics 74 (1-2) (2007) 34 58 , fracture of Concrete Materials and Structures. doi:10.1016/j.engfracmech.2006.01.034. URL http://www.sciencedirect.com/science/article/pii/S0013794406000464

[18] J. Sanahuja, L. Dormieux, G. Chanvillard, Modelling elasticity of a hydrating cement paste, Cement and Concrete Research 37 (10) (2007) 1427 -1439. doi:10.1016/j.cemconres.2007.07.003 URL http://www.sciencedirect.com/science/article/pii/S0008884607001548

[19] S. Ghabezloo, Association of macroscopic laboratory testing and micromechanics modelling for the evaluation of the poroelastic parameters of a hardened cement paste, Cement and Concrete Research 40 (8) (2010) 1197 - 1210. doi:10.1016/j.cemconres.2010.03.016 URL http://www.sciencedirect.com/science/article/pii/S0008884610000852

[20] B. Pichler, C. Hellmich, J. Eberhardsteiner, J. Wasserbauer, P. Termkhajornkit, R. Barbarulo, G. Chanvillard, Effect of gel-space ratio and microstructure on strength of hydrating cementitious materials: An engineering micromechanics approach, Cement and Concrete Research 45 (2013) $55-68$. doi:10.1016/j.cemconres.2012.10.019

URL http://www.sciencedirect.com/science/article/pii/S0008884612002384

[21] P. Termkhajornkit, Q. H. Vu, R. Barbarulo, S. Daronnat, G. Chanvillard, Dependence of compressive strength on phase assemblage in cement pastes: Beyond gel-space ratio - experimental evidence and micromechanical modeling, Cement and Concrete Research 56 (2014) 1 - 11. doi: 10.1016/j.cemconres.2013.10.007

URL http://www.sciencedirect.com/science/article/pii/S0008884613002160

[22] K. van Breugel, Simulation of hydration and formation of structure in hardening cement-based materials, Ph.D. thesis, T.U. Delft (1991).

[23] D. P. Bentz, A three-dimensional cement hydration and microstructure program. I hydration rate, heat of hydration, and chemical shrinkage, Tech. Rep. NISTIR 5756, National Institute of Standards and Technology (1995).

[24] S. Bishnoi, K. L. Scrivener, pic: A new platform for modelling the hydration of cements, Cement and Concrete Research 39 (4) (2009) 266 - 274. doi:10.1016/j.cemconres.2008.12.002 URL http://www.sciencedirect.com/science/article/pii/S0008884608002214

[25] V. Šmilauer, Z. Bittnar, Microstructure-based micromechanical prediction of elastic properties in hydrating cement paste, Cement and Concrete Research 36 (9) (2006) 1708 - 1718. doi:10.1016/j. cemconres.2006.05.014

URL http://www.sciencedirect.com/science/article/pii/S0008884606001499

[26] Z. Qian, G. Ye, E. Schlangen, K. van Breugel, 3d simulation of micromechanical behavior of cement paste, in: Fracture Mechanics of concrete and concrete structures- Recent advances in Fracture Mechanics of concrete, 2010, pp. 313-319.

[27] L. Buffo-Lacarrière, A. Sellier, G. Escadeillas, A. Turatsinze, Multiphasic finite element modeling of concrete hydration. Cement and Concrete Research 37 (2) (2007) 131 -138. doi:10.1016/j.cemconres. 2006.11 .010 URL http://wWw.sciencedirect.com/science/article/pii/S0008884606003036

[28] B. Z. Dilnesa, B. Lothenbach, G. Renaudin, A. Wichser, D. Kulik, Synthesis and characterization of hydrogarnet ca3(alxfe1 - x)2(sio4)y(oh)4(3-y), Cement and Concrete Research 59 (2014) $96-111$. doi:10.1016/j.cemconres.2014.02.001 URL http://www.sciencedirect.com/science/article/pii/S000888461400043X

[29] M. Vespa, E. Wieland, R. Dähn, B. Lothenbach, Identification of the thermodynamically stable fecontaining phase in aged cement pastes, Journal of the American Ceramic Society 98 (2015) 2286-2294. doi:10.1111/jace.13542.

URL http://dx.doi.org/10.1111/jace.13542

[30] B. Lothenbach, T. Matschei, G. Möschner, F. P. Glasser, Thermodynamic modelling of the effect of temperature on the hydration and porosity of portland cement, Cement and Concrete Research 38 (1) (2008) 1 - 18. doi:10.1016/j.cemconres.2007.08.017. URL http://www.sciencedirect.com/science/article/pii/S0008884607001998

[31] V. Waller, Relations entre composition des bétons, exothermie en cours de prise et résistance en compression, Ph.D. thesis, École Nationale des Ponts et Chaussées (1999).

[32] M. Thiery, G. Platret, E. Massieu, G. Villain, V. Baroghel-Bouny, Un modèle d'hydratation pour le calcul de la teneur en portlandite des materiaux cimentaires comme donnée d'entrée des modèles de carbonatation, Tech. rep., Journée d'Ouvrages d'Art, Laboratoire Central des Ponts et Chaussées (2005).

[33] M. D. Nguyen, Modelisation des couplages entre hydratation et dessication des matériaux cimentaires à l'issue du décoffrage. etude de la dégradation des propriétés de transfert, Ph.D. thesis, École Nationale des Ponts et Chaussées (2009).

[34] D. Gawin, M. Wyrzykowski, Modelling and experimental study of hydration for ordinary Portland cement, Journal of Architecture Civil Engineering Environment 3 (3) (2010) 45-54.

[35] V. G. Papadakis, M. N. Fardis, C. G. Vayenas, Hydration and carbonation of pozzolanic cements, ACI Materials Journal 89 (2) (1992) 119-130. doi:10.14359/2185.

URL https://www.concrete.org/publications/internationalconcreteabstractsportal.aspx?m= details\&ID $=2185$

[36] M. Avrami, Kinetics of phase change. I general theory, The Journal of Chemical Physics 7 (12) (1939) 1103-1112. doi:10.1063/1.1750380. URL http://scitation. aip.org/content/aip/journal/jcp/7/12/10.1063/1.1750380

[37] M. Avrami, Kinetics of phase change. II transformation-time relations for random distribution of nuclei The Journal of Chemical Physics 8 (2) (1940) 212-224. doi:10.1063/1.1750631. URL http://scitation. aip.org/content/aip/journal/jcp/8/2/10.1063/1.1750631

[38] W. Jander, Reaktionen im festen zustande bei höheren temperaturen. reaktionsgeschwindigkeiten endotherm verlaufender umsetzungen, Zeitschrift für anorganische und allgemeine Chemie 163 (1) (1927) 1-30. doi:10.1002/zaac.19271630102 
URL http://dx.doi.org/10.1002/zaac.19271630102

[39] A. Khawam, , D. R. Flanagan, Solid-state kinetic models: Basics and mathematical fundamentals, The Journal of Physical Chemistry B 110 (35) (2006) 17315-17328, pMID: 16942065. arXiv:http: //dx.doi.org/10.1021/jp062746a, doi:10.1021/jp062746a.

URL http://dx.doi.org/10.1021/jp062746a

[40] H. Brouwers, The work of Powers and Brownyard revisited: Part 2, Cement and Concrete Research 35 (10) (2005) 1922 - 1936. doi:10.1016/j.cemconres.2005.04.009

URL http://www.sciencedirect.com/science/article/pii/S0008884605001171

[41] H. Taylor, D. Newbury, An electron microprobe study of a mature cement paste Cement and Concrete Research 14 (4) (1984) 565 - 573. doi:10.1016/0008-8846(84)90134-0

URL http://www.sciencedirect.com/science/article/pii/0008884684901340

[42] S. A. Rodger, G. W. Groves, Electron microscopy study of ordinary portland cement and ordinary portland cement-pulverized fuel ash blended pastes, Journal of the American Ceramic Society 72 (6) (1989) 1037-1039. doi:10.1111/j.1151-2916.1989.tb06265.x.

URL http://dx.doi.org/10.1111/j.1151-2916.1989.tb06265.x

[43] B. Dilnesa, E. Wieland, B. Lothenbach, R. Dähn, K. Scrivener, Fe-containing phases in hydrated cements, Cement and Concrete Research 58 (2014) $45-55$. doi:10.1016/j.cemconres.2013.12.012 URL http://www. sciencedirect. com/science/article/pii/S0008884614000118

[44] L. J. Parrott, D. C. Killoh, R. G. Patel, , in: 8th International Conference on the Chemistry of Cement, Vol. 3, 1986, pp. $46-50$

[45] O. Jensen, Thermodynamic limitation of self-desiccation, Cement and Concrete Research 25 (1) (1995) 157 - 164. doi:10.1016/0008-8846(94)00123-G URL http://www.sciencedirect.com/science/article/pii/000888469400123G

[46] R. J. Flatt, G. W. Scherer, J. W. Bullard, Why alite stops hydrating below $80 \%$ relative humidity, Cement and Concrete Research 41 (9) (2011) 987 - 992. doi:10.1016/j.cemconres.2011.06.001. URL http://www.sciencedirect.com/science/article/pii/S0008884611001621

[47] H. Chen, M. Wyrzykowski, K. Scrivener, P. Lura, Prediction of self-desiccation in low water-to-cement ratio pastes based on pore structure evolution, Cement and Concrete Research 49 (2013) 38 - 47 . doi: $10.1016 / j$.cemconres.2013.03.013

URL http://www. sciencedirect.com/science/article/pii/S0008884613000677

[48] P. Lura, O. M. Jensen, K. van Breugel, Autogenous shrinkage in high-performance cement paste: An evaluation of basic mechanisms, Cement and Concrete Research 33 (2) (2003) $223-232$, papers presented at the Fall 2001 Materials Research Society Symposium on Design, Characteristics and Properties of Cementitious Materials. doi:10.1016/S0008-8846(02)00890-6 URL http://www.sciencedirect.com/science/article/pii/S0008884602008906

[49] F. Lin, C. Meyer, Modeling shrinkage of portland cement paste, ACI Materials Journal 105 (3). doi:10.14359/19828

URL https://www.concrete.org/publications/internationalconcreteabstractsportal.aspx?m= details\&i=19828

[50] E. Koenders, Simulation of volume changes in hardening cement-based materials, Ph.D. thesis, T.U. Delft (1997).

[51] A. C. A. Muller, K. L. Scrivener, A. M. Gajewicz, P. J. McDonald, Densification of c-s-h measured by $1 \mathrm{~h} \mathrm{nmr} \mathrm{relaxometry.} \mathrm{The} \mathrm{Journal} \mathrm{of} \mathrm{Physical} \mathrm{Chemistry} \mathrm{C} 117$ (1) (2013) 403-412. arXiv:http: //dx.doi.org/10.1021/jp3102964, doi:10.1021/jp3102964. URL http://dx.doi.org/10.1021/jp3102964

[52] A. C. A. Muller, Characterization of porosity and C-S-H in cement pastes by $1 \mathrm{H}$ NMR, Ph.D. thesis, Ecole Polytechnique Fédérale de Lausanne (2014).

[53] P. Freiesleben Hansen, J. Pedersen, Maturity computer for controlled curing and hardening of concrete, Nordisk Betong 1 (1977) 19-34.

[54] L. Granger, Comportement différé du béton dans les enceintes de centrales nucléaires : analyse et modélisation, Ph.D. thesis, Ecole Nationale des Ponts et Chaussées (1995).

[55] itech, Cesar-lcpc v5 analyse du béton au jeune âge, Tech. Rep. TexoMexo-V10-FR, IFSTTAR (2011) URL http://www.itech-soft.com/cesar/download/fr/CESAR-LCPCv5-TexoMexo-V10-FR.pdf

[56] M. Briffaut, G. Nahas, F. Benboudjema, J.-M. Torrenti, Numerical simulations of the qab and langavant semi-adiabatic tests : Analysis and comparison with an experimental measurement campaign, Bulletin des Laboratoires des Ponts et Chaussées (2010) 5 - 18

[57] M. Briffaut, F. Benboudjema, J.-M. Torrenti, G. Nahas, Analysis of semi-adiabiatic tests for the prediction of early-age behavior of massive concrete structures, Cement and Concrete Composites 34 (5) (2012) 634 - 641. doi:10.1016/j.cemconcomp.2011.09.001 URL http://www.sciencedirect.com/science/article/pii/S0958946511001582

[58] X. Xiong, K. van Breugel, Isothermal calorimetry study of blended cements and its application in numerical simulations, HERON 46 (3) (2001) 151-159. URL http://heronjournal.nl/46-3/2.pdf

[59] X. Pang, Effects of curing temperature and pressure on the chemical, physical, and mechanical properties of Portland cement, Ph.D. thesis, Columbia University (2011).

[60] K. Maekawa, R. Chaube, T. Kishi, Modeling of concrete performance : hydration, microstructure formation and mass transport, Taylor \& Francis, London, 1999.

[61] L. D'Aloia, G. Chanvillard, Determining the "apparent" activation energy of concrete: Ea-numerical simulations of the heat of hydration of cement, Cement and Concrete Research 32 (8) (2002) 1277 1289. doi:10.1016/S0008-8846(02)00791-3

URL http://ww..sciencedirect.com/science/article/pii/S0008884602007913

[62] A. K. Schindler, Effect of temperature on hydration of cementitious materials, ACI Materials Journal 101 (1) (2004) 72-81. doi:10.14359/12990.

[63] F. Lin, Modeling of hydration kinetics and shrinkage of Portland cement paste, Ph.D. thesis, Columbia University (2006).

[64] J. L. Poole, Modeling temperature sensitivity and heat evolution of concrete, Ph.D. thesis, University 
of Texas (2007).

[65] Y. Suzuki, Y. Tsuji, K. Maekawa, H. Okamura, Quantification of hydration-heat generation process of cement in concrete, in: C. L. of JSCE (Ed.), Translation from Proceedings of JSCE, No. 414/V-16, 1990, pp. 111-124.

[66] S. V. Talekar, Temperature dependence of activation energies for self-diffusion of water and of alkali ions in aqueous electrolyte solutions. a model for ion selective behavior of biological cells, International Journal of Quantum Chemistry 12 (S4) (1977) 459-469. doi:10.1002/qua.560120741

URL http://dx.doi.org/10.1002/qua.560120741

[67] D. D. Wagman, W. H. Evans, V. B. Parker, R. H. Schumm, I. Halow, S. M. Bailey, K. L. Churney, R. L. Nuttall, The nbs tables of chemical thermodynamic properties. selected values for inorganic and c1 and c2 organic substances in si units, Journal of Physical and Chemical Reference Data 11 (1982) 1-407, supplement No. 2.

URL http://www.nist.gov/data/PDFfiles/jpcrdS2Vol11.pdf

[68] AFNOR, Méthodes d'essais des ciments partie 9 : Chaleur d'hydratation - méthode semi-adiabatique, Tech. Rep. NF EN 196-9, AFNOR (2010).

URL http://www . boutique. afnor .org/xml/967072

[69] C. Boulay, J.-M. Torrenti, J.-L. André, R. Saintilan, Quasi-adiabatic calorimetry for concretes: Influential factors, Bulletin des Laboratoires des Ponts et Chaussées 278 (1) (2010) 19-36.

[70] I. Odler, 6 - hydration, setting and hardening of portland cement, in: P. C. Hewlett (Ed.), Lea's Chemistry of Cement and Concrete (Fourth Edition), fourth edition Edition, Butterworth-Heinemann, Oxford, 1998, pp. 241 - 297. doi:10.1016/B978-075066256-7/50018-7. URL http://www.sciencedirect.com/science/article/pii/B9780750662567500187.

[71] H. F. W. Taylor, 5 hydration of the calcium silicate phases and 6 hydrated aluminate, ferrite and sulphate phases, in: H. F. W. Taylor (Ed.), Cement Chemistry, Academic Press, London, 1990, pp. $123-197$.

[72] K. Fujii, W. Kondo, Communications of the american ceramic society estimation of thermochemical data for calcium silicate hydrate (c-s-h), Journal of the American Ceramic Society 66 (12) (1983) C220-C-221. doi:10.1111/j.1151-2916.1983.tb11011.x.

URL http://dx.doi.org/10.1111/j.1151-2916.1983.tb11011.x

[73] P. Blanc, X. Bourbon, A. Lassin, E. Gaucher, Chemical model for cement-based materials: Temperature dependence of thermodynamic functions for nanocrystalline and crystalline $\mathrm{c}-\mathrm{s}-\mathrm{h}$ phases, Cement and Concrete Research 40 (6) (2010) 851 - 866. doi:10.1016/j.cemconres.2009.12.004.

URL http://www.sciencedirect.com/science/article/pii/S0008884609003500

[74] B. Andra, Cementitous phases, Tech. rep., Andra, BRGM (2014).

[75] J. Ederová, V. Šatava, Heat capacities of c3ah6, c4ass̄h12 and c6as̄̄3h32, Thermochimica Acta 31 (1) (1979) 126 - 128. doi:10.1016/0040-6031(79)80016-7 URL http://www.sciencedirect.com/science/article/pii/0040603179800167

[76] T. Matschei, Thermodynamics of cement hydration, Ph.D. thesis, University of Aberdeen (2007).

[77] M. W. Chase, Jr., C. A. Davies, J. R. Downey, Jr., D. J. Frurip, R. A. McDonald, A. N. Syverud, Nist standard reference database 13 nist janaf thermochemical tables 1985 v1.0. Tech. Rep. V1.0, NIST (1985). URL http://kinetics.nist.gov/janaf/

[78] P. Lu, G. Sun, J. F. Young, Phase composition of hydrated dsp cement pastes Journal of the American Ceramic Society 76 (4) (1993) 1003-1007. doi:10.1111/j.1151-2916.1993.tb05326.x. URL http://dx.doi.org/10.1111/j.1151-2916.1993.tb05326.x

[79] D. P. Bentz, E. J. Garboczi, D. A. Quenard, Modelling drying shrinkage in reconstructed porous materials: application to porous vycor glass, Modelling and Simulation in Materials Science and Engineering 6 (3) (1998) 211. URL http: //stacks . iop. org/0965-0393/6/i=3/a=002

[80] J. Olek, M. D. Cohen, C. Lobo, Determination of surface area of portland cement and silica fume by mercury intrusion porosimetry, ACI Materials Journal 87 (5) (1990) 473 - 478. doi:10.14359/1864.

[81] K. D. Weerdt, M. B. Haha, G. L. Saout, K. Kjellsen, H. Justnes, B. Lothenbach, Hydration mechanisms of ternary portland cements containing limestone powder and fly ash, Cement and Concrete Research 41 (3) (2011) 279 - 291. doi:10.1016/j.cemconres.2010.11.014. URL http://www.sciencedirect.com/science/article/pii/S0008884610002577

[82] T. Mori, K. Tanaka, Average stress in matrix and average elastic energy of materials with misfitting inclusions, Acta Metallurgica 21 (5) (1973) 571 - 574. doi:10.1016/0001-6160(73)90064-3 URL http://www.sciencedirect.com/science/article/pii/0001616073900643

[83] R. Hill, A self-consistent mechanics of composite materials, Journal of the Mechanics and Physics of Solids 13 (4) (1965) 213 - 222. doi:10.1016/0022-5096(65)90010-4. URL http://www.sciencedirect.com/science/article/pii/0022509665900104

[84] P. D. Tennis, H. M. Jennings, A model for two types of calcium silicate hydrate in the microstructure of portland cement pastes, Cement and Concrete Research 30 (6) (2000) 855 - 863. doi:10.1016/ S0008-8846(00) 00257-X URL http://www.sciencedirect.com/science/article/pii/S000888460000257X

[85] J. Zhang, E. A. Weissinger, S. Peethamparan, G. W. Scherer, Early hydration and setting of oil well cement, Cement and Concrete Research 40 (7) (2010) 1023 - 1033. doi:10.1016/j.cemconres.2010. 03.014

URL http://www.sciencedirect.com/science/article/pii/S0008884610000839

[86] D. Lootens, D. P. Bentz, On the relation of setting and early-age strength development to porosity and hydration in cement-based materials, Cement and Concrete Composites 68 (2016) 9 - 14. doi: 10.1016/j.cemconcomp.2016.02.010 URL http://www.sciencedirect.com/science/article/pii/S0958946516300221

[87] J. M. Taplin, A method for following the hydration reaction in portland cement paste, Australian Journal of Applied Science 10 (3) (1959) 329-345.

[88] W. Lerch, C. L. Ford, Long-time study of cement performance in concrete, Journal of the ACI 19 (8) 
(1948) 745-795.

[89] M. K. M. I. ul Hassan Bernhard Pichler Christian Hellmich, Downscaling based identification of nonaging power-law creep of cement hydrates, Journal of Engineering Mechanics 142 (12). arXiv:http://ascelibrary.org/doi/pdf/10.1061/ \%28ASCE \\%29EM.1943-7889.0001169, doi:10.1061/(ASCE)EM.1943-7889.0001169

URL http://ascelibrary .org/doi/abs/10.1061/\%28ASCE\%29EM. 1943-7889.0001169

[90] I. Richardson, Tobermorite/jennite- and tobermorite/calcium hydroxide-based models for the structure of c-s-h: applicability to hardened pastes of tricalcium silicate, -dicalcium silicate, portland cement, and blends of portland cement with blast-furnace slag, metakaolin, or silica fume, Cement and Concrete Research 34 (9) (2004) 1733 - 1777, h. F. W. Taylor Commemorative Issue. doi:10.1016/j . cemconres. 2004.05 .034

URL http://www.sciencedirect.com/science/article/pii/S0008884604002364

[91] W. Kreher, Residual stresses and stored elastic energy of composites and polycrystals, Journal of the Mechanics and Physics of Solids 38 (1) (1990) 115 - 128. doi :10.1016/0022-5096(90) 90023-W URL http://www.sciencedirect.com/science/article/pii/002250969090023W

[92] X. CONG, S. GONG, D. DARWIN, S. L. McCABE, Role of silica fume in compressive strength of cement paste, mortar, and concrete, Tech. rep., University of Kansas (april 1990).

[93] R. . Brenner, R. . A. . Lebensohn, O. . Castelnau, Elastic anisotropy and yield surface estimates of polycrystals, International Journal of Solids and Structures 46 (2009) 3018-3026.

[94] T. Oliphant, S. Developers, scipy.stats.ncx2, https://docs.scipy.org/doc/scipy-0.19.0/reference/ generated/scipy.stats.ncx2.html (2017). URL https://docs.scipy.org/doc/scipy-0.19.0/reference/generated/scipy.stats.ncx2.html

[95] F. Lavergne, R. Brenner, K. Sab, Effects of grain size distribution and stress heterogeneity on yield stress of polycrystals: A numerical approach, Computational Materials Science 77 (0) (2013) 387 - 398. doi:10.1016/j.commatsci.2013.04.061

URL http://www.sciencedirect.com/science/article/pii/S0927025613002334

[96] B. D. Lubachevsky, F. H. Stillinger, Geometric properties of random disk packings, Journal of Statistical Physics 60 (1990) 561-583.

[97] F. Lavergne, K. Sab, J. Sanahuja, M. Bornert, C. Toulemonde, Investigation of the effect of aggregates' morphology on concrete creep properties by numerical simulations, Cement and Concrete Research 71 (2015) $14-28$. doi:10.1016/j.cemconres. 2015.01 .003 URL http://www. sciencedirect.com/science/article/pii/S0008884615000101

[98] H. Moulinec, P. Suquet, A numerical method for computing the overall response of nonlinear composites with complex microstructure, Computational Methods in Applied Mechanics and Engeneering 157 (1998) 69-94.

[99] D. J. Eyre, G. W. Milton, A fast numerical scheme for computing the response of composites using grid refinement, The European Physical Journal Applied Physics 6 (1999) 41-47. doi:10.1051/epjap: 1999150 .

URL http://www.epjap.org/article_S1286004299001500

[100] J. Escalante-García, J. Sharp, Effect of temperature on the hydration of the main clinker phases in portland cements: part i, neat cements, Cement and Concrete Research 28 (9) (1998) 1245 - 1257. doi: 10.1016/S0008-8846(98) 00115-X

URL http://ww. sciencedirect.com/science/article/pii/S000888469800115X

[101] V. Kocaka, Development and evaluation of methods to follow microstructural development of cementitious systems including slags, Ph.D. thesis, École Polytechnique Fédérale de Lausanne (2009).

[102] M. De Schepper, K. De Buysser, I. Van Driessche, N. De Belie, A hydration study by xrd/rietveld analysis of cement regenerated from completely recyclable concrete, in: V. Bilek, Z. Kersner (Eds.), NTCC2014 : international conference on non-traditional cement and concrete, Novpress, 2014, p. 6.

[103] I. Pane, W. Hansen, Investigation of blended cement hydration by isothermal calorimetry and thermal analysis, Cement and Concrete Research 35 (6) (2005) 1155 - 1164. doi:10.1016/j.cemconres.2004. 10.027 . URL http://www. sciencedirect.com/science/article/pii/S0008884604004818

[104] F. Tomosawa, T. Noguchi, Relationship between compressive strength and modulus of elasticity of high-strength concrete, in: Third International Symposium on Utilization of High Strength Concrete, Symposium in Lillehammer, 1993, pp. 1247-1254.

[105] C.-J. Haecker, E. Garboczi, J. Bullard, R. Bohn, Z. Sun, S. Shah, T. Voigt, Modeling the linear elastic properties of portland cement paste, Cement and Concrete Research 35 (10) (2005) 1948 - 1960. doi: $10.1016 / j$.cemconres.2005.05.001

URL http://www .sciencedirect.com/science/article/pii/S0008884605001201

[106] AFNOR, Méthodes d'essais des ciments partie 1 : Détermination des résistances mécaniques, Tech. Rep. NF EN 196-1, AFNOR (2006)

[107] M. Hlobil, V. Šmilauer, G. Chanvillard, Micromechanical multiscale fracture model for compressive strength of blended cement pastes, Cement and Concrete Research 83 (2016) 188 - 202. doi:10.1016/ j.cemconres.2015.12.003 URL http://www.sciencedirect.com/science/article/pii/S0008884615002999

[108] E. Gallucci, X. Zhang, K. Scrivener, Effect of temperature on the microstructure of calcium silicate hydrate (c-s-h), Cement and Concrete Research 53 (2013) 185 - 195. doi:10.1016/j.cemconres. 2013. 06.008

URL http://www.sciencedirect.com/science/article/pii/S0008884613001439

[109] R. G. Burg, The influence of casting and curing temperature on the properties of fresh and hardened concrete, Tech. Rep. R\&D Bulletin RD113T, PCA R\&D Serial No. 2023, Portland Cement Association (1996).

[110] M. Königsberger, C. Hellmich, B. Pichler, Densification of c-s-h is mainly driven by available precipitation space, as quantified through an analytical cement hydration model based on $\{\mathrm{NMR}\}$ data, Cement and Concrete Research 88 (2016) 170 - 183. doi:10.1016/j.cemconres.2016.04.006 URL http://www.sciencedirect.com/science/article/pii/S0008884616303374 
[111] F.-J. Ulm, M. Vandamme, C. Bobko, J. Alberto Ortega, K. Tai, C. Ortiz, Statistical indentation techniques for hydrated nanocomposites: Concrete, bone, and shale, Journal of the American Ceramic Society 90 (9) (2007) 2677-2692. doi:10.1111/j.1551-2916.2007.02012.x URL http://dx.doi.org/10.1111/j.1551-2916.2007.02012.x

[112] M. Vandamme, F.-J. Ulm, P. Fonollosa, Nanogranular packing of $\mathrm{c}-\mathrm{s}-\mathrm{h}$ at substochiometric conditions, Cement and Concrete Research 40 (1) (2010) 14-26. doi:10.1016/j.cemconres.2009.09.017 URL///www.sciencedirect.com/science/article/pii/S0008884609002701

[113] D. P. Bentz, C. F. Ferraris, S. Z. Jones, D. Lootens, F. Zunino, Limestone and silica powder replacements for cement: Early-age performance Cement and Concrete Composites 78 (2017) 43-56. doi:10.1016/ j.cemconcomp.2017.01.001.

URL //www.sciencedirect.com/science/article/pii/S0958946516301561

[114] Z. P. Bažant, S. Prasannan, Solidification theory for aging creep, Cement and Concrete Research 18 (6) (1988) 923 - 932. doi:10.1016/0008-8846(88)90028-2

URL http://www.sciencedirect.com/science/article/pii/0008884688900282

[115] J. D. Eshelby, The determination of the elastic field of an ellipsoidal inclusion and related problems, Proc. R. Soc. London A 241 (1957) 376-396.

[116] T. Mura, Micromechanics of Defects in Solids, Mechanics of Elastic and Inelastic Solids, Springer Netherlands, 1987.

[117] L. Lam, Y. Wong, C. Poon, Degree of hydration and gel/space ratio of high-volume fly ash/cement systems, Cement and Concrete Research 30 (5) (2000) 747 - 756. doi:10.1016/S0008-8846(00) 00213-1. URL http://www.sciencedirect.com/science/article/pii/S0008884600002131

[118] M. Berglund, M. E. Wieser, Isotopic compositions of the elements 2009 (iupac technical report), Pure and Applied Chemistry 83 (2) (2011) 397-410. doi:10.1351/PAC-REP-10-06-02. URL http://www .iupac.org/publications/pac/83/2/0397/

[119] S. Meille, E. J. Garboczi, Linear elastic properties of 2d and 3d models of porous materials made from elongated objects, Modelling and Simulation in Materials Science and Engineering 9 (5) (2001) 371. URL http://stacks . iop.org/0965-0393/9/i=5/a=303

[120] S. Kamali, M. Moranville, E. Garboczi, S. Prené, B. Gérard, Hydrate dissolution influence on the young's modulus of cement pastes, in: Fracture Mechanics of Concrete and Concrete Structures 5, 2004. URL http://framcos .org/FraMCoS-5/kamali.hydrate.pdf

[121] J. D. Bass, Elasticity of Minerals, Glasses, and Melts, American Geophysical Union, 2013, pp. 45-63. doi:10.1029/RF002p0045.

URL http://dx.doi.org/10.1029/RF002p0045

[122] P. J. Monteiro, C. Chang, The elastic moduli of calcium hydroxide, Cement and Concrete Research 25 (8) (1995) 1605 - 1609. doi:10.1016/0008-8846(95)00154-9

URL http://www.sciencedirect.com/science/article/pii/0008884695001549

[123] E. C. Arvaniti, M. C. G. Juenger, S. A. Bernal, J. Duchesne, L. Courard, S. Leroy, J. L. Provis, A. Klemm, N. De Belie, Determination of particle size, surface area, and shape of supplementary cementitious materials by different techniques, Materials and Structures 48 (11) (2015) 3687-3701. doi:10.1617/s11527-014-0431-3.

URL http://dx.doi .org/10.1617/s11527-014-0431-3 